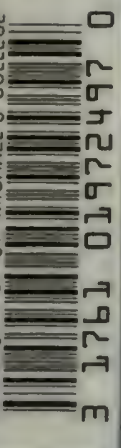

FI I MAR DITY OF ACOUIRED

MARACIERS IN PLANTS

RIV. G. HENSLOW 


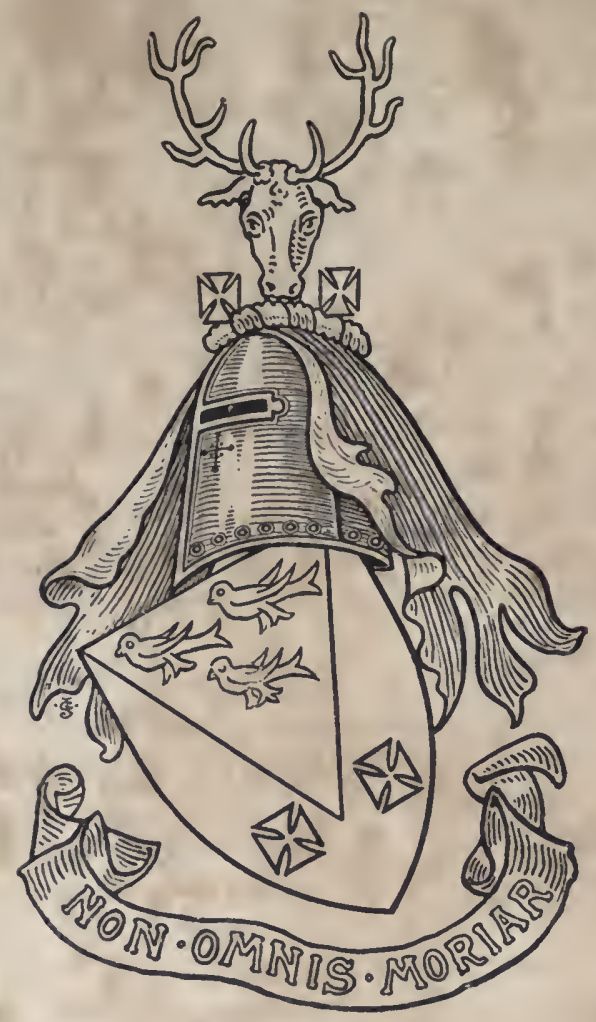

EX LIBRIS.

Hiertram $\mathfrak{c}$. A. cêtinde,

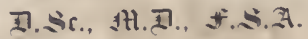




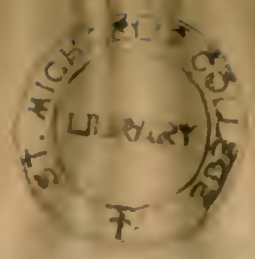

7 HOSE who have closely followed the controversy 1 respecting the various theories of Heredity will not have failed to notice that-apart from a large portion of the work on the Mendelian theory-most of the writers have been professional zoologists and most of their views have been founded on the behaviour of animals. The Rev. Professor Henslow in his book (The Heredity of Acquired Characters in Plants. London: John Murray. 1908. Price 6s. net) alludes to this fact and insists that the study of plants leads to a totally different conclusion from that arrived at by many who have devoted their attention to the animal kingdom. More especially he insists upon the need for ecological study of plants if the problem of heredity is to be properly attacked.

Now the ecologist studies "plants at home" and not with any idea of classification, "but solely for the sake of their physiological peculiarities connected with habit of growth and evolution." (p. 45.)

And as a result of this study he "groups plants into ' associations' according to their environments, and calls plants of dry districts xerophytes; of moist, marshy places, hygrophytes; true aquatic plants being hydrophytes, and all of an intermediate character, mesophytes." (p. 24.) Then he proceeds to his second step, which is to ascertain how these plants came to acquire the adaptive structures which enable them to exist under such very different conditions as we know that plants are capable of existing under. The author's reply to this question may be found in the following passages.

The origin of Variations in Structure (upon which alone species are based) is due to an inherent Power within the Plant, by means of which it Responds to the Direct Action of changed conditions of Life. (p.6.)

And again 
F It is my object to show how variations do arise, viz.: by the plant responding to changed conditions of life; and, secondly, that the altered structures in adaptation to the new environment do become hereditary, if the plants, generation after generation, continue to live long enough in the new surroundings. That is the true and only method of Evolution. (p. I 8).

Numerous examples of this process are given in the Professor's very interesting book. We cannot spare space here to cite them but may direct the attention of readers to an example in the production of parasitism in Passiflora. (p. 69.)

Of course the views expressed in this book cut diametrically across those of the Weismannites and of the Neo-Darwinians.

Plantecologists have already abandoned natural selection, in the sense Darwin used it; but still recognise the usefulness of the term as meaning the survival of the better adapted under the circumstances in the struggle for life. (p. 28.)

It will be noticed that the Professor postulates whatone would imagine-all reasonable observers must postulate, namely the inherent power of the plant or the animal to vary, a postulate which is evaded by many, one might almost say most, of those who write upon the subject, but, all the same, a postulate on which the whole edifice of heredity rests. We are hardly at the beginning of the search for this factor, however much some may try to lead us to believe that all difficulties are solved and all questions cleared up.

Those who have any such illusions might well be advised to study the work under review. It will suggest some wholesome thoughts and may be commended to the attention of all persons interested in botany or in the larger biological problems.

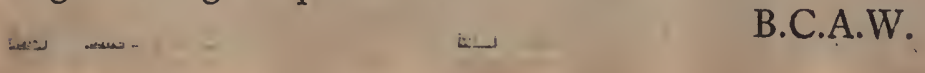




\section{THE HEREDITY OF ACQUIRED CHARACTERS IN PLANTS}


Digitized by the Internet Archive in 2007 with funding from Microsoft Corporation 


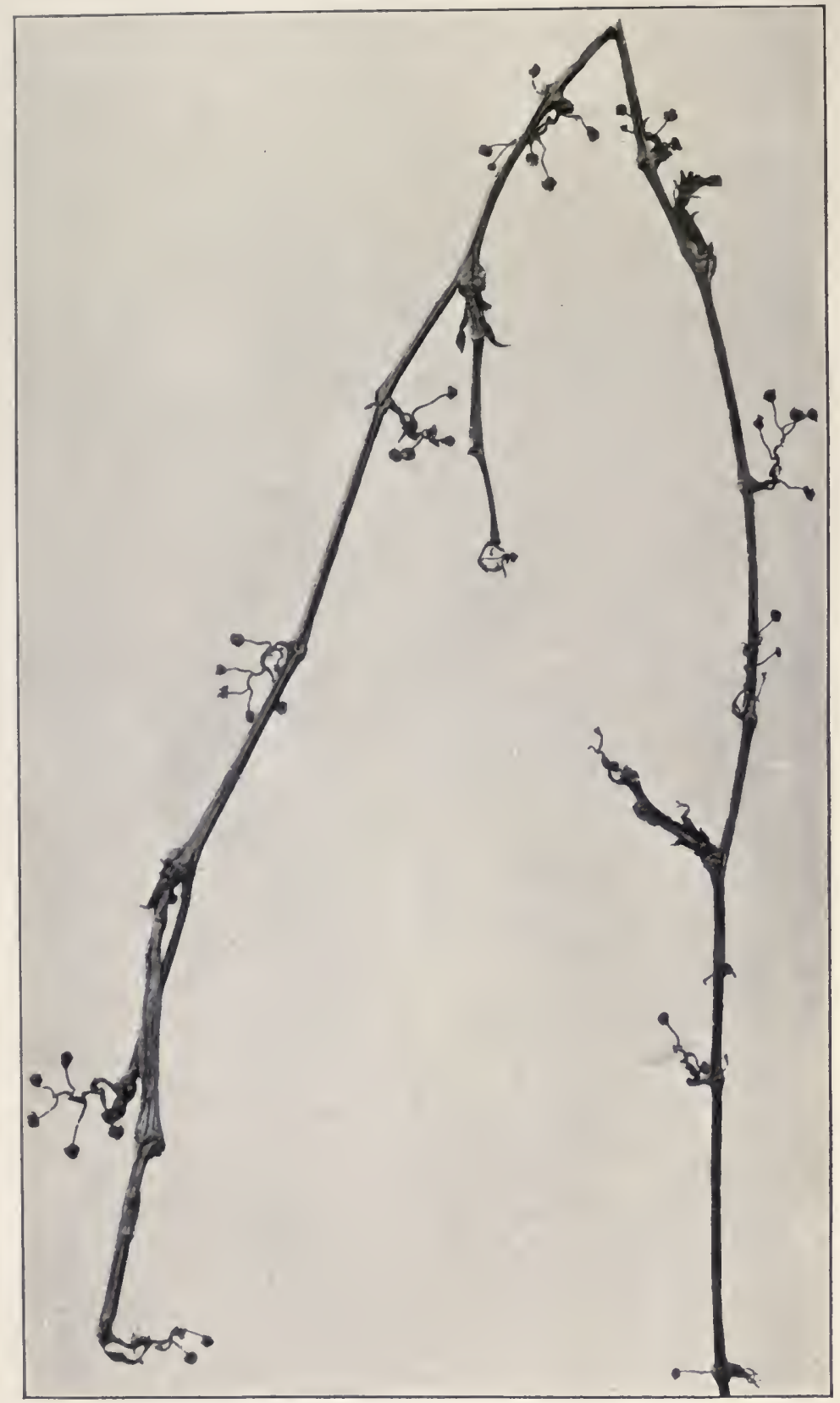

Fig. 1.-Anipelopsis Veitchii; hereditary tendrils adhering to a wall by means of adhesive pads, formed before contact. (See 1. 10.) 


\title{
THE HEREDITY OF ACQUIRED CHARACTERS IN PLANTS
}

\author{
BY THE REV. PROFESSOR \\ GEORGE HENSLOW, M.A., F.L.S., \\ AUTHOR OF "THE ORIGIN OF PLANT STRUCTURES"; "THE ORIGIN \\ OF FLORAL STRUCTURES"; "THE MAKING OF FLOWERS"; "AN \\ INTRODUCTION TO PLANT ECOLOGY"; "HOW TO STUDY \\ WILD FLOWERS," ETC., ETC.
}

WITH ILLUSTRATIONS

\section{LONDON}

JOHN MURRAY, ALBEMARLE STREET, W. 1908 



\section{PREFACE}

THE object of this book is to prove that Evolution-so far as Plants are concerneddepends upon the Inheritance of Acquired Character's. This was Darwin's contention. Dr Weismann and his followers assert that no such characters can ever be hereditary unless the influence of the environment can reach and affect the reproductive organs, or his hypothetical substance "germ-plasm." As all the characters of the vegetative system, or the soma of plants, which are regarded as specific, are acquired long before any reproductive organs exist at all, and therefore before any vegetative cell has begun to assume a reproductive character, Dr Weismann's proviso is inappplicable to plants.

Present-day Ecologists who study plants in nature, are all at one in accepting the fact that evolution in plants is the result, not only of a natural response to the direct action of changed conditions of life, by means of which 
they evolve new structures in adaptation to their new environments, but that these acquired characters can become hereditary.

Now this was exactly Darwin's own alternative to his original theory expressed by the title of his book, "The Origin of Species by Means of Natural Selection."

A curious fact will be disclosed in the first chapter, viz., that present-day Darwinians contradict Darwin in several ways; whereas not a line or a word in the whole of this book itself is opposed to Darwin's own description of what he briefly called "the Definite Action" of the environment; by which, as he asserts "new sub-varieties arise without the aid of selection." I have, therefore, called this process "The True Darwinism." 1

Darwinians assert that variations are spontaneous and congenital, appearing in the seedlings of plants and young of animals; then, by means of natural selection, the "unfit" are supposed to be eliminated and the "fittest" to survive. It would seem that this view is a sequel to Dr Weismann's assertion, that, as acquired characters cannot be inherited, the new variations must originate in the germ-plasm, there being no other theory conceivable.

1 "Nineteenth Century and After," November 1906, p. 795. 
But, it will be seen by an abundance of examples-and many more might be giventhat new and changed structures in plants do arise as acquired characters, and that they can be hereditary, and so become fixed as varietal or specific characters.

Lastly, as the spontaneous and congenital variations are supposed to arise without any connection with the environment in their adaptations to it, there is no natural law discoverable in the process of adaptation.

On the other hand, as plants adapt themselves during their development by responding to new external conditions, one soon discovers this to be a universal natural law; obviating all the hypothetical difficulties involved in the death of the majority of offspring which are bornaccording to Darwinism-with " injurious," that is, death-bringing variations of structure.

G. H.

July, 1908. 



\section{CON'TEN'TS}

CHAP. PAOE

I. INTRODUCTION . . . . . . . . 1

11. ON SUPPOSED METHODS OF EVOLUTION AND THE HEREDITY OF ACQUIRED CIIARACTERS . . . . . . 9

III. ECOLOGY AND ITS IMPORTANCE. . . . . . 23

IV. IJLUSTRATIVE PROOFS OF EVOLUTION BY DIRECT ADAPTATION, WITI HEREDITY OF ACQUIRED CHARACTERS :-THE STRUCTURE OF STEMS, SPINES, AND AQUATIC LEAVES -

V. ILLUSTRATIVE PROOFS OF EVOLUTION BY DIRECT ADAPTATION, WITH IIEREDITY OF ACQUIRED CIARACTERS :CLINBING PLANTS . . . . . . . . . 38

VI. ILLUSTRATIVE PROOFS OF EVOLUTION BY DIRECT ADAPTATION, WITH HEREDITY OF ACQUIRED CIIARACTERS :SUCCULENT PLANTS

VII. ILLUSTRATIVE PROOFS OF EVOLUTION BY DIRECT ADAPTATION, WITII IIEREDITY OF ACQUIRED CHARACTERS :EPIPIYTES, PARASITES AND SAPROPHYTES . . .

VIII. ILLUSTRATIVE PROOFS OF EVOLUTION BY DIRECT ADAPTATION, WITII HEREDITY OF ACQUIRED CHARACTERS :AIPINE AND ARCTIC PILANTS • . . . . .

IX. ILLUSTRATIVE PROOFS OF EVOLUTION BY DIRECT ADAPTATION, WITH IEREDITY OF ACQUIRED CHARACTERS :SWOLLEN ROOTS AND TUBRROUS STRUCTURES . . .

x. ILLUSTRATIVE PROOFS OF EVOLUTION BY DIRECT ADAPTATION, WITH HEREDITY OF ACQUIRED CHARACTERS :DEGENERATION . . . . . . .

XI. ILLUSTRATIVE PROOFS OF EVOLUTION BY DIRECT ADAPTATION, WITH HEREDITY OF ACQUIRED CHARACTERS :-THE ORIGIN OF HONOCOTYLEDONS . . . . . . . 90 INJEX 



\section{LIST OF ILLUSTRATIONS}

1. Ampelopsis Veitchii, with adhesive pads . Frontispiece

2. Effects of drought and moisture on timber - To face page 8

3. Ononis spinosa, experiments with . . . , , 16

4. Zilla myagroides. Desert and cultivated forms ", 22

5. Ranunculus heterophyllus . . . . , , 28

6. R. heterophyllus, experiments with . . . , , 34

7. R. trichophyllus, (a) with submerged and (b) aerial foliage . . . . . . , , 32

8. Proserpinaca palustris, experiments with . , , 34

9. Cyrilla, with aerial and submerged foliage . , , 36

10. Trichosanthes, with adhesive pads . . . " , 38

11. Plocamium coccineum, with adhesive pads . " , 40

12. Convolvulus lanatus, a non-climbing desert species . . . . . . . " 42

13. Periwinkle (vincr major), climbing in darkness , " 44

14. Corydalis claviculata, showing transitions between leaves and tendrils . . . , , 46

15. Vine, showing transitions between tendril and inflorescences . . . . . . , 48

16. Salicornia herbacen, a physiological xerophyte; and Littorella lacustris, a hydrophyte . "

17. Melampyrum pratense, showing details of parasitism. . . . . . "

62

18. Passiflora carulea, accidentally parasitic on Euonymus japonicus; and Melampyrum arvense, parasitic on Tare . . . . 
19. Nardus stricta and Sagina procumbens; examples of hereditary depauperism

20. Asparagus, Tamus and Avena, showing two cotyledons . . . . . .

21. $R$. heterophyllus, germinating seeds with arrested axial root

22. Mustard, germinating in water with arrested axial roots

23. Bidens cernua. Anatomy of roots of a land (a) and aquatic form $(b)$ :

24. Young plants of Victoria regia and Sagittaria sagittifolia, showing analogous forms . 


\section{THE HEREDITY OF ACQUIRED CHARACTERS IN PLANTS}

\section{CHAPTER I}

\section{INTRODUCTION}

IT does not seem to be generally known that Darwin supplemented his theory of " 'The Origin of Species by Means of Natural Selection" by another interpretation of the Methods of Evolution. Though he states in the following passage that the two occur in nature, in reality they are mutually exclusive. The first trace of the alternative is found in the Preface of the first edition of "The Origin of Species by Means of Natural Selection," whereon he says :

"Natural selection is the main but not exclusive means of modification." This is explained on p. 11 as: "Some slight amount of change may, I think, be attributed to the direct action of the conditions of life."

He does not say how he conceived they could be combined; but in 1868 he had completely differentiated them:

"The direct action of changed conditions leads 
to definite or indefinite results. By the term 'definite action' I mean an action of such a nature that when many individuals of the same variety are exposed during several generations to any change in their physical conditions of life, all, or nearly all, the individuals are modified in the same manner. A new subvariety would then be produced without the aid of selection."1

The reader will note the cause of both "indefinite" and "definite" variations is attributed to changed conditions of life. Sir E. R. Lankester distinguished the former as "birthvariations" "spontaneously (arising) by innate variability." ... "Nothing done to them after birth ... causes the desired characteristic [in breeding]. It appears unexpectedly, almost unaccountably as an inborn quality." 2

$\mathrm{He}$ is here alluding to what Darwin called "individual differences." ${ }^{3}$ From such, natural selection is supposed to select the fittest to survive. "The characteristics of a race or species are maintained by natural selection, just as much as they are produced by it." In these words Sir E. R. Lankester is evidently not in accordance with Darwin, who attributes indefinite variations to the external conditions of

\footnotetext{
1 An. and Pl. under Dom., ii., p. 271.

2 "Science from an Easy Chair," Daily Telegraph, 22nd February 1906.

3 "Origin," etc., 6th ed., p. 34.
} 
life, which bring about their production, before natural selection can do anything. But elsewhere in his article he says: "'These variations have no necessary fitness or correspondence to the changed conditions which have produced them." 'The last four words are apparently an echo from Darwin; but they do not seem to agree with "innate" or "spontaneous" birthvariation or "produced" by natural selection.

'Though Darwin based his theory on "individual differences," it would seem that Dr Wallace repudiates them as "specific." He says :

"In securing the development of new forms in adaptation to the new environment, natural selection is supreme. Hence arises the real distinction .... between specific and non-specific or developmental characters. . . . The latter are due to the laws which determine the growth and development of the organism, and therefore rarely coincide exactly with the limits of a species." 1

With regard to "definite" variations, Sir E. R. Lankester is also at variance with Darwin. These are now regarded by him as what are called "acquired characters"; which, he asserts, "cannot be handed on by inheritance to a new generation." "They are," he says, "a direct reaction to the environment." . . . "It does not affect the stirps, the inner reproductive germs." 
In plants, however, the latter are not in existence when the vegetative organs are affected. On the other hand, Darwin says that definite variations give rise to "a new sub-variety" . . . "without the aid of selection."

It is nearly forty years ago since I began studying plants to see how far direct observations could support "Darwinism" - a theory I never accepted from my first reading of the "Origin" in $1859^{1}$ - I never succeeded in finding a case in nature in support of it. "Individual differences" or variations are everywhere, but I soon saw that these were not the materials of evolution. On the other hand, proofs accumulated on every side of Darwin's "definite" variations, now called simply "Adaptations." My accumulated materials were gradually worked up into the two volumes published in the International Scientific Series. But I by no means stood alone. Botanists abroad had been at work on precisely the same lines. 'Three years after my "Origin of Plant Structures" appeared (1895), M. Costantin issued his "Les Végétaux et les Milieux Cosmiques" (1898).

Now, ecological botanists are ubiquitous, all being at one in practically accepting Darwin's alternative of " The Origin of Species by Response

I In 1872, I was fortunate in gaining the "Actonian Prize," on the subject proposed by the Royal Institution-"The Theory of Evolution of Living Things "- butInever referred to natural selection. 
to the Direct Action of Changed Conditions of Life." The object of this book is to put before the reader a few of the incontestible facts establishing the heredity of acquired characters upon which the evolution of plants is based. It is no theory like "Darwinism," but the process may be seen everywhere by the observant eye.

It is based on two lines of evidence-Induction and Experimental Verification. The first is simply that when innumerable and independent coincidences are found, all conspiring to secure one and the same end, it is a perfectly legitimate and logical conclusion to recognise as a fact identically the same "cause and effect" at work in each case. Such is always accepted as a genuine "Natural Law"; by which is always meant that the same results follow the same causes under the same conditions.

In my work "On the Origin of Floral Structures, by Insect and other Agencies," ${ }^{1}$ I was obliged to rely almost entirely on Induction; because it is impossible by experiment to convert a "regular" into an "irregular" flower, which has always some special structures adapted to insects, etc.; but in this book one has the great advantage of putting pretty well every induction to the test of experiment. The result in every case regularly confirms it, so

1 Intern. Sci. Ser., vol. lxiv. 1888; and see The Making of Flowers, S.P.C.K., 1891. 
that the conclusion drawn may be stated as follows: The Origin of Variations in Structure (upon which alone species are based) is due to an inherent Power within the Plant, by means of which it Responds to the Direct Action of changed conditions of Life. The result being what Darwin called "Definite" Adaptations.

Darwinians say that the influence of the environment may affect the "vegetative" organs of plants, or the soma, but that anything so "acquired" cannot affect the "reproductive" germ-cells, and therefore cannot be hereditary. Darwin himself maintained that such variations, on the contrary, are hereditary. His words are :

"With respect to what I have called the indirect action of changed conditions, namely, through the reproductive system being affected, we may infer that variability is thus induced. Many facts clearly show how eminently susceptible the reproductive system is to very slight changes in the surrounding conditions." 1

It must be remembered that no germ- or sperm-cells are in existence in plants when the environment acts upon their roots, stems or leaves. Nevertheless the effects are hereditary, as will be seen hereafter.

Now there is an abundance of experimental verification, and what may be called Nature's own experiments - which may be seen wherever

1 "Origin of Species," etc., 6th ed. p. 7. 
plants grow in somewhat different conditions than usual-clearly prove that Darwin was right, and that Neo-Darwinians are wrong.

What is meant by "acquired characters" will be explained and defined in the next chapter; they may always become hereditary, whenever the conditions which caused them are sufficiently prolonged.

M. E. A. Carrière in his work "Sur la Production et la Fixation des Variétés," observes from his great experience:

"C'est loi générale que, dans la nature, tout tend à se reproduire et même à s'étendre que - par conséquent les modifications peuveut devenir héréditaires" (1865).

Darwin agrees with $\mathbf{M}$. Carrière in saying:

"Perhaps the correct way of viewing the whole subject would be to look at the inheritance of every character whatever as the rule, and non-inheritance as the anomaly." ${ }^{1}$

The inducement to write this book arose from reading an article by Dr Wallace on "Evolution and Character" in the Fortnightly Review (January 1908), in which he restates his original belief in natural selection, and strongly recommends the reader to study $\mathbf{M r}$ G. Archdale Reid's work on "The Principles of Heredity," and Mr W. Platt Ball's book on "Are the Effects of Use and Disuse Inherited?" This, I

1 "Origin of Species," etc., 1st ed., p. 13; 6th ed., p. 10. 
have therefore done, and am more than ever convinced that while Mr Reid's arguments are professedly hypothetical only, they do not in the least conform to what present-day ecologists are agreed upon, i.e., as to the true cause of the changes of structure and function which occur in plants as soon as the environment is changed.

In 1876 Darwin had become a true ecologist. In this year he wrote to Professor Moritz Wagner as follows:

"The greatest mistake I made was, I now think, I did not attach sufficient weight to the direct influence of food, climate, etc., quite independently of natural selection. When I wrote my book, and for some years later, I could not find a good proof of the direct action [i.e., in producing definite variations] of the environment on the species. Such proofs are now plentiful." 1

Plant ecologists, as modern botanists are called who "study" plants "at home," i.e., as growing wild in their various sorts of physical conditions, are accepting "Adaptation" by response as a proved fact. Germany, France, Denmark, the United States, South Africa, abound with ecologists. A complete change of front has taken place within the last twenty years; but as Darwin himself was the first to profound this view, I called it "The True Darwinism."

1 " Life and Letters," vol. iii., p. 159. 

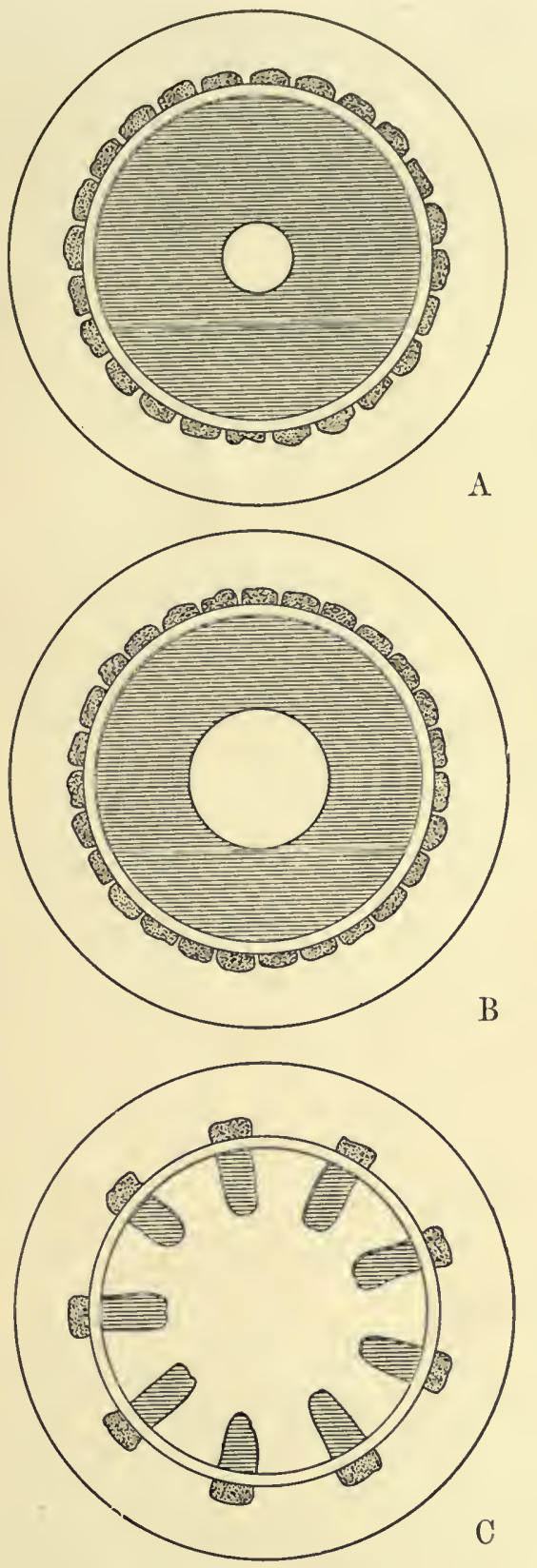

Fig. 2.-Experiments on stems in a very dry air $(a)$, a very moist air (c), and normally (b). (See p. 31.)

[To face page 8. 



\section{CHAP'TER II}

ON SUPPOSED METHODS OF EVOLUTION; AND THE HEREDITY OF ACQUIRED CHARACTERS

SrNCE zoological writers strictly limit " acquired characters" to certain kinds of structure and habits of animals, ${ }^{1}$ of which only a portion can apply to plants, it is necessary to explain the usage of these words in the vegetable kingdom. I would, therefore, venture to define them as the results of any change of structure (morphological and anatomical) from the normal characters of any part or parts of the plant. (i.e., in comparison with others of the same species or genus which have not changed at all) through the means of a response to some new and direct action of the external influences of the environment, or "changed conditions of life." To take an example in illustration. The adhesive

1 "All the effects of exercise are acquirements-for example, the enlargement which exercise causes in muscles. The effects of lack of exercise are also acquirements-for example, the wasting of a disused muscle. The effects of injury are acquirements-for example, the changes in a diseased being or an injured arm." - "The Principles of Heredity," G. A. Reid, p. 5, note. These scarcely apply to plants, but Mr Reid does admits that "No doubt, to a limited extent some use-acquirements are made by plants" (note, p. 32). To this further allusion will be made. 
pads formed on the tips of the thread-like tendrils of the American Virginia creeper (Ampelopsis hederacea) are never formed until contact with a wall or rock, etc., has taken place. They result from the irritation; but they are not hereditary. It is only the power to make them which is hereditary.

On the other hand, in the Japanese species (A. Veitchii, ${ }^{1}$ fig. 1) they are already formed, but only partially developed before any contact at all. In this species, therefore, they are hereditary, but quite useless until contact has taken place; when they at once begin to develop into perfectly adaptive structures. Such is obviously a result of a Response with Adaptation to a purely mechanical contact of the soma with the wall, and before any reproductive germ-cells exist. There are many other cases of permanent and hereditary results of the influence of simply physical forces, such as pressure, weight, etc. 'These are quite sufficient to call out a responsive action by which, sometimes temporary, at others hereditary, results accrue.

Moreover, these effects are altogether connected with the soma or vegetative system, long before any reproductive organs exist; yet, when these put in an appearance, the seeds have some-

"Similar "pads" are hereditary in Bignonia haplophyllum and Arthrophyllum cirrhatum. 
how been so influenced that they reproduce the results effected long before by the soma alone. Now botanists have this great advantage; they have facts to deal with and no theories whatever to maintain. There will be no need to write an octavo volume of $\mathbf{3 5 0}$ pages like Mr Reid's. All I need do and have done before, is to put facts before the reader, and trust him to consider them with an unbiassed, still less, a prejudiced mind.

Dismissing teleology and the "bathmic" theory of evolution, according to which it "has occurred in obedience to, and under the immediate direction of a Deity," ${ }^{1} \mathrm{Mr}$ Reid adds :

"Either the environment has acted on species, which have reacted to it, or, their adaptive changes were miraculous. There is no third alternative. If the environment caused the adaptation, it must have done so by means of Natural Selection; or, by causing individuals to make adaptive acquirements which were transmitted to offspring."

I have italicised the last sentence as it exactly describes the whole contention of plant-ecologists of to-day, and is what I am advocating in this book, and of which I have just given a preliminary illustration.

Now I cannot emphasise the fact too strongly that I am, and have done so for upwards of ${ }^{1}$ Op. cit., p. 13. 2 Op. cit., p. 14. 
twenty years, following in Darwin's footsteps; who, in his later years, advanced precisely what ecologists now maintain, "that sub-varieties can be formed without the aid of Natural Selection."

Darwinians usually make a somewhat sharp distinction between permanent hereditary structures as hands and muscles, and their development from infancy to the adult stage as being acquirements due to use. Thus, Mr Reid tells us that "adaptive acquirements" are, e.g., a muscular or a weak arm. Such being the results of use and disuse respectively.

"But modifications acquired as a result of use and disuse are clearly never transmitted ${ }^{1}$ ... nearly all the developmental changes which occur between infancy and manhood are attributable to it." 2

\section{He had previously observed :}

"An infant's limb never attains to the adult standard except in response to stimulation similar to that which developed [but what first evolved] the parent's limbs ? ${ }^{3}$ Plainly, then, that which is transmitted to the infant is not the modification, but only the power of acquiring the modification under similar circumstances" (Author's italics).

1 Op cit., p. 34. But if the strong muscles of a cat, by which it makes great leaps for its size, be not hereditary, how is it that tiny kittens can make similar leaps-several times their own heightwithout any practice at all? A baby can support its own weight.

- Op cit., p. 35 . $\quad$ Op cit., p. 34. 
'To apply this statement to plants, Mr Reid's words would have to be altered somewhat as follows :

"The power of acquiring a modification under similar circumstances is a general one, belonging to living protoplasm and its nucleus, so that plants of no affinity can, and do, acquire precisely similar modifications of structure in different continents, as the Cactacece in Mexico, and species of Euphorbia in Africa."

But the words, "That which is transmitted to the infant is not the modification," would have to be changed to:

What is transmitted is the power, not only of acquiring the modification anew under similar circumstances, but of actually reproducing them without the latter, and in a totally dissimilar environment, provided the conditions of life which first induced them to arise, have continued for a sufficiently long series of generations, till fixity has been secured. 'Thus, the dissected foliage of certain submerged plants is reproduced when the seed is sown on land, and that peculiar form of leaf-it will be shown-was purely an "acquired character" by response to the water.

But even supposing that Mr Reid was right, it is beside the really important question, as to how came the rudiments (say, of the bones and muscles which require to be exercised for their 
full development) to exist at all in the unborn infant? These, like all other inborn and hereditary structures, have to be accounted for in any question of evolution. For it is on structures alone upon which species are founded. All "acquired characters" seem to be recognised by Neo-Darwinians as beside this allimportant question. I may here say at once that I regard all structures, hereditary or not, as having been primarily acquired.

To explain how this "power of acquiring fit modifications in response to appropriate stimulation" arose, Mr Reid says it

"provides a short cut by means of which qualities, too numerous to be evolved and maintained as inborn traits by Natural Selection (owing to the immense mortality which would be involved) are evoked at need. . . . The chief aim (if we may use the expression) of Natural Selection has been to evolve it." 1

No proofs are given to substantiate this statement, and when we recall Darwin's warning that natural selection is only a metaphor to express the fact that many die and few survive under the struggle for existence, ${ }^{2}$ one wonders how any "power" can be evolved by it.

I am only concerned with the question as to the hereditary character of structures, as these I repeat alone are concerned in the estimation

${ }^{1}$ Op cit., p. 35. 2 "Origin," etc., 6th ed., p. 63. 
of species, as all systematists will at once acknowledge; for the botanists at Kew have nothing else whereon to base their descriptions of plants in the Kew Herbarium. This was a point which never entered Malthus' mind when he wrote his Essay on Population. He was only concerned with one single species-Homo sapiens.

Darwin, by taking Malthus' conclusions as to the elimination of the sick and needy in a time of scarcity of food, obviously applied a process which has nothing to do with the origination of new structures; and although Darwin assumed the existence of variations of structure, to account for their destruction (to explain the fact that myriads of offspring are born, but few survive every year) he supposed the majority of seedlings or young animals were born with "injurious," that is, "inadaptive" structures, which per se killed off the unfitted to survive. This was a pure and unwarrantable assumptioneven Malthus did not assume this. Mr Reid in following Darwin endorses this assumption, for he says:

"Nature has eliminated with greater or lesser certainty all individuals incapable of withstanding want, hardship, or disease, or who are deficient in endurance, speed, sight, scent, hearing, taste, digestion, and so forth." 1

He brings forward no proof or examples that 1 op. cit., p. 16. 
Nature ever produces such defects in the structure and functions of seedling plants, or young animals. Moreover, he makes no mention of the nature of any "injurious" structures which Darwin assumed to account for these defective senses. It is all a pure assumption to support the theory of natural selection, in order to account for the imaginary way by which the elimination of the great majority was supposed to take place.

The real causes are as follows among plants. As the whole of the animal kingdom ultimately lives upon the vegetable, plants must supply the entire quantity of food required, not to add innumerable vegetable parasites as well, for both young and old. Myriads of germinating seeds perish accordingly, being destroyed by slugs and other mollusca, and "mildews," etc. But far more seeds and spores-about 50,000,000 of these it is calculated can be borne in a single malefern ${ }^{2}$-never germinate at all. They fall where the conditions of life are unfavourable, and perish. This misfortune is not due to any inadaptiveness in themselves, but to the surrounding conditions, which will not let them germinate. Thus thousands of acorns and other fruits, as of elder, drop upon the ground in and by our hedges, roadsides, copses, and elsewhere ; but scarcely any or even no seedlings are to be seen round the trees.

1 Bower's, "The Origin of a Land Flora," p. 23. 


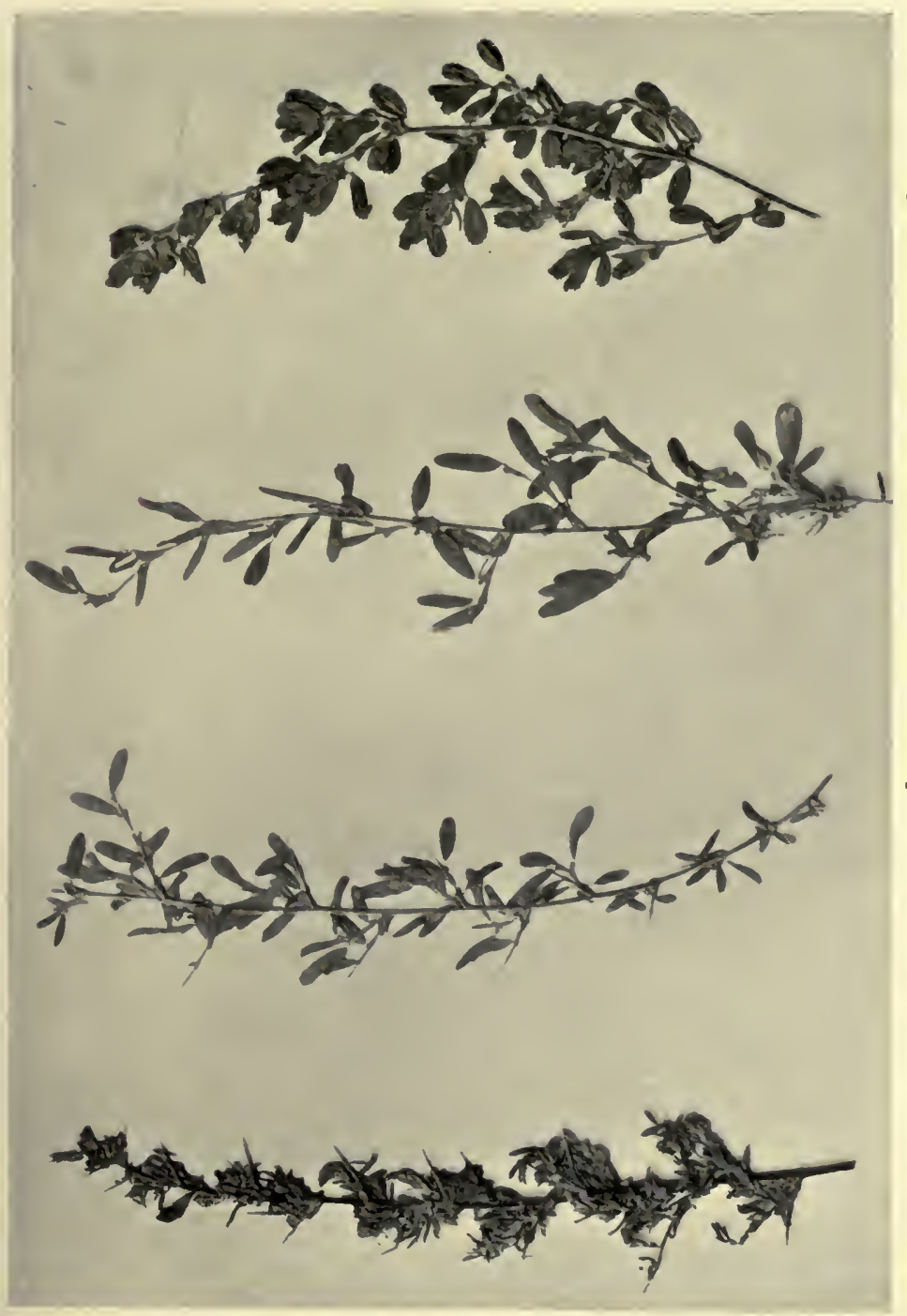

吾骂

के हूँ हू

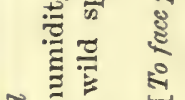

$\approx \approx$

$\Xi$

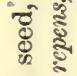

อิ

๘

ㄹ.

嗼

- हु

$\rightarrow$

剀

ऽ

मै

ซึ

D

쮸

ฮั ช

$>0$

궁

항

in

을

\& क

.ึँ हैं हैं

की

跑

○

। $0 \dot{0}$

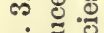
我艺 

With herbaceous plants, the seedlings often spring up in masses, but as no two seeds are absolutely equal in point of size and in the amount of nourishment stored up within them for the embryo, they come up at different rates, so that the first get the start and smother the later and smaller plantlets; so that there are at least three great causes of destruction - "fortuitous" as Darwin called them. But in all cases the seedlings would have grown perfectly well had the environment been propitious. 'This is the true field or operation of natural selection. A bad term, because there is no real "selection" whatever. It is simply natural ill-luck for the deceased and good fortune for the survivors. It is merely the better adapted under the circumstances which live. Darwinians, as $\mathrm{Mr}$ Reid tells us in the above quotation, also use the term "acquired characters" for mutilations and scars. I at once would say that evolution has nothing to do with such things, and all assertions that they are not usually inherited may be doubtless true; for if they were, and if lost members were not reproduced, the offspring of warriors might have very little left to inherit, if lost arms and legs could not be reproduced!

The question before us is the same as Darwin's -What is "The Origin of Species?" But Darwin avoided dealing with the actual origin of variations, i.e., "incipient species," as he called them, 
merely assuming that they arose out of " individual differences," and then, taking for granted that the "fittest to survive out of indefinite variations" would be hereditary. It is my object to show how variations do arise, viz.: by the plant responding to changed conditions of life; and, secondly, that the altered structures in adaptation to the new environment do become hereditary, if the plants, generation after generation, continue to live long enough in the new surroundings. That is the true and only method of Evolution.

The response usually shows itself at once, i.e., as soon as growth commences under the new conditions. As the soma or vegetative system precedes the appearance of the reproductive organs, the influence or "direct áction," as Darwin called it, is solely upon it, but the effects lie dormant till the reproductive organs put in an appearance. It may be a year afterwards, as in biennials, or longer still, even years, as in trees, when the seeds ripen, so that it is not till the following, the second, or other year that the original effects reappear in the offspring.

The exact or immediate origin of "sports," i.e., the sudden appearance of some very wellmarked structure, colour, etc., in parts of plants or in seedlings, cannot always be traced, and at present must be assumed-from our positive 
basis of response to environment-to be either due to some more marked influence of substances in the soil or of "crossing," or of the accumulation of effects lying dormant till the marked changes suddenly appear in an offspring. 'That "recessive" characters may be dormant is well known to all who have studied Mendelism, so that at present there is no need to assume any other cause for sports or "mutations" as De Vries calls them. " They are so rare in nature, and so common under cultivation where prepared soils are very different from the more uniform conditions in the wild state, that the induction has strong support in the innumerable coincidences between the appearance of varieties and sports in the artificially prepared soils. The cabbage, for example (Brassica oleracea), has no wild varieties, but they are innumerable under cultivation. The wild chrysanthemum has a very small and yellow flower, yet hardly any plant sports more in colour than the cultivated varieties. Numerous other illustrations might be given as all cultivators of flowers and vegetables know.

Since the present year began another book on "Heredity" has appeared, by Mr J. Arthur Thomson. Being a zoologist, like Mr Reid

${ }^{1}$ I have pointed out that the so-called "mutations" of Einothera have not characters of sufficient importance to be designated as "species" ("Species and Varieties: their Origin by Mutation." A criticism of De Vries, Journal of the Royal Horticultural Society, 1907). 
and Dr Wallace, he is not familiar with plant ecology. On p. 179 ff., he mentions nine "misunderstandings." The first is a common question: How can there be progressive evolution if acquired characters are not transmitted? To this the author replies: (1) "Our first business is to find out facts of the case." The reader will discover that I have done nothing else than follow this sound advice. (2) "In the supply of germinal variations, whose transmissibility is unquestioned, there is ample raw material for evolution." This at once raises the question-What proofs are there that the cause of their appearance did not lie in "acquired characters?" That they originate in germ-cells is a pure assumption.

No. II.-Interpretations are not facts. He refers to Lamarckian interpretations, but $\mathrm{Mr}$ Thomson ignores the force and importance of induction. When one discovers scores of plants of no affinity putting on precisely the same structures under identically the same conditions of life, we are justified in recognising a cause and effect; and when similar results are produced under artificial conditions, and moreover proved to be hereditary without those conditions, nothing more is wanted to convince any one who has not' a preconceived theory to support.

No. IV.-Mistaking the reappearance of a modification for transmission of a modification. 
Darwinians often maintain that the supposed acquired character reappears in an offspring only because the same conditions act on the offspring as on the parent, and, therefore, all that is acquired is the capacity for reproducing the characters. The answer to this is that the acquired character may or may not be inherited. The difference depends on the time, i.e., number of generations to which the plant has been subjected - about six years is the average with cultivators. The reader will find several instances of both kinds herein recorded. There is nothing, therefore, in Mr 'Thomson's book which affects plants, whether it be true or not with regard to animals, with which I have nothing to do. ${ }^{1}$

Mr J. Arthur Thomson wrote an article called "Synthetic Summary of the Influence of the Environment upon the Organism," 2 and concluded as follows:

"This much seems certain, that no attempt to explain the adaptation of the organism to its environment can be complete without a recognition that external influences in the widest sense, and in various degrees of directness, have and have had an important transforming and adaptive action."

To this I cordially agree.

$1 \mathrm{Mr}$ Thomson refers to my book "The Origin of Floral Structures by Insect and other Agencies," gives a wrong date, and ignores "The Origin of Plant Structures."

${ }^{2}$ Proceedings of the Royal Physical Society, Edinburgh, vol. ix., pt. $3,1888$. 
The question of the heredity of acquired characters he here appears to leave open, but he had previously summed up Darwin's and Weismann's views by saying:

"The question, in fact, is not whether direct environmental action may occur or not, nor whether it may be inherited or not, but simply how soon the influence may so saturate through the organism, as to become, by affecting the reproductive elements, transmissible." 1

Indeed the author observes that

"He (Weismann) allows indeed that in the course of generations, if the conditions of change persist, the variations will become more deeply rooted, the reproductive elements will somehow come to feel the change, and the modification will be transmitted and, for a time at least, stereotyped."

My object is to prove that these hypothetical admissions are positive facts, as far as plants are concerned. 

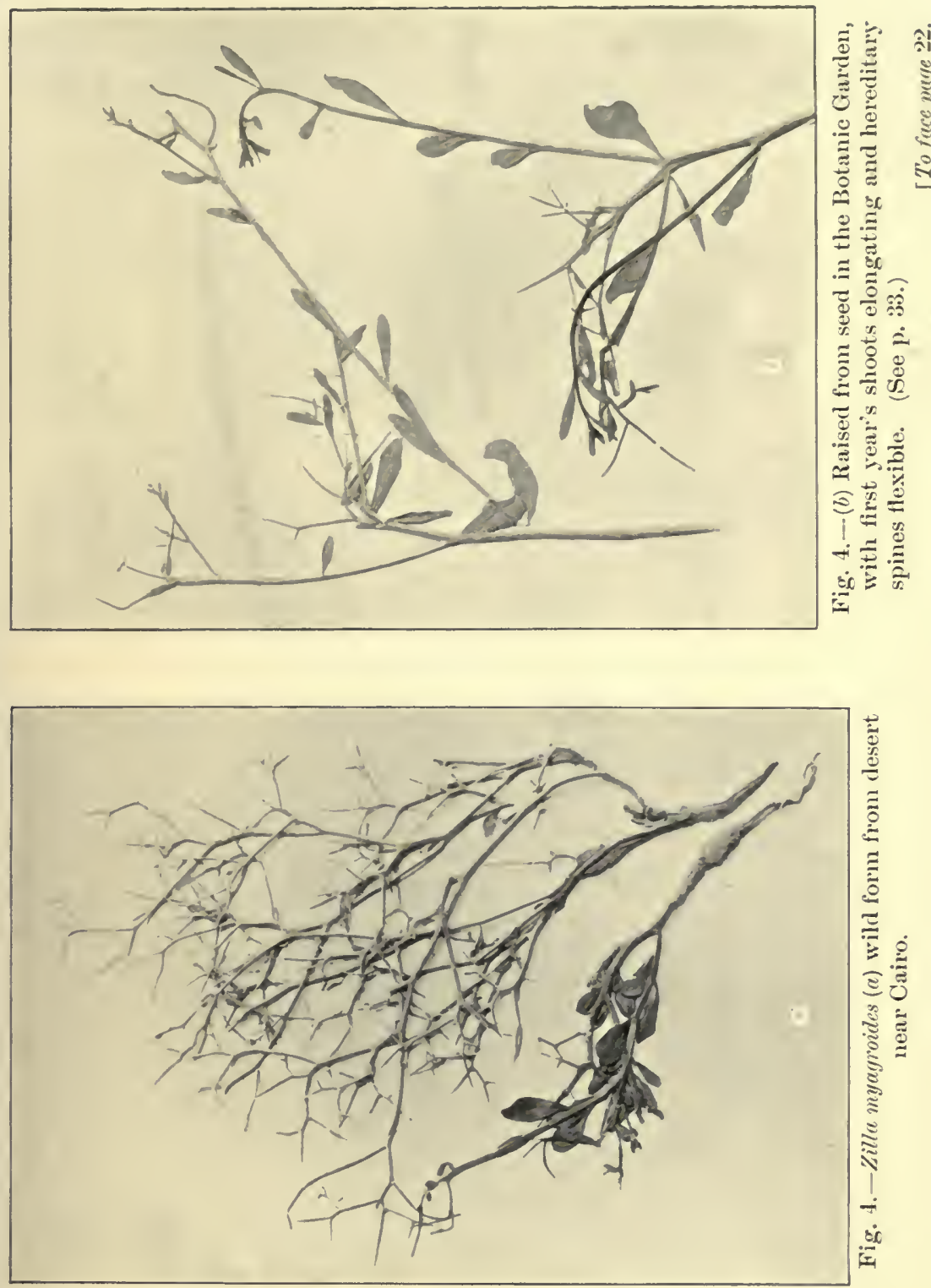



\section{CHAPTER III}

\section{ECOLOGY AND ITS IMPORTANCE}

IT is a noticeable fact that the chief men of eminence who are now Darwinians of to-day are zoologists, and if Dr Wallace, Sir E. R. Lankester, Mr G. A. Reid, and Mr Thomson may be regarded as leaders, it is at least unfortunate that they do not appear to be well posted in the latest conclusions of plant ecology. At all events they do not allude to it; for equally eminent botanists take precisely opposite views. Plant ecology is now well established on the Continent and in America, and especially in the north of England and Scotland; but as far as Dr Wallace's paper, Mr Thomson's and Mr Reid's books are concerned, the conclusions of ecologists are totally ignored.

The great advantage of ecology is that the botanist, as the word explains, "studies" plants "at home," i.e., as they grow in nature; and they do not, nor have any need to theorise upon the origin of species at all. They no longer study plant-structures with the view of detecting agreements and differences for the purpose of 
classification-such being the professed and useful work of the older botanists as Bentham and the Hookers and the present systematists at Kew. The ecologist asks of nature what is the meaning or use of every point in the details of structure observed, morphological and anatomical; and he finds, by noting as well, every detail of the surrounding conditions of the plant under investigation that the first result of direct ecological observation, is that their structure is in adaptation to the environment.

$\mathrm{He}$ then groups plants into "associations" according to their environments, and calls plants of dry districts xerophytes; of moist, marshy places, hygrophytes; true aquatic plants bring hydrophytes, and all of an intermediate character, mesophytes. Of course, every degree of transition between such typical groups occurs, and special sub-types can be recognised. 'Thus, high Alpine and Arctic plants are sub-types of xerophytes, as well as succulent, maritime plants, etc.

The second step is to find out how the plants acquired their adaptive structures. $\mathrm{He}$ first proceeds inductively, by noticing that similar structures are found in plants of no affinities in widely separated countries, but possessing similar conditions of soil and climate. Hence arise "representative" or "mimetic" forms, as those alluded to, the Cactaceo of Mexico, and 
the fleshy-stemmed Euphorbias and Stapelias of Africa. Similarly Arctic and Antarctic plants are much like those of high Alpine regions. All aquatic plants have certain features in common. Such "parallels" are innumerable.

What conclusion can be drawn from these universal facts? It is a perfectly safe induction, based on an immense number of coincidences, that the same causes have produced the same effects under similar conditions. 'That is, a true natural law is recognisable.

What, then, is the cause? 'There is nothing else than the surrounding conditions under which the plants grow alike. These constituting the environment are the "cause," or supply the "direct or definite action," as Darwin calls it, to which the plants, or we might say, the living protoplasm and its nucleus respond; and so build up identically the same structural forms.

This is a perfectly legitimate argument, the coincidencies are innumerable, and occur in all members of the plant world, so that the ecologist says: "We are invincibly forced to see" the direct cause in the environment (M. Costantin).

Now, it is a most important fact which I would reiterate, that this was exactly Darwin's later view, as an alternative to his theory of natural selection, to which Darwinians persistently adhere. I have already quoted Darwin's 
interesting and remarkable letter to Wagner; which is in fact a refutation of his own theory of natural selection. This complete change of front in Darwin I would most strongly emphasise; because, I repeat, it is precisely the view now taken by ecologists. Indeed "now" is incorrect. It was accepted by botanists twenty years ago ; but Darwinians of to-day completely ignore it.

Having thus established a firm conviction by induction, ecologists next proceed to look for experimental verification. Of this there is an abundance, both artificial and natural; for Nature is constantly making experiments; as e.g., with amphibious plants, which grow quite differently when in water or air. Before giving illustrations of inductive and experimental evidence, it will be advisable to quote the views of a few eminent ecologists as to the conclusions arrived at. I have already alluded to $\mathrm{Mr}$ J. Arthur Thomson's remarks in 1888; but he seems now to limit hereditary variations to spontaneous origins in the germcells. My own book on "The Origin of Floral Structures by Insect and other Agencies" 1 also appeared in $\mathbf{1 8 8 8 .}$

Professor Warming of Copenhagen, in alluding to adaptations in xerophytic, i.e., "drought" plants, observes :

I International Scientific Series, vol. Ixiv. 
"I answer briefly to the question which arises, namely, whether these adaptations to the medium should be regarded as a result of natural selection, or whether they owe their origin to the action, in modifying forms, exercised directly by the conditions of the medium. I adopt this latter view . . . the characters of adaptation thus directly acquired has become fixed." I

Similarly, M. Costantin, speaking of Arctic plants, says :

"We are led to think, so to say, invincibly, that one can only explain the general characters of Arctic plants by adaptation-e.g., if all Arctic plants are perennial, it is because they live near the Pole. It is the conditions of life which have caused this hereditary character." ${ }^{2}$

Though both Dr Wallace and Dr Weismann are "Darwinians" yet they cannot help taking the opposite view when striking cases come before them; Dr Wallace observed that local varieties of butterflies and other groups of insects "seem to indicate that climate and other physical causes have, in some cases, a very powerful effect in modifying specific form and colour, and thus directly aid in producing the endless variety of nature." 3

Similarly Dr Weismann came, eighteen years afterwards, to precisely the same conclusion, for he says :

1 "'Lagoa Santa," p. 465.

2 "Les Végétaux etles Milieux Cosmiques"; also "La Nature Tropicole."

" "On Natural Selection," p. 179 (1877). 
"It must be admitted that there are cases, such as the climatic varieties of certain butterflies, which raise some difficulties against this explanation (direct influences upon the germcells). I myself, some years ago, experimentally investigated one such case, and somehow I cannot explain the facts otherwise than by supposing the passive acquisition of characters produced by the direct influence of climate." 1

We shall see, too, how Mr Reid was impressed with the acquired characters of the Kauri pine. I shall have occasion to quote another early, but like conclusion by Mr Hiern, as to the adaptation of a circular outline to the leaves of water-lilies in 1872. The fact is, that as soon as the relationship between any organ and its surrounding condition occupies the attention, it at once becomes obvious that the result was due to response only. That is all that is required, as the fundamental basis of evolution, the acquired characters being hereditary.

This is why plant-ecologists have already abandoned natural selection, in the sense Darwin used it; but still recognise the usefulness of the term as meaning the survival of the better adapted under the circumstances in the struggle for life. ${ }^{2}$

1 "Essays upon Heredity," etc., Eng. ed., p. 99.

2 "Introduction to Plant Ecology" (Stanford). 


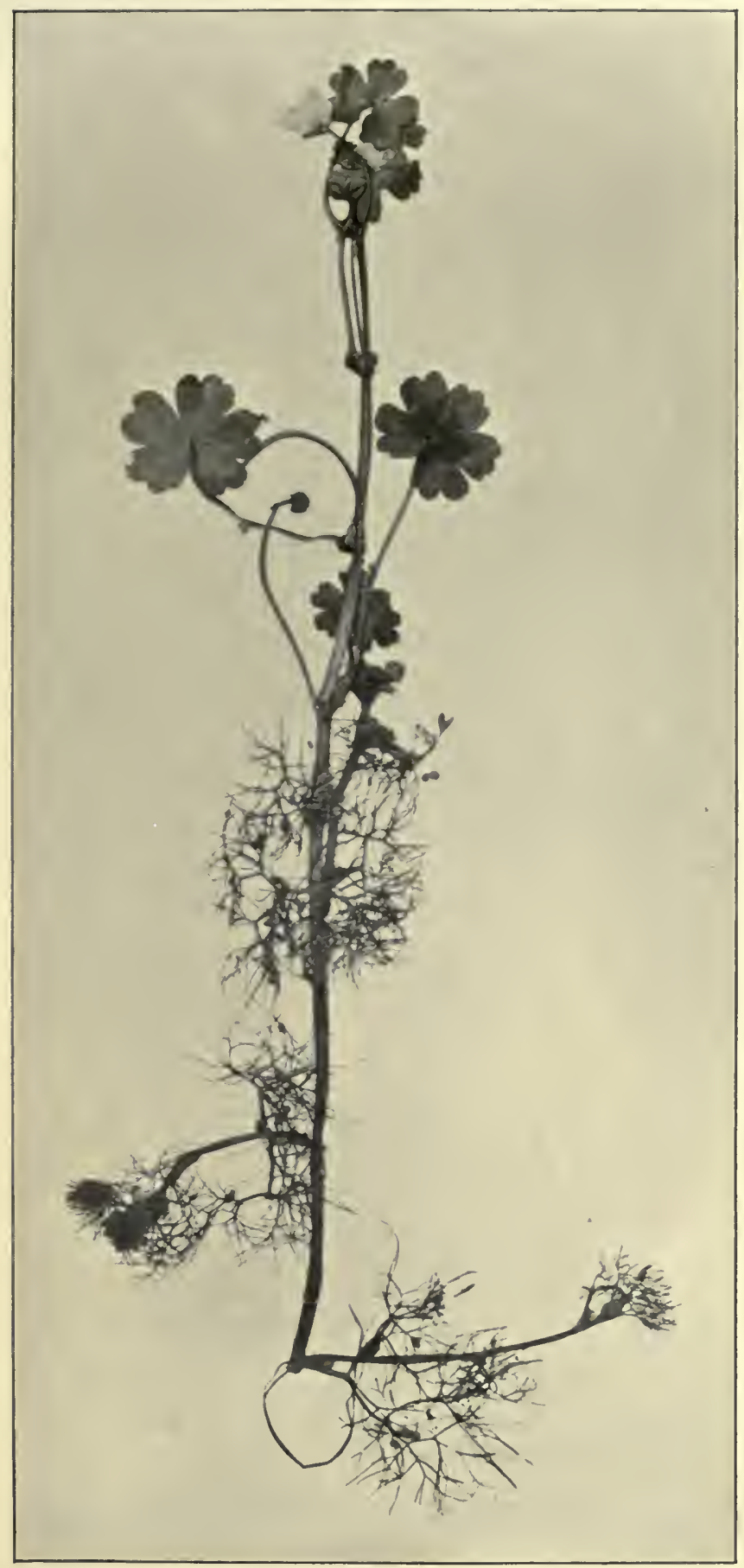

Fig. 5.-Ranunculus heterophyllus, with submerged dissected leaves and completely formed floating leaves. Note:-A leaf at the water level has a forked segment in the air, fully formed, the rest of the leaf submerged is dissected. (See p. 3t.) 



\section{CHAP'TER IV}

ILLUSTRATIVE PROOFS OF EVOLUTION BY DIRECT ADAPTATION WITH HEREDITY OF ACQUIRED CHARACTERS :- THE STRUCTURE OF STEMS, SPINES, AND AQUATIC LEAVES.

IN the preceding chapters enough has been said for the reader to understand the difference between the old and the True Darwinism. He will now ask for proofs. This and the remaining chapters will furnish a selection, taken from different parts of plants; the proofs being primarily of induction, secondarily corroborated by experimental verification. More than these no scientist can secure, nor is any required.

Mr Reid, in alluding to the Lamarckian theory of evolution, which in certain respects applied more to animals than plants, stated that it "can explain hardly a single fact in the whole world of plants." ${ }^{1}$ The two facts which are apparently only known to him are delegated to a footnote, in which he writes as follows:

"No doubt, to a limited extent some useacquirements are made by plants. Thus the

1 Op. cit., p. 15. 
Kauri pines of New Zealand, when taken from exposed hillsides, yield timber much tougher and more durable, and therefore more valuable though less easily sawn than timber taken from sheltered valleys. The ingenious timber merchant endeavours on occasion to sell his valley planks as the product of the hillside. Climbing plants also "use ' their tendrils." 1

So far from these being " uses of a limited extent," they are really " adaptations by response to changed advironments," such being of universal extent, as far as wood or timber is concerned, while climbing processes are extremely common and of great variety; and in every case there is the inductive evidence that the process of climbing has resulted from a response to the external conditions of life, and the climbing adaptation has become hereditary, as explained above in the case of the Japanese Ampelopsis Veitchii.

What he has here observed with regard to the Kauri pine is applicable to all other trees; willows and poplars frequenting brook-sides, etc., have quite worthless wood. On the other hand in Cape Colony, being an excessively dry country, all the trees are remarkable for the durability and hardness of their wood. Moreover, this character is hereditary, for the Araucaria imbricata of Chile is naturally a strong xerophyte, and produces very hard wood

${ }^{1}$ Op. cit., p. 32, note. 
in its native mountain sides. The tree is raised from seed, and much grown in England. I had occasion to cut an old tree down, and the man found that he was unable to saw it through, just as Mr Reid describes the Kauri pine, and so chopped it down with an axe.

This hardness is solely due to drought. M. Ph. Eberhart ${ }^{1}$ experimented with many kinds of woody stems, growing them in ordinary air, very moist conditions and a very dry one, respectively. The results were most marked, all the "mechanical tissues" such as wood being strongly developed, as well as "sclerenchyma" of the bast; whereas, all such tissues at once failed to be well developed under the second, as compared with stems grown normally under the first (fig. 2). He thus proved by experimental verification the general truth of the inference which $\mathrm{Mr}$ Reid drew from the Kauri pine alone.

If we take the Kauri pine and the Araucaria as extreme types of xerophytic trees, and compare the structure of their stems, first with mesophytes, and then with hydrophytes, we see at once how wood and other mechanical tissues decrease until, in a submerged stem they are almost entirely wanting. The inference is irresistible that the structure of the stem is in response to climatal and other con-

1 Ann. des Sci. Nat., tom. xviii., p. 61, 1903. 
ditions of the environment; and although they may at once begin to change if the environment is changed, the original tissues last long enough to prove that they have been acquired and are hereditary, since they are reproduced when the trees are raised from seed in a totally different locality and environment, as the Araucaria in England, and the water crowfoot in a garden.

As it is with timber so is it with the stems and woody shrublets. There are many spiny xerophytes, the spines may be abortive or arrested branches as of the sloe, hardened like the wood described above, or they may be spinescent leaves as in the barberry; or both branches and leaves, as in the furze. On growing any such plant in moist air and soil, the inevitable result is the gradual disappearance of the spines and spiny leaves, and the corresponding elongation into branches bearing fully-developed leaves.

The following is an experiment I made with the common rest-harrow (Ononis spinosa, L., fig. 3), growing wild in a very dry situation by a roadside. I collected some seeds, and also took cuttings. These I planted in a garden border, keeping this well moist with a hand light over it, and a saucer of water so that the air should be thoroughly moist as well. Its natural conditions were thus completely reversed. They all grew vigorously. The new branches of the first year's growth bore spines, proving 


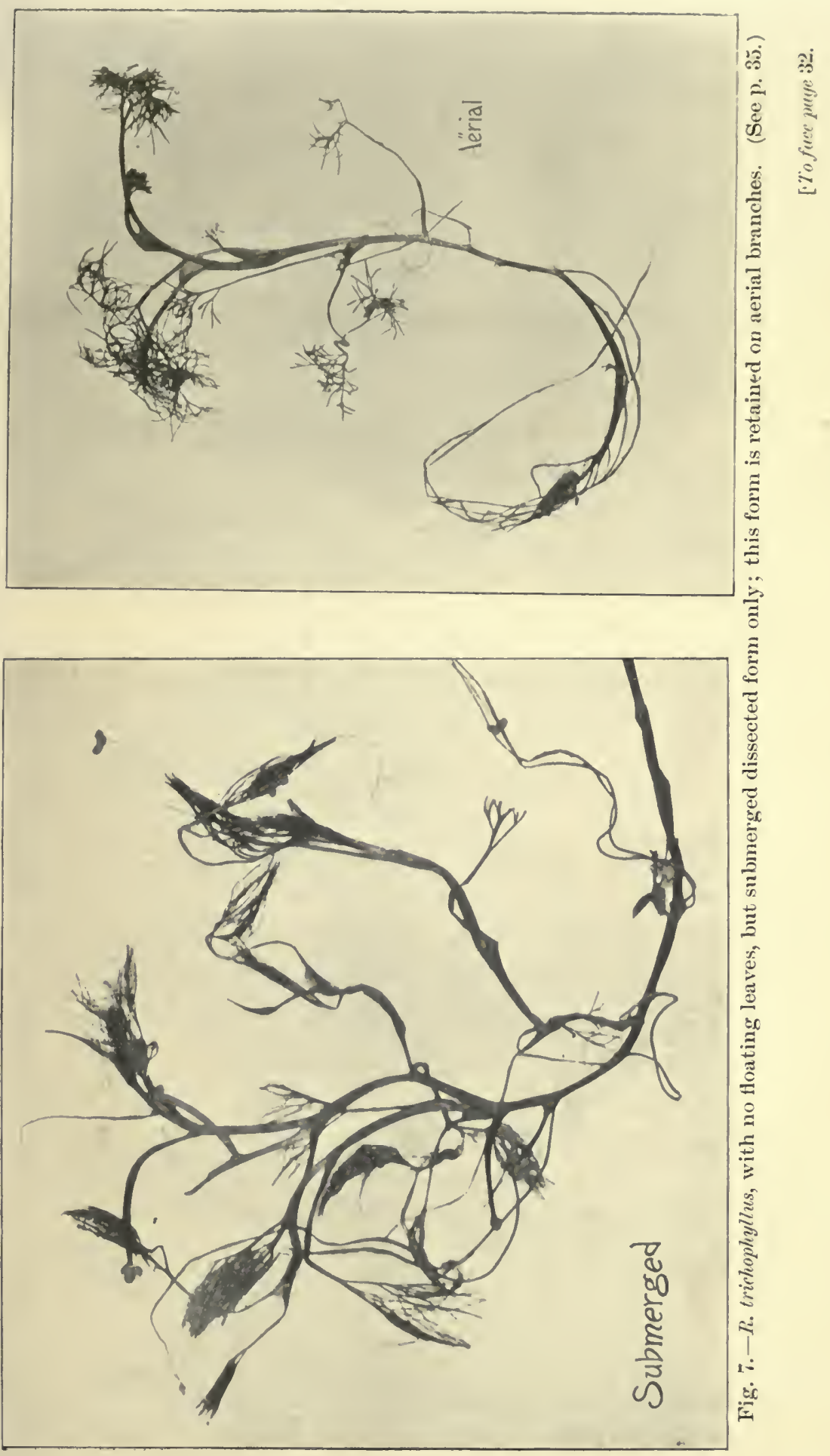



their hereditary character, but instead of their being long and stout, they were not an inch long, and like needles. This proved the spines to be an hereditary feature. In the second year there were none at all; moreover, the plants blossomed, and, taken altogether, there was no appreciable difference from $O$. repens, $\mathbf{L}$.

As an example of experimental cultivation, the late Dr Sickenberger of the School of Medicine, Cairo, raised a plant of Zilla myagroides (fig. 4) in the Botanic Garden. It is common in the Waddys of the desert, being a crucifer about 3 feet high, and intensely spiny. Spines were produced in the first year by heredity; but they had already begun to be arrested, for I found the anatomical structure to be far less consolidated, the woody and sclerenchymatous tissues very lax compared with that of the spines in the desert. To judge by their appearance they would probably have required more than one year to disappear altogether.

From these and many other instances, such as wild, spinescent trees, e.g., plum and pear, which lose their spines under cultivation, we may safely generalise; for a careful search will soon show Nature at work in modifying plants, and changing them from xerophytes to mesophytes, or vice versâ, so that, first, by the accumulation of coincidences or induction; secondly, by experiments, both artificial and 
natural, the contention is overwhelmingly established that xerophytic characters are always acquired by the soma or vegetative organs long before there are any flowers with germ-cells, and yet they prove to be hereditary, for a shorter or longer time, until the environment is changed again, and new adaptations arise afresh; at the same time they retain their hereditary floral characters of affinities, which themselves had been originally and similarly acquired.

Similar conclusions are arrived at by reversing the conditions from water to air. I experimented with a variety of the water crowfoot (Ranunculus heterophyllus, fig. 5). Sowing the seeds in garden soil, about one hundred and fifty to two hundred seedlings appeared. They were all alike, and first bore finely-dissected leaves, as if they were under water, but the entire anatomical structure was changed, having a true epidermis and stomates, which do not exist on submerged leaves. After a time the completely formed floating type of leaf appeared, as if the stems had reached the surface of imaginary water, and, lastly, flowers were borne in the air, as always is the case. This experiment proves that the two kinds of leaf were hereditary. I took some of the plants as soon as the aerial type of the dissected foliage was well developed, and transferred them to a 



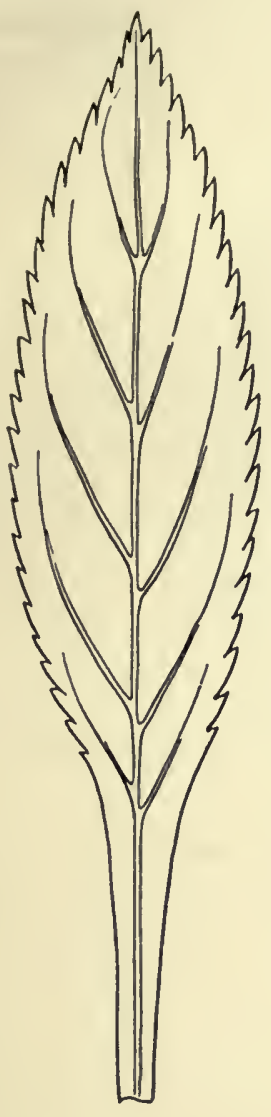

a
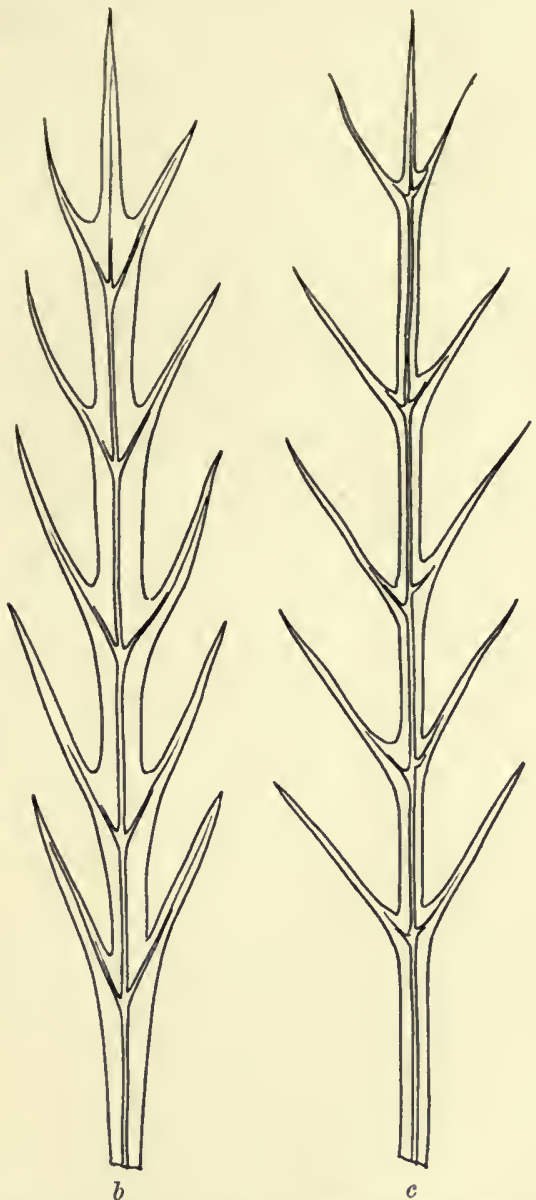

Fig. 8.-Proserpinaca palustris, $(a)$ aerial leaf; $(b)$ semi-dissected leaf in moist air; $(c)$ completely dissected submerged leaf. (See p. 36.) 

bowl of water. In a few days all the leaves adapted to air perished, but the stems at once proceeded to develop new dissected leaves, but adapted to live submerged (fig. 6).

Nature frequently performs analogous experiments, for small ponds may dry up for a season, and if the water crowfoot grows in it, it flourishes equally well on the mud in air, if not better than in water. If the crowfoot grows very crowded, it often happens that branches get thrust up into the air. When this occurs the anatomical structure changes at the water level, all above it being in adaptation to air as occurs often with $\boldsymbol{R}$. trichophyllus (fig. 7 ).

'The values of these experiments reside first in the rapid or immediate response made by the plants to totally new conditions, which strengthens the induction that the submerged type of leaf, like the aerial one, is induced to be formed by the external conditions. But experimental verification is not wanting. Mr MacCallum, of the United States, starting with the $\dot{a}$ priori assumption that the plant is unable to complete the full development of the leaf, in consequence of the super - saturation of the living substance, protoplasm; and in order to test this "working hypothesis" he made the water denser by dissolving nutritive substances in it. These he assumed would, by "osmotic" action, cause the extra water to be withdrawn from the protoplasm; 
then, he argued, the plant might perhaps be able to complete the leaves by filling in the interstices between the "ribs," or, as we call it, the "skeleton" of the leaf.

He took a plant (Proserpinaca palustris, fig. 8 of the United States-we do not possess it, but it is allied to our Mare's tail) which bears complete leaves out of water, but dissected ones below it. He began his experiments with a saturated atmosphere. This was quite sufficient to check the development of the leaves, so that, although in air, the dissected type was commenced; but with regard to the leaves on the submerged part of the stem, all the nerw leaves produced under the water holding nutritive salts in solution were full sized. ${ }^{1}$

Hence the proof is complete; that such structures, namely, spines in drought, and fennellike leaves under water are the actual results of the responsive power of the plant, bringing about new and adaptive structures, under the influences of the direct action of changed conditions of life.

But these experiments carry us further. They prove the contrary to what Dr Wallace maintains, that "the transmission of the modifications of individuals due to . . . climate, food, or other external agencies, has no valid evidence," for having settled the point that the above

1 Bot. Gaz., vol. xxxiv., p. 93. 


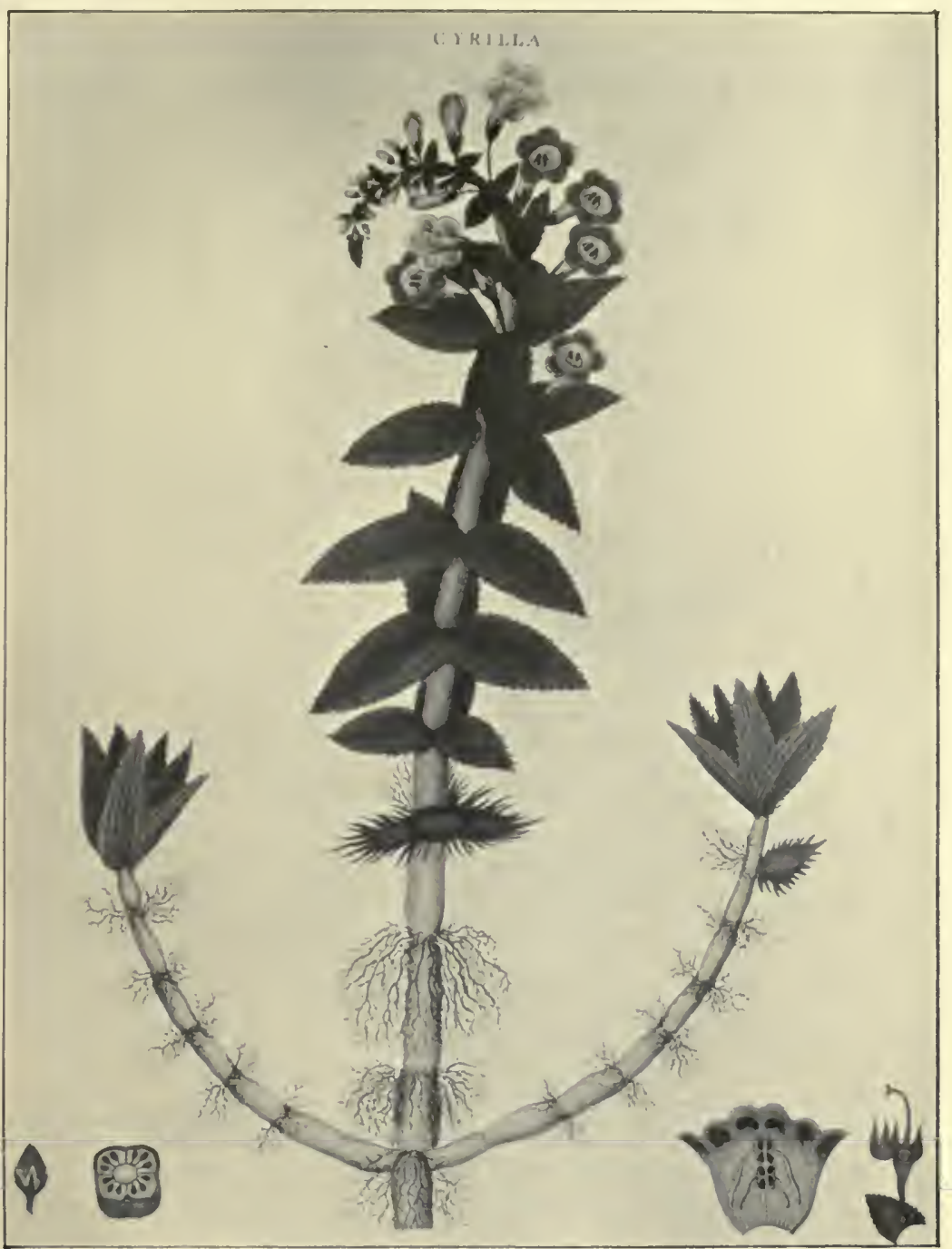

Fig. 9.-Cyrilla (Achymenes), aquatic plant with stem partly in air; the submerged leaves are finely dissected, the acrial being complete. Note: -the lowest aerial is partly dissected, being imperfectly affected by the water. (See p. 37.) 

described structures are due to the direct action of air, water, soil, etc., my experiment with the water crowfoot showed that both types of leaf appeared by heredity when the seed was sown in earth and air, and not in water. No further proof is required.

Proserpinaca palustris is like Cyrilla (fig. 9). They both grow in water, but the stems reach into the air, so that they habitually produce both kinds of leaves. One leaf of Cyrilla is represented with a laciniate margin. This is due to its growing partly in air and partly in water. It is a common feature in the floating leaves of Ranunculus heterophyllus. A leaf may be found standing obliquely, so that half the blade has grown in air, the other half being submerged. The result is that the former half of the blade is completed, but the latter dissected.

Another feature is noticeable in these two plants (Cyrilla and Proserpinaca). Always forming both kinds of leaves, they are only formed in air or water respectively, and neither can be formed under reversed conditions. But in Ranunculus the dissected type has become so rigidly fixed that, as I have shown, it is now formed in air. So that while only the capacity of forming them is heredity in the former, the actual structure itself is hereditary in the water crowfoots. 


\section{CHAPTER V}

\section{CLIMBING PI.ANTS}

Mr REID also attributes "use" to climbing by "tendrils"; but this is only one of an infinite variety of uses which plants have acquired. The same word is applicable to the ivy which climbs by roots on the stem against a wall or trunk of a tree, etc.; to the Clematis which "uses" the sensitive petioles or leaf-stalks for the same purpose; to the pea, which has converted many of its leaflets into tendrils; to the Virginia creeper and others which have superadded adhesive pads to the tips of the tendrils. These latter are not foliar but metamorphosed flowering branches. Again, a vast number of tropical lianes and temperate plants climb by their stems, as the hop, scarlet-runner and Convolvulus of this country. These all have peculiar structures which, like their properties, have been "acquired" and are now hereditary " uses." Corresponding with the external forms there is always specialised internal anatomical structures in each case. These latter originally only arise when the special responsive action takes place, 


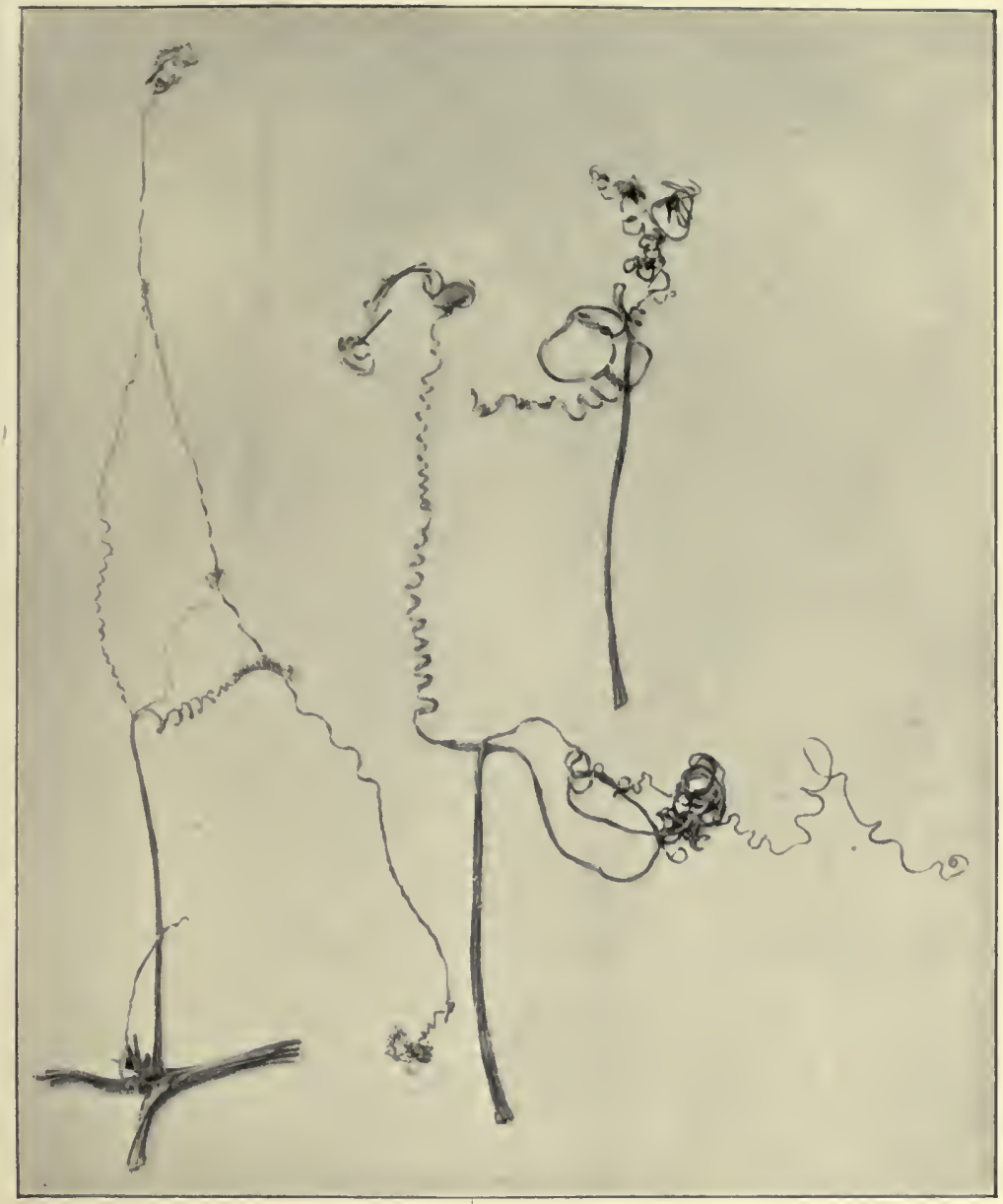

Fig. 10.-Trichosanthes, tendrils bearing very small adhesive pads. (See p. 41.)

[To face page 38 . 

as will be described below; but they may become so fixed as to be hereditary and then appear in anticipation of their use.

I have mentioned the ivy. This often supplies a good illustration both of direct adaptation and heredity of an acquired character. If any shoot happens to creep along the ground, it develops ordinary roots which penetrate the soil for nourishment. But if it touch a wall or tree-trunk, it develops quite different roots adapted for climbing. Here, then, we have two results of immediate response to two different conditions. That the latter kind of roots can be hereditary as well, is seen in the fact that when shoots hang down in a shady place reithout touching a wall, they often have rudimentary roots, as if ready to be fixed upon a wall if it could find one.

But this is by no means a unique example. Strawberry runners root at the joints for propagative purposes, the formation of roots being a universal result of the presence of a damp soil; but if a young runner be trained to grow erect up a stick, roots make their appearance but cannot develop properly in the air. Hence the "stages of acquirements" may be stated thus: First, the "direct action" of the environment calls out the responsive power in the plant, and it develops the appropriate structure. If the influence be continued long enough, i.e., through 
many generations, the species not only acquires a much greater facility of response, but the resulting structure becomes "improved" ; ${ }^{1}$ and structural changes of much complexity follow; so that petioles (e.g., of Clematis) become tendrils (e.g. Naravelia); and of leaf-blades, the midribs become tendrils as of the pea; or flowering branches as of the vine and Virginia creeper, and all these structural adaptations are hereditary.

Of course Darwinians will say all these adaptive structures arose by "spontaneous congenital variations," without any aid from any direct action of the environments. If so, the burden of proof lies with them, by bringing forward some illustrations either from Nature or experiments. At present they make no proposal of doing so. All Mr Reid does is to credit natural selection with the power of accounting for everything; ${ }^{2}$ but ecologists, who do not theorise, prove their statements by vast inductions, if experimental verification is impossible; but so often is it available that the general conclusion is completely verified. Take e.g., the adhesive pads, we have seen that they are formed by contact only in the American species; but the Japanese species of Ampelopsis anticipates it in a partially formed manner. Now, could these adhesive pads arise spon-

1 This, for instance, is seen in the minute pads of Trichosanthes compared with the well developed ones of Ampelopsis (see below).

${ }^{2}$ Mr Reid calls natural selection a Deus ex Machiná ! 


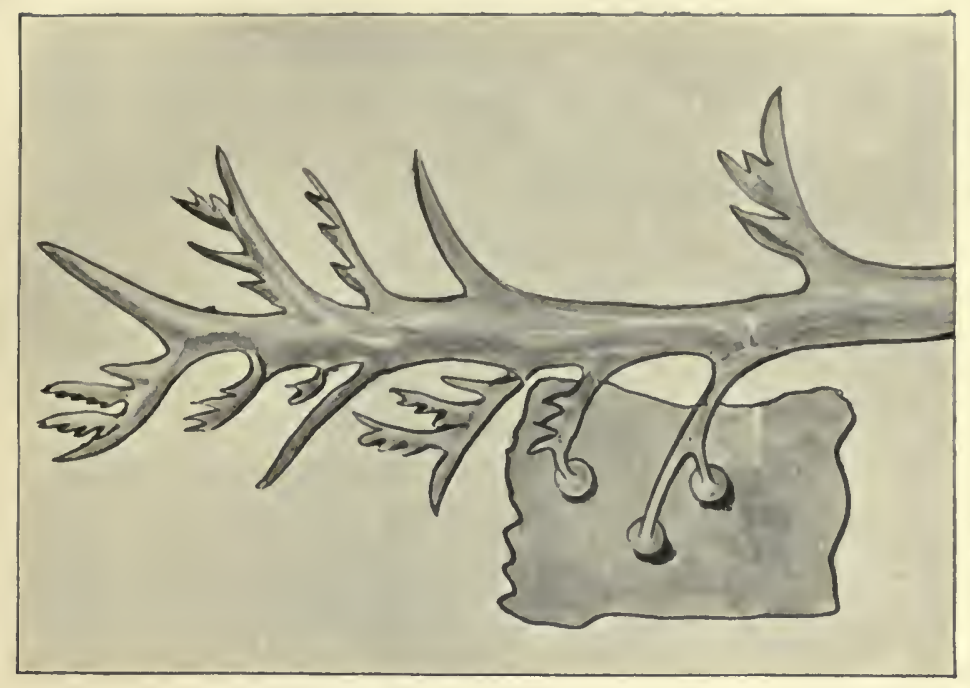

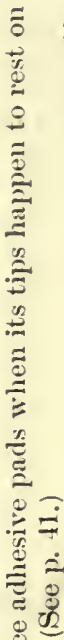

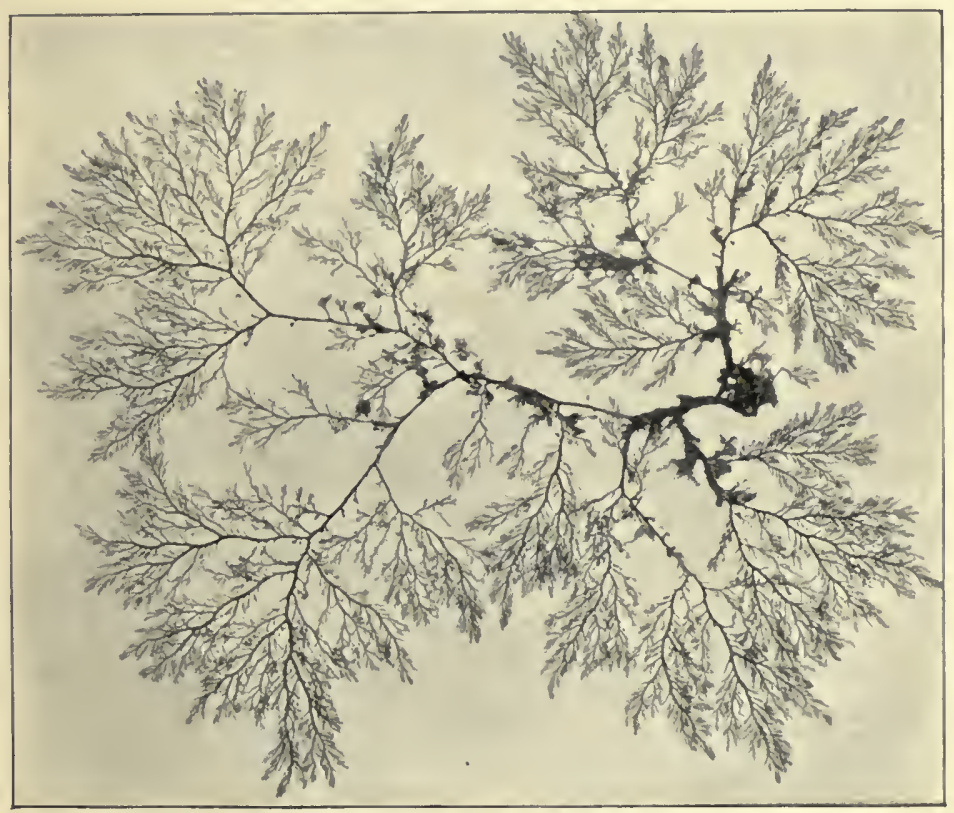

ב⿱艹 

taneously at first by congenital variation, and then have been "selected" etc.? Or was it the actual contact which excited the protoplasm, so to say, to invent and then make them; and so they became hereditary in course of generations?

Analogy will throw some light upon this. Members of the cucumber family, which climb like the wild bryony, have long tendrils which twine round the supporting object; but a certain plant of a Trichosanthes happening to have its tendrils touching the wall of the glass frame in which it grew, instantly developed a number of minute pads which adhered to the wall (fig. 10), though such a structure is not known to exist in the cucumber family at all. Here, then, as far as has been observed, the pads suddenly arose de novo, merely by the accidental irritation of the tips of the thread-like tendrils.

A common sea-weed Fiocamium coccineum (fig. 11), is known to make similar pads if a tip happen to press against another sea-weed; though it has no need to climb. But there are many cases of a mere mechanical force producing through response hereditary structures.

It is well known that the stems of lianes are very anomalous in their internal anatomy, the prevailing features are a degradation of the supportive or woody tissues, and much increase of the cellular structures, as the medullary rays and cortex. 'This is in accordance with habit, for 
as the stems are supported, atrophy presumably follows from disuse as in the animal world. Water having to be carried to great distances, in many cases, as some lianes are from 300 to 400 or more feet in length, large vessels are also a prominent feature. These differences which are found between erect stems and those supported, are well seen in Wistaria sinensis when grown as a standard, and conversely on a trellis. The former never sends out long shoots every year, as the latter does, sometimes to a length of 30 feet in one season in the United States. An examination of shoots of the same diameter from each sort revealed at once a marked difference. These of the "tree" form, the pith was as 65 to 95 in comparison with the supported one. The wood being in the proportion of 35 to 15 ; the number of vessels in that of 30 to 40 . The diameter of the largest of the vessels was 3 to $3 \frac{1}{2}$ or 4 in the trained.

Precisely analogous differences occur between ivy shoots which are self-supporting, and those supported by roots against a wall. Again, similar differences will be found in one and the same shoot of the bittersweet (Solanum Dulcamara) before and after it has secured a support. That the anomalous wood is "caused" by the shoot being supported is obvious from innumerable instances. On the one hand, the wood of a self-supporting stem is symmetrically arranged 


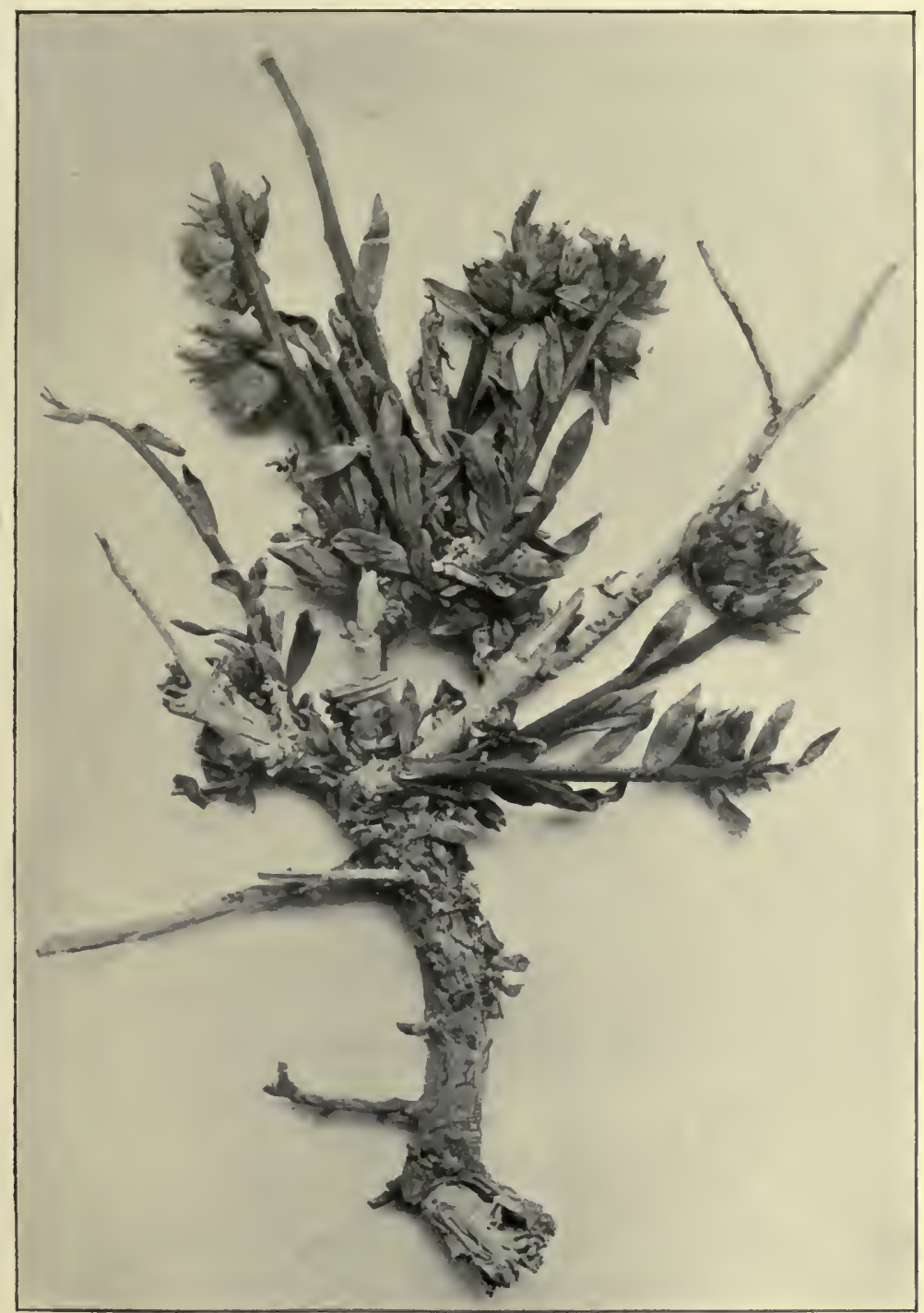

Fig. 12.-Convolvulus lanutas, a non-climbing, woody species, from the desert near Cairo (Natural size). (See p. 44.)

[To face page 42. 

in concentric cylinders, these being practically a combination of girders, the pith being the "web," and its frequent absence by decay being a matter of indifference, as the cylinder is then simply a hoop with a "tire" consisting of the whole length of the stem in width. On the other hand, the support of a liane or climber being extraneous, the stem degenerates. It may be observed that a young liane has cylindrical wood for a year or two, but acquires the characteristic anomalies on climbing.

'These facts quite dispose of Huxley's contention that

" one-half of Lamarck's arguments were obsolete in 1850 , and the other half erroneous or defective, in virtue of omitting to deal with the various classes of evidence which had been brought to light since his time. Moreover, his one suggestion as to the cause of the gradual modification of species-effort excited by change of conditions-was, on the face of it, inapplicable to the whole vegetable world."

If we assume that the degradations of climbing stems (i.e., as compared with self-supporting erect stems of non-climbers or as of timber) arose in anticipation of the stems becoming climbers by accidental or spontaneous variations, the supposition remains to this day an unproven, à priori assumption. But when we see that

1 "Life and Letters of Charles Darwin," vol. ii., p. 189. Huxley, unfortunately, was not a botanist. 
the anomalies arise as soon as, but not before contact in many cases, we are justified in inferring we have a distinct cause and effect. This, moreover, is corroborated by the fact that, plants whose stems are, as a rule, climbers, such as Convolvulus, having nothing to climb up, become creeping herbs, as $C$. arvensis, or stunted woody shrublets, as are other. species of Convolvulus in the deserts near Cairo (fig. 12). The probabilities are greatly increased on the acquirement of climbing by use, and the loss of it by disuse. Many living as shrublets in the desert develop climbing varieties in forests. Both Professor Warming and Fritz Müller drew the same conclusion independently, as follows: Warming says :

"Climbing plants (by stems or tendrils, etc.) owe their development to the dense shade of forests. ${ }^{1}$ The young plant developed in the shade appears to explain it in the following manner; it is forced to grow in height, its branches elongate and grow slender. The first degree of evolution is presented to us by the plants which simply rest upon the boughs of shrubs and trees. These sarmentous plants are numerous in the flora of Lagoa Santa, they belong to Amarantacece, Compositce, Boraginece, Euphorbiacea, Violacece and even Cyperacece. -The adaptation is more accurately effected in the branching plants, of which the branches are inserted at right angles with the stem. Thanks to this peculiarity, they lie easily upon

${ }^{1}$ He is speaking of Lagoa Santa, Brazil. 


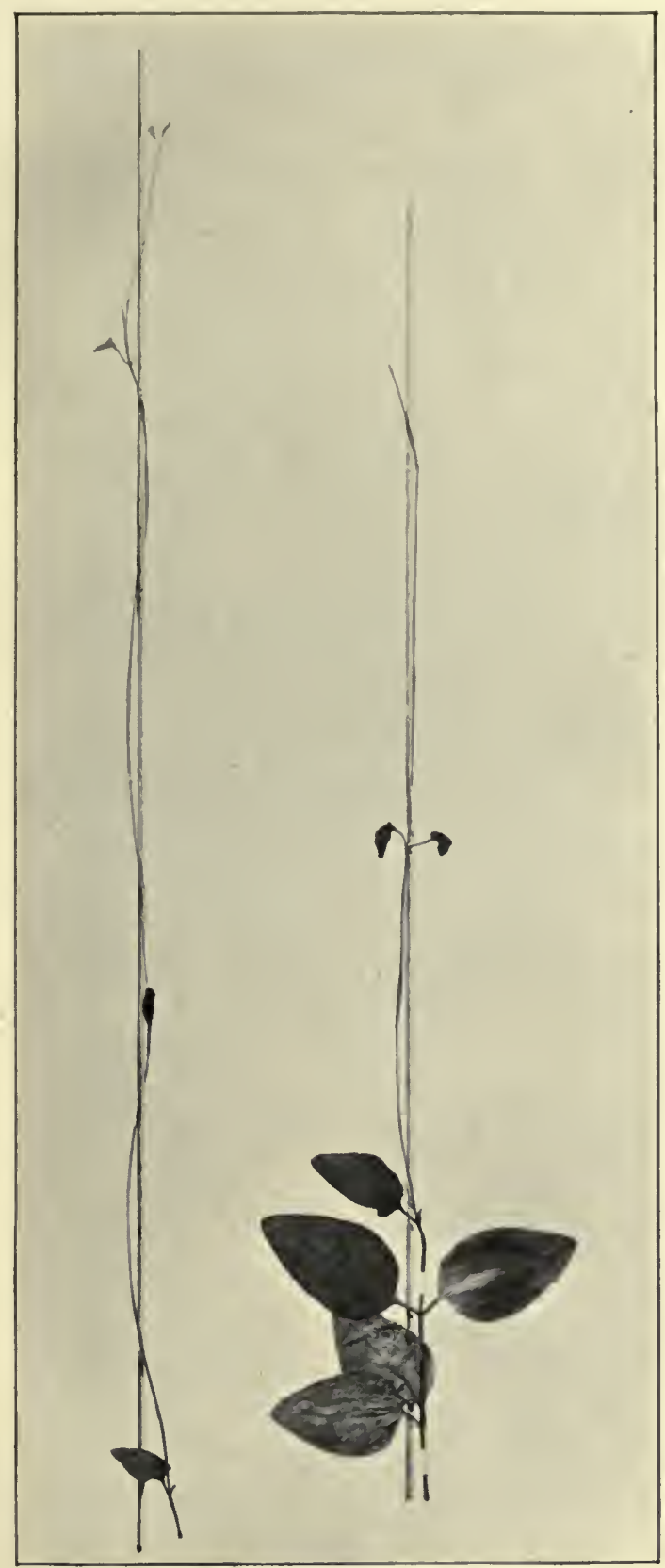

Fig. 13. - Vinca major (Periwinkle), the long shoots climbing rods in darkness. (See p. 46.) 

other branches. This is the case in Chiococca brachiata, Buddleia brachiata, for some species of Strychnos and Hippocratea. Next, as to climbing stems. 'The nutation of the stem is now an advantageous property. 'To this category belong a great number of species of Apocynea, Dilleniacex, Boraginex, Dioscoreaceo, Compositoe, Boussingaultia gracilis, Asclepiadaceo, Malpighiaceo and Euphorbiaceoe."

I would in passing invite the reader's special attention to this passage as illustrating the methods of true ecologists. It will be noticed how the writer refers to a large number of families of plants, not with any object of their classification, as all older botanists would have done, but solely for the sake of their physiological peculiarities connected with habit of growth and evolution.

If the idea that the anomalous anatomical structure of the stems of lianes, such as the ribbon-like ones of Bauhinia, was congenital, appearing first in seedlings among indefinite variations, the fact has to be explained that the wood of these stems, as stated, is not anomalous for one, two, or more years, but quite cylindrical, as in ordinary self-supporting stems ; after having escaped the struggle for existence during germination, then the anomaly puts in its appearance.

Experimental proofs of the acquisition of the

${ }^{1}$ Revue Générale de Botanique, tom. v., p. 213. See also F. Müller's similar conclusions, Journ. Lin. Soc. Bot., ix., p. 445. 
climbing power in stems is easily forthcoming. John Hunter, the eminent surgeon, thus wrote in $1833:^{1}$

"A bean, which when strong, seems to depend entirely upon its own powers; yet if it grows weakly, as when not in the sun, or any other cause acting to hinder strength when growing -in such, if a stick is put into the ground close to it, it will twine round it in loose spiral turns."

This experiment I have imitated with the periwinkle. This plant makes long summer shoots which, like those of the blackberry, bend downwards by their weight till they touch the ground, and then strike root; but they do not climb. Growing a plant in darkness and placing slender sticks close to the growing shoots, they also made "loose spiral turns" round the sticks (fig. 13). We here see, as in everything else, a rapid response to new environmental conditions. Still the question remains: Is the effect hereditary? The power to climb is certainly hereditary, for if this be originally acquired in deep shade or total darkness, as in the experiment, it is now available when the shoots or stems are green and in sunlight, as in the convolvulus, etc. And this power now inherited was acquired by twiners or stem-climbers solely on the soma, long before the reproductive organs were developed. 1 "Memoranda of Vegetation," p. 7. 


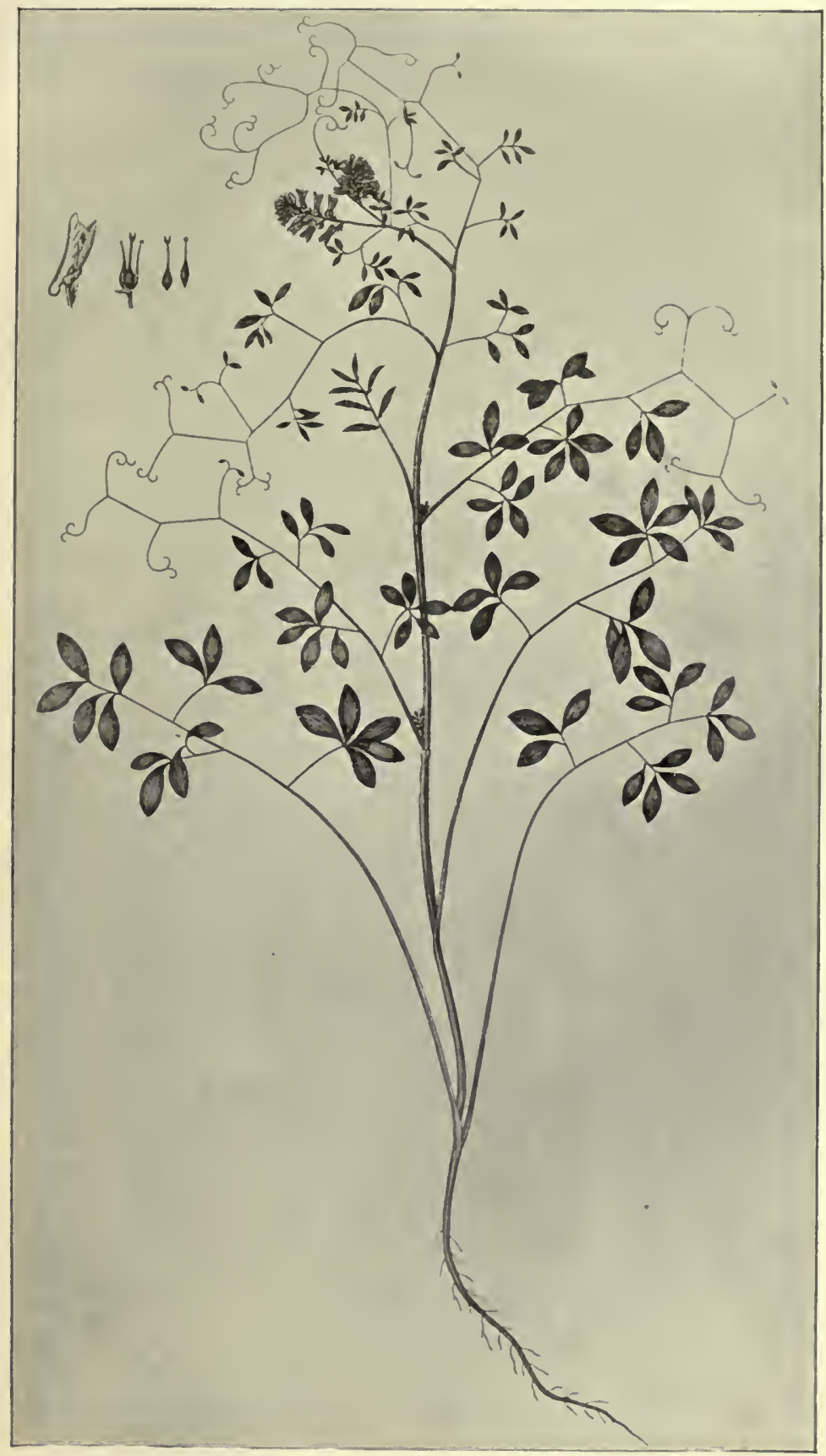

Fig. 14.-Corydalis claviculata, showing transitions between leaves and tendrils. (See p. 48.) 

Though ordinary climbing stems remain more or less straight, if they fail to twine, mostly lying on the ground; yet many tendrils that fail to catch any support, if they do not fall off, subsequently coil up tightly as in the Passion flower, showing that the coiling process is hereditary without the stimulus of the object to induce it to coil.

The power of climbing may be in abeyance and reappear subsequently. Thus dwarf French beans may be sown in a row where one or more may grow long and climb if supported. A cultivated tree with a thick stem which I observed in the Ezbekieh Gardens of Cairo, called Hiptage mandablota of India, sends up one or more long slender shoots which twine around neighbouring bamboos to a height of 10 feet or so. It belongs to the family Malpighiacea, one characterised by having many climbing members; but this species has become a tree. Much more evidence could be given but the above, I think, ought to be sufficient to prove that the property of and structures for climbing were all acquired by response to the conditions of life till they became hereditary. For further facts and details I would refer the reader to my book. ${ }^{1}$

There is by no means an uncommon feature in plants, which $\mathbf{I}$ do not remember alluded 1 "The Origin of Plant Structures," chap. x., pp. $197 \mathrm{ff}$. 
to by Darwinians, and that is transitional structures. Suppose they arose by spontaneous variations, how are we to distinguish between the original stage, the completed alteration, and the half-and-half mean? Climbing plants afford good illustrations. Clematis climbs by means of the petioles of the leaves, the blades being unaltered; only the petiole has acquired a sensitiveness to touch, and coils round an object against which it is pressing. Naravelia differs from Clematis in having the leaves with some of the blades in the form of thread-like tendrils -but not all. The garden pea is in the same condition, but in Lathyrus Aphaca of the pea family the blades are wanting, the entire leaf being changed. If the half-and-half stage, as of Corydalis claviculata (fig. 14), is to be a "mean," then why is not this always the character of leaf-tendrils?

The tendrils of the vine are, as stated, metamorphosed flowering branches and, as a rule, bear no flower-buds; but such may soon be found if a vine be searched (fig. 15). And when they do occur, it is easy to see that this "mean" condition is a disadvantage to the plant, as a portion of sensitiveness is lost. The "maximum" or perfect and complete tendril is obviously the most efficient. Mr Reid recognises the hereditary character of tendrils and that the plants "use" them. Though no one 


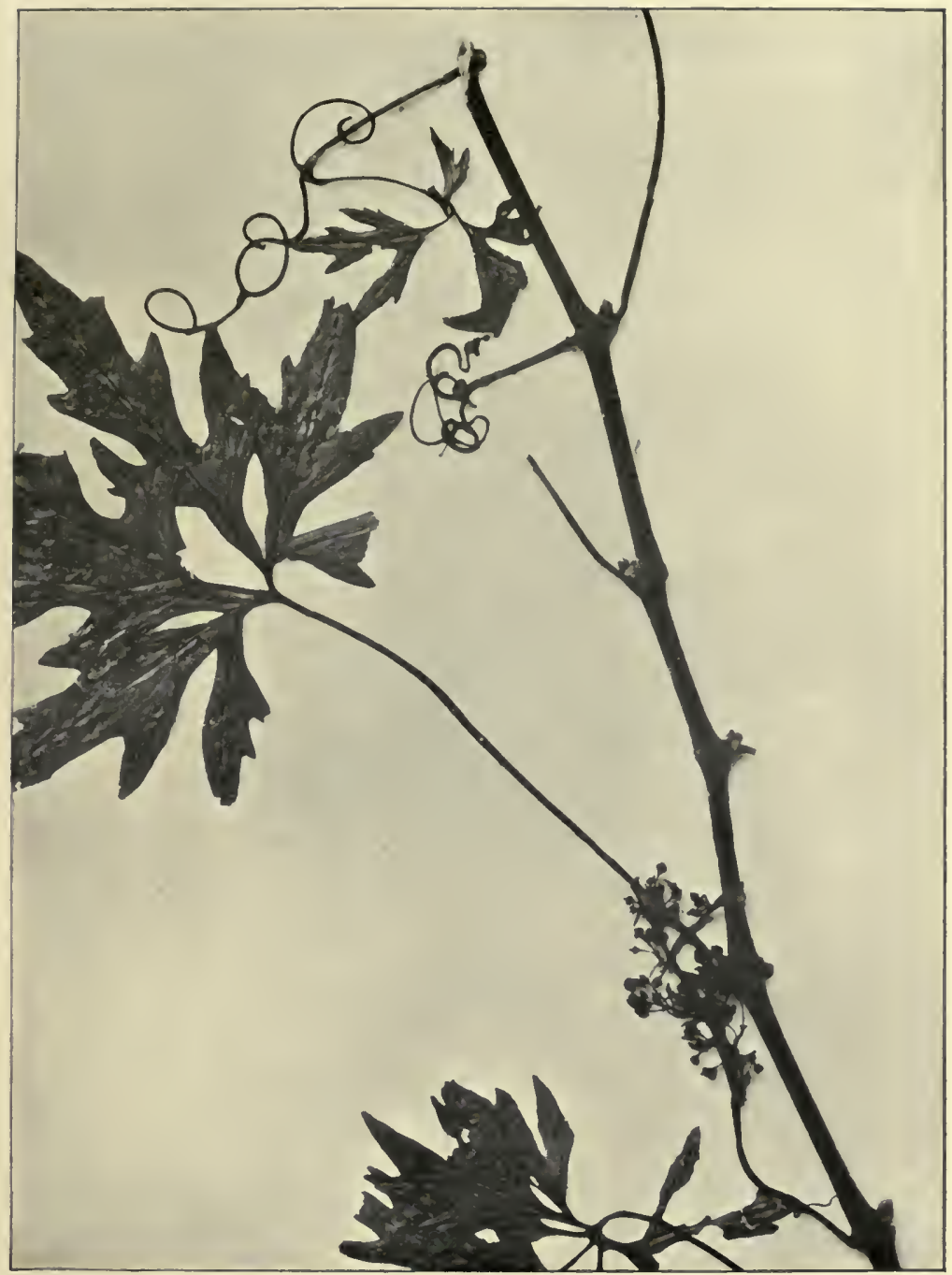

Fig. 15.-Vine, showing transitions between tendrils and inflorescences.

[To face page 48 . 

has succeeded experimentally in converting a leaf into a tendril, the origin of them is obviously, inductively considered, the result of the responsiveness of the protoplasm to mechanical irritations. Darwin shows how both form and sensitiveness of the peduncle of a flowering branch of the vine become more and more of the nature of a true tendril in proportion as the number of buds decreases, and vice versâ. "The gradations," he says, "from the ordinary state of a flower stalk to that of a true tendril is complete." 1 Sometimes the tendril, which arises from the same stalk as the bunch of grapes, becomes a duplicate one. A "double cluster" is then produced.

Now, as all these changes may go on in the same vine, one cannot see what natural selection has to do with the evolution either of a bunch of grapes or a tendril. But, once recognise both the origin of function and of structure to be due to the inherent responsiveness of the protoplasm and nucleus, then everything is at once explained.

1 “Climbing Plants," p. 141. 


\section{CHAPTER VI}

\section{SUCCULENT PLANTS}

These have thick, fleshy stems or leaves, or both together, being true xerophytes, and growing in excessively dry situations or in maritime districts and in saline marshes, in which the salt has been experimentally proved to be the cause of the succulency; for although they may be abundantly watered by sea-spray, as is the samphire on rocks, while the marsh-samphire actually grows in the saturated salt marshes, they are called "physiologically" xerophytic, inasmuch as the effect of the salt is to hinder the absorption of water by the roots, the result in structure being the same as if it were deficient, as in the deserts. About Cairo, as it happens, there is much chloride of sodium and magnesium in the sand, which furnish a curious advantage to certain plants. Thus the Tamarisk and another plant of the same family, Reaumuria, a little herb, excrete these salts, when water is abundant in spring and is transpired, which encrust the surface at the "water pores." In the hottest time of the year, when dews are 
very heavy, they absorb this water and convey it to the interior of the plants.

The use of the fleshiness is to store up water by preventing an excess of transpiration, so that the desert plants do not become desiccated in the prolonged rainless period of drought in the hottest summer months.

I will now give an epitome of the evidence that succulency is due to response in the plants to drought or salts; and that when this result has been thoroughly established, in the majority of cases it is hereditary, inasmuch as no change takes place when the seeds are sown and plants raised in totally different environments.

The following paragraphs are quoted, in part, from my Ecological work on "The Origin of Plant Structures, by Self-Adaptation to the Environment," ${ }^{1}$ to which I would refer the reader for further details.

The presence of salts has been proved experimentally by $\mathbf{M}$. Lesage to be the immediate cause of succulency in maritime plants of temperate climates; as he was able to induce it in garden plants. To these plants of salt marshes may now be added. At Bad Nauheim, near Frankfort, the brine from the natural salt spring is pumped up to some $\mathbf{1 0 0}$ feet over an election of faggots. As the water trickles down and is collected below, it of course evaporates and the

${ }^{1}$ International Scientific Series, vol. lxxvii. 1895, p. 48. 
brine is condensed. A consequence of this is that a number of wild plants growing within a short distance of the erection have acquired a considerable degree of fleshiness, not possessed by the same species elsewhere. ${ }^{1}$ A remarkable fact is the abundance of Plantago maritima (?), though the nearest sea-board is, at least, 200 miles distant. It may have been evolved on the spot from $\boldsymbol{P}$. Coronopus or some other species.

As another example of adaptation, Littorella lacustris may be mentioned as being closely allied to the plantain (fig. 16). This has become an aquatic plant, and acquired all the structures found in such plants, such as airchambers, a narrow leaf, growing very long and ribbon-like in deep water, just as those of the arrow-head does, etc. The common figwort (Ranunculus Ficaria) betrays its aquatic ancestry by having similar air-canals in the stems and petioles, showing that aquatic characters become hereditary, after the conditions which produced them no longer exist, as the figwort is now a terrestrial plant.

The marsh samphire (Salicornea herbacea) (fig. 16), common in salt marshes by the coast, illustrates the succulent type of maritime plants.

That the succulency is due to the direct action of the salt is shown by the results of experiments in which the normal fleshiness is made

${ }^{1}$ I collected a considerable number of these. 


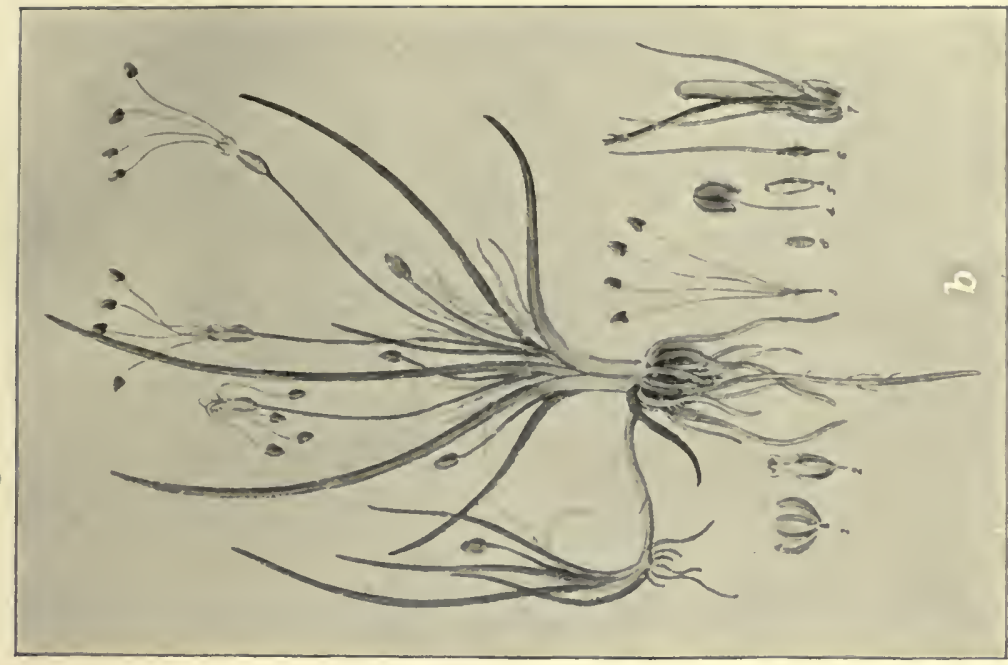

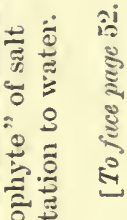

ซิ

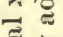

ฮี

है

$\div 3$

요

อิ

$\div 5$

들

के

E

¿

के

ב菉

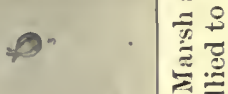

ares

is

Q

8

ชี

के

$\Xi$

.

ปิ

๘

胫

흐

@ᄋ

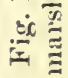



to disappear when a new combination of surrounding conditions is supplied to the plant: thus M. Battandier ${ }^{1}$ cultivated Sedum Clusianum, and the leaves at once began to assume a flatter character; and he remarks as a coincidence that the two species, $\boldsymbol{S}$. stellatum and $\boldsymbol{S}$. tuberosum, which are not rupicolous in France, but inhabit wet places, have flat leaves. On the other hand, I have found those of $\boldsymbol{S}$. stellatum growing in cracks between the flat slabs of rock in Malta in an exposed, heated spot, were always cylindrical. M. Battandier also says that two other species were not rupicolous, but grow in dry earth, viz: -S. rubens and S. Magnoli, have flat leaves in a wet season, but cylindrical ones in a dry summer. Similarly, the common maritime fleshy samphire, Crithmum maritimum, when cultivated in a garden, become luxuriant, and had flat and smooth leaves.

As another example, M. Costantin observed ${ }^{2}$ that Salsola Kali, our common saltwort, grows up sandy rivers from the maritime salt marshes, when it passes into $S$. Tragus by losing the usual character of its leaves.

The most elaborate series of experiments to test the source of the succulency of maritime plants was carried out by M. Lesage, who showed, conclusively, that the presence of salt

1 Bull. de la Soc. Bot. de Fr., 1886, p. 191.

2 Journ. de Bot., 15 Mars, 1887. 
is, at least, a potent cause in its production. He succeeded in making plants, such as gardencress, succulent, by watering them with salt water - this of course is a motive for salting asparagus beds. $\mathrm{He}$ also testifies to the hereditary effects, in that plants raised from seed, obtained from plants of cress, which were somewhat succulent in the first year's experiment, became still more so in the following; so that an increment was added in the second year to the hereditary succulency of the first generation.

"From all the above facts, natural and experimental, the conclusion is inevitable, that while succulency is of benefit to the plants under the conditions in which they naturally grow, it is in all cases actually brought about by the direct action of the environment itself, coupled with the responsiveness of the protoplasm of the plant. It then becomes hereditary."

'There are great differences in the plasticity of succulent plants. In the above I have given instances of easy transitions from thick to thin leaves or vice versâ; but plants grown from "time immemorial" under natural xerophytic conditions now resist the direct action of changed conditions; so that species of Mesembryanthemum, Crassula, etc., etc., still retain their succulency under cultivation in this climate, though raised from seed.

There is a remarkable tenacity of life in these 
xerophytes, no doubt due to the inability to lose water. Some echeverias had been put with other plants in a tin box and forgotten for several weeks. When opened the box contained a black mass of corruption, but turning it out the echeverias only were found to be alive. They were planted and grew well. As another example, a flowering spray of an epiphytal orchid had been cut off, laid in the stage in the hothouse and forgotten. It was still in bloom quite unfaded, after six weeks' abandonment! Such epiphytal orchids grow on the upper branches of tropical trees, and are consequently xerophytes, having tuberous stem-joints for storing water, though the trees themselves and the verdure below may be hygrophytic in consequence of the abundance of water.

The general result of these observations on the structure of succulent plants is thus seen to be distinctly parallel with those of other kinds; in that, while on the one hand similar characteristics are noticeable in plants of no affinity, but living in the same circumstances, experimental proofs show how these features can be produced or restrained; but these characters are regarded by systematic botanists as varietal, specific or otherwise when hereditary. ${ }^{1}$

1 See Anatomical Notes on Strand Plants, by M. A. Chrysler (Bot. Gaz., xxxvi. p. 461, 1904). 


\section{CHAPTER VII}

EPIPHYTES, PARASITES AND SAPROPHYTES

Epiphytal Plants. - A feature especially characteristic of tropical forest floras is that many plants, such as orchids, members of the pine-apple family, some rhododendrons and ferns, make the surface of trees, whether dead or alive, their permanent home. It is chiefly those plants which have very light seeds or spores which get blown up even to the tops of lofty trees.

Curious adaptations occur in these epiphytic plants to secure a permanent foothold and to supply themselves with water and food. In the orchids aerial roots, having lost the normal tendency of roots to grow down into the soil, clasp the tree-bough in any direction best suitable, the epidermal cells growing out and gluing the surface of the root by a sort of gummy secretion. Then these roots absorb water with great avidity. These orchids have become adapted to a small amount of light, and as many grow on the tops of high trees, where they are subjected to periodical scorching 
weather, they have to store up water and food. This they do in their leaves or stems, called "pseudo-bulbs," or sometimes in their roots. 'They are mostly fixed at one spot, but some can creep along the branches (as Zygopetalum rostratum) in the Guiana forests. They are, therefore, xerophytical in their nature, as the amount of water at their disposal is a more or less limited quantity, situated as they often are at the tops of trees, though the ground below in the moist tropical forest may be saturated.

In some cases epiphytes may have no roots, when the leaves act as adherent absorptive organs ; as in Tillandsia usneoides (a plant allied to the pine-apple of the order Bromeliacece). This clothes the branches of tropical trees like a grey moss.

Some epiphytic ferns have two kinds of leaves. One sort is applied to the stem, the other growing out freely. 'The former absorbs the water necessary for growth, etc., the latter assimilates the carbonic acid of the air and bears the fructification. Platycerium grande, the elk's-horn fern, is an example often grown in greenhouses, bearing a large shield-like frond below and divided fronds above.

Summarising the distribution of epiphytes in tropical countries, it is found that this aerial flora can exist in very different conditions. It 
58 EPIPHYTES, PARASITES, SAPROPHYTES [CHAP.

is found within forests and in open places. In the former there are two types-those which live on the lower branches as members of the Bromeliacece, orchids without tubercles as Zygopetalum, and the filmy ferns, as species of Hymenophyllum.

Secondly, there are those which grow upon the summits of the trees, as Tillandsia, orchids with tubers or pseudo-bulbs, coriaceous polypodys, etc. ${ }^{1}$

In the Savannahs or open plains the drought is greater, in these, besides Tillandsias, there are cactaceous plants, as the jointed leafless Rhipsalis, thick-leaved orchids, and aroids.

Without going into further details, the reader will gather that this epiphytic habit, correlated with corresponding structures, is totally different from allied terrestrial species, as are all our own English orchids; and the question arises, are they the results of spontaneous seedling variations, i.e., without any influence from their surroundings, and then naturally selected; or, did they arise by means of the responsive power of adaptation to epiphytal conditions? Here induction must suffice; and the conclusion isas in all other cases-forced upon us that the same natural law holds good with them as in all other cases.

Darwinians will not allow that variations

1 Our common English polypody often takes to the habit of growing ou trees by roadsides, etc. 
have any "fitness or correspondence to the changed conditions which have produced them" (Lankester). But, what are the chances that these admirable adaptations to an epiphytal life should arise only whenever and wherever the seeds of terrestrial species happened to be blown up to, and lodge upon, the boughs of trees? Epiphytal characters are never known to appear - even if only to perish as being inadaptive to live-on the ground. Surely the probabilities alone would be immensely greater that the adaptations arose in response to the "conditions which have produced them." Is not the theory introducing a needless difficulty; especially since response with adaptations is provable in so many cases as to be recognisable as a natural law?

I have here gone into considerable detail in regard to epiphytes, and shall do so again in discussing parasites and saprophytes; because I want the reader to see that as point is added to point, the difficulties of Darwinism become cumulative, till at last the theory becomes unthinkable; while, on the other hand, adaptation by response, coupled with the heredity of all the numerous points of structure, as well as the capabilities or functions, is the only and easy interpretation of all the phenomena presented by these curious plants.

Parasitic and Saprophytic Plants.-These 
are distributed over many orders of flowering plants as well as genera of fungi. In the division Thalamiflorce of Dicotyledons there is only one; in Gamopetaloe, several; in Incompletce, five; while in Monocotyledons there are four.

The same argument applies to fungi. There are many species which attack plants, being peculiar to their "hosts," respectively. Was it more probable that the fitness-say of AEcidium Berberidis-arose from an innate adaptiveness to that bush, while the spore itself was being formed from the "teleuto-spore" of the mildew of wheat? or did it acquire its parasitic adaptation by direct contact with a leaf of the barberry? Induction supports the latter.

The most obvious feature, in a large proportion at least, is the total absence of any green colouring matter or chlorophyll. All such are, therefore, incapable of assimilating purely inorganic food materials, and must depend wholly upon living plants as hosts, or decayed organic matter in the soil.

Since it is presumable, on the score of structural affinity, that greenless parasites and saprophytes have descended from green plants, it is not surprising to find that many such are parasitic, although they can derive nourishment to some limited extent by their ordinary roots and leaves. As an example, species of winter green (Pyrola), among the heath family, supply 
us with a transition through a leafless species to the order Monotropacece, which some botanists separate from Ericacece because of their totally greenless condition. It includes four genera, one of which, the plant called "Bird's - nest" (Monotropa Hypopitys), is British. Again, the order Scrophularinea, which contains numerous non-parasitic genera, as the fox-glove, snapdragon, musk, etc., has a tribe containing eighteen genera, six of which are British, and all but one have green leaves. They are also all parasitic on grass or other roots. From this tribe one passes to the order (Orobanchacece) or broom-rapes, which are entirely greenless.

Flowering parasites attach themselves by penetrating root-hairs to their "host-plants," or by means of suckers called haustoria; these are disk-like elevations produced by the superficial tissues, from the centre of which the root-like process arises, which penetrates the stem of the host, and then grafts itself upon the living tissues beneath the surface of the latter.

As examples of illustrations of methods of parasitism, I will take a leafy parasite, the cowwheat (Melampyrum) (figs. 17, 18), and a leafless one, the dodder (Cuscuta). The former possesses green leaves, and is not always attached to hostplants ; for many individuals fix themselves, often indeed the greater number, on decomposing pieces of wood or even simply to a packet of humus very 
rich in organic matters. The cow-wheat sometimes, indeed, has no attachment to a host-plant at all, and so far becomes a saprophyte instead. It has, therefore, three methods of obtaining nourishment, by normal, by saprophytic roots, and by parasitic suckers. The external cause of their formation appears to be the stimulus excited by the contact of a body living or dead, which encloses nutritious matters useful to the plant. The first stage of the development of a sucker in this plant consists of a slight protuberance due to a swelling of the cortex or superficial tissues of the root of the parasite $(a)$. The cell of the epidermis, where contact takes place, enlarges tangentially until it acquires a breadth six to eight times greater than its primitive size. It is thus enabled to give rise to a cluster of cells which elongate outwards into papillæ or root-hairs $(a)$. These latter now undergo a remarkable change. They form a conical bundle, more or less compact, and are thus enabled to penetrate into the tissues of the host-plant $(c)$. If such a sucker pass into dead vegetable matter, the extremities branch and ramify through it $(b)$. The corresponding cells, beneath this terminal cluster of root-hairs, of one or two subjacent layers, undergo analogous modifications. Each of them is now transformed into a row of cells along the axis of the sucker till there are about ten rows forming a bundle 


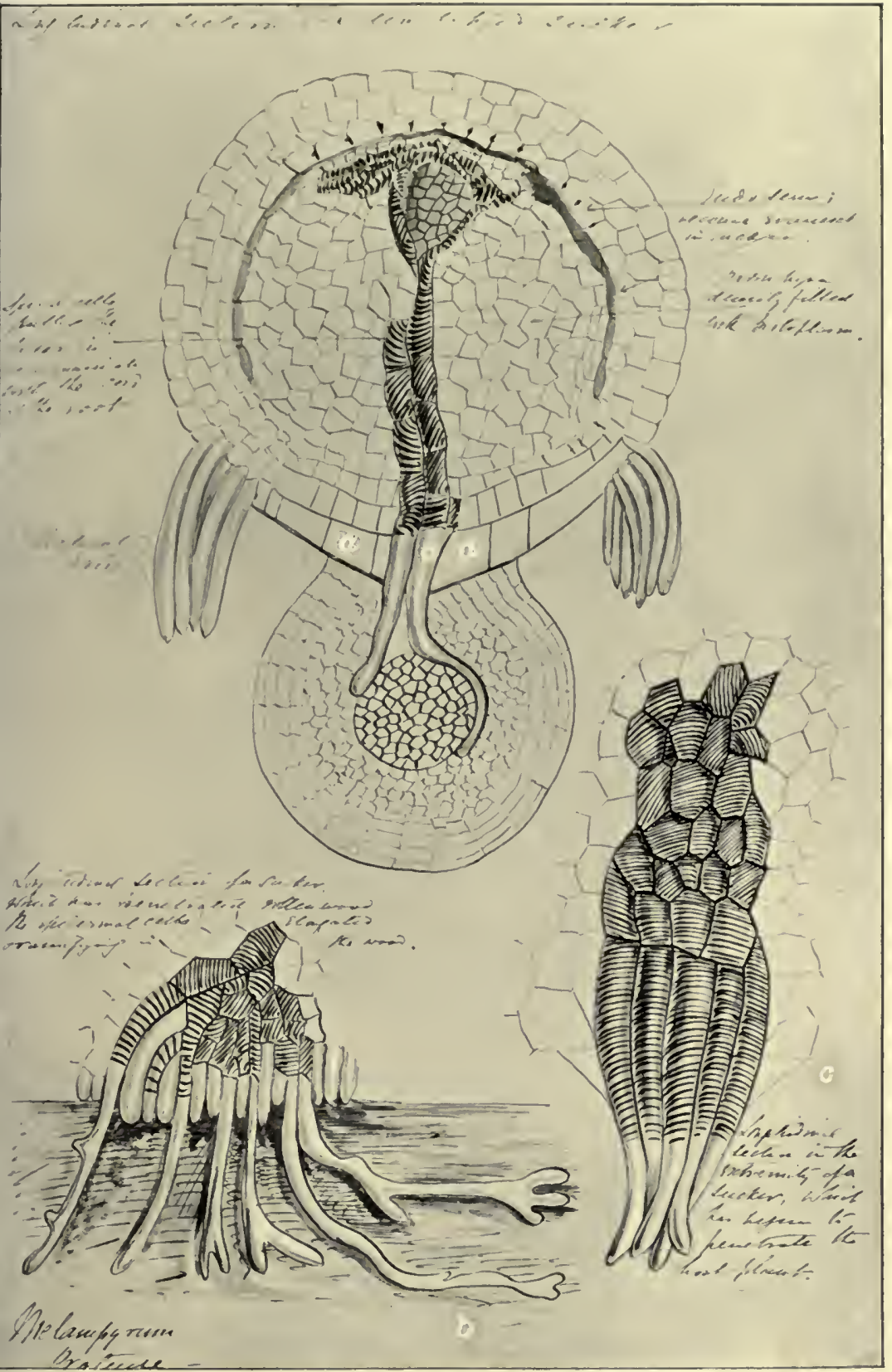

Fig. 17. - M. pratense, with details of structure, showing how the parasitism is effected. (b) Also, as a saprophyte on rotten wood. (See pp. 61ff.) 

running up the sucker into the root of the parasite and down to the root of the host. These acquire spiral thickenings, and so become "tracheids" in communication with the spiral vessels in the root of the parasite $(a)$. At the other end the bundle of root-hairs, now modified as absorbing organs, penetrates the cortex of the root of the host-plant, dissolving and consuming it by means of a ferment; but they are stopped by the woody central cylinder which resists the solvent action of the ferment; consequently they bend round and invest the central cylinder $(a)$.

The part of the sucker of cow-wheat which enters the host-plant has thus the epidermal layer for its origin. In the yellow rattle additional root-hairs (i.e., besides those forming the penetrating cone) can invest the root of the host and take part in absorbing nourishment from it. 'These, however, do not become spiral tracheids like the former. Other genera show various slight differences, but the general principle on which the suckers are formed in the tribe Euphrasiea is the same; that is to say, the sucker is epidermal. From the above brief description it would seem that these leafy parasites supply us with a somewhat primitive type of parasitism: first, in their having green leaves; and secondly, in that the effect of the irritation is more superficial than in the greatly degraded state of leafless and greenless parasites, 
such as dodder, to be next described, in which the irritation acts more minutely on the deeperseated cortical tissues, wherein is formed the absorbing organ, while in the Euphrasiece, as we have seen, the suckers are formed by the epidermis alone.

The method by which an aerial leafless parasite fixes itself to a host-plant is well illustrated by the dodder. The seed of this plant has no cotyledons and resembles a minute coiled thread. It germinates by fixing its club-shaped root-end in the soil, and draws up water by means of roothairs; it then sends up a thread-like stem, which "circumnutates" like a tendril in search of a support. As soon as it comes in contact with a suitable host-plant, it quickly forms an adhesive "haustorium," 1 and from that moment the lower part dies and the dodder becomes entirely parasitic and grows rapidly all over the host-plant. If the seedling fails to find a host its stem falls to the ground, and provided the soil be moist, the apex will grow while the root-end dies. The nourishment is then continually being transferred from one end to the other, as the stem, as well as the root-end, dies from below upwards. The little plant thus "moves" along, as it were, by growth until it may come in contact with some suitable plant. If it fail to do so, it will of course perish in time. In circumnutating it

1 The analogous process in the clinsbing pads of the Virginia creeper is very suggestive (see p. 10). 
forms two kinds of spirals. If it be growing rapidly, the coils are loose and it fails to form haustoria; but when this period of rapid growth is over, it coils in more horizontal spirals closely adpressed to the host-plant. It is on these alone that the haustoria are formed. The sucker originates at a point within the cortex, where a focus of "merismatic," or rapidly-dividing embryonic tissue is formed. 'This invades the central region of the stem of the dodder and also extends outwards. Vessels are now formed in this, and become united to the central cylinders of both host and parasite. In dodder the epidermal cells of the aerial stem become "claspers," and then the sucker penetrates through the middle of them. This fixation of the cup-like clasper appears indispensable to complete the development of the penetrating sucker. For when the epidermal cells do not prolong themselves into clasping organs, the sucker which arises within them undergoes an arrest of development, and does not form vessels. From this it appears that either the hairs are the vehicle of irritation, which must be kept up, and by conduction influences the deeper tissues, which in response begin to form the absorbing organ from within; or it may be that the "purchase" required for the necessary force to drive the sucker-root into the host is insufficient. The epidermal cells between any 
two suckers help mechanically to fix the plant. Their cuticle presents fine indentations, which mould themselves upon the corresponding asperities, fitting into depressions of the cuticle between the adjacent cells of the host. And they adhere still more firmly by means of a gummy secretion. The means by which the root-sucker or haustorium penetrates the host is mainly by pressure, leverage being secured by the closeness of the coils together with the superficial adhesion mentioned above. Besides this the central epidermal papillate cells dissolve a passage and absorb the nutriment which is conveyed to the root immediately below them. As they are not the true sucker (as in the Euphrasiece), this epidermal sucker is called the "pre-haustorium."

Experiments show that although no chlorophyll is visible in dodder as a rule, it can be induced to form it; for if short lengths be cut off a branch, the failure of sufficient nutrition - in the supply of food from below, necessary for the formation of haustoria, being removed-is now compensated for by the immediate formation of chlorophyll. Similarly, if the dodder be attached to a feeble host, or to one which cannot nourish it properly, it puts on chlorophyll so as to be more independent of its host. When, however, fresh haustoria have been made on a fitting host, then the 
chlorophyll disappears, and perfect parasitism is again recovered.

That the power to become parasitic is a general one seems obvious from the fact that parasites occur in widely different orders; but why some roots when in contact with others are stimulated by the latter into producing suckers, rather than vice versâ, or why they are not mutually parasitic, is as obscure as the answer to the question why some marsh plants have become insectivorous, while others associated with them have not.

The point, however, which may be insisted upon is, that parasitism is a consequence of organic irritation, as described in cow-wheat. This, when once fully set up and continued for generations induces a hereditary predisposition to parasitism; as seen in many of the tribe Euphrasica of the order Scrophularinea. Then, again, by further degradation in the structure of the parasite, as in all which are devoid of chlorophyll, it becomes a fixed, hereditary and absolutely necessary condition of life.

There would seem to be an impossibility in applying natural selection to account for all the above described details of parasitism; for, if it be contrary to evolution to allow the first formation of haustoria to be in anticipation of their use, for such would be teleological; then it must be those seedlings which had 
already some stronger capacity for producing them in contact with a host-plant. But this capacity is a general one in protoplasm so far as one can presume from the existence of parasites in widely distant families of no affinities, and one may add the case of the Passion flower, described below.

So that parasitism must have been acquired and become hereditary solely by self-adaptation to other plants. But, further, the normal method of absorption by roots is by means of epidermal root-hairs, so that their presence must also be somehow explained by natural selection. When, however, a seedling of cowwheat is made to germinate where no other roots are present, no haustoria are formed, but the root-fibres are densely clothed with hairs. When, however, some other roots are present, abundance of haustoria are formed, but scarcely any root-hairs are produced; so that it would seem impossible to account for these two, totally different organs, being on the same rootlets by natural selection and compensating for each other, ${ }^{1}$ just as stated with regard to vinetendrils which are metamorphosed flowering branches, when they "revert" and bear a few flower-buds, the acquired sensitiveness tends to disappear.

1 For the details of structure of Melampyrum, I am indebted to M. Leclerc du Sablon:-Bull. de la Soc. Bot. de Fr., 1886, p. 154; and Ann. des. Sci. Not., vi., 1887, p. 90. 
The proof that parasites have acquired their peculiar habit by actual adherence to other plants is not easily derivable from actual experiment, but it is based on much induction. I have, therefore, gone somewhat into details of anatomical structure to explain the nature of parasitism, and to show the reader how impossible it is to conceive that it should arise by "spontaneous congenital variation" without any necessary reference to the host-plant itself, as it must have done according to the Darwinian theory. Nature, however, sometimes comes to our help. M. E. Pée-Laby described ${ }^{1}$ a remarkable case in which a Passion flower (Passiflora coerulea, fig. 18), having its roots accidentally in contact with those of a shrub of Euonymus Japonicus, adhered to it; a haustorial root penetrated within that of the host and became genuinely parasitic upon it, thus actually revealing how parasites can arise, and probably all have originated in nature. Having thus established the process, it has become hereditary in all true parasites.

The probable origin of many greenless Saprophytes of temperate regions, is that they were formerly parasites which have changed their habit of life in now living solely on decomposing organic matter, for we do not find that rich humus or decaying vegetable matter has per se

1 Revue Général de Botanique, vol. xvi., p. 453. 
the effect of producing such degradations of structure as are found in the foliage of colourless parasites; rather, indeed, the reverse; for if, e.g., wheat has its leaves of a deep rich green colour, this signifies that it is consuming too much nitrogen from the soil. Greenless saprophytes, therefore, were perhaps in some cases at first parasites, their parasitic habit being changed to one of saprophytism, their degraded structures being retained.

In tropical forests, however, where there is ever-forming decayed vegetation, and the greater number of saprophytes exist, the darkness prevailing is probably the primary influence, which induces etiolation in germinating plants which have "taken to" saprophytism in self-preservation in the struggle for life.

Although this would seem probably to have been the case, it does not preclude the possibility of an ordinary green plant becoming saprophytic. As a case in point, a species of fern (Gramatophyllum) has been known to produce its aerial roots among decayed vegetable matter. In this case, on a careful examination, I found that the surface of the roots in contact with it had developed quantities of "absorbent hairs." These were doubtless induced to be formed by the presence of nutritive matter. ${ }^{1}$

As another case, I found that the rhizomes

'Journal of the Royal Horticultural Society, vol. xvi., p. xxiii., 1893. 


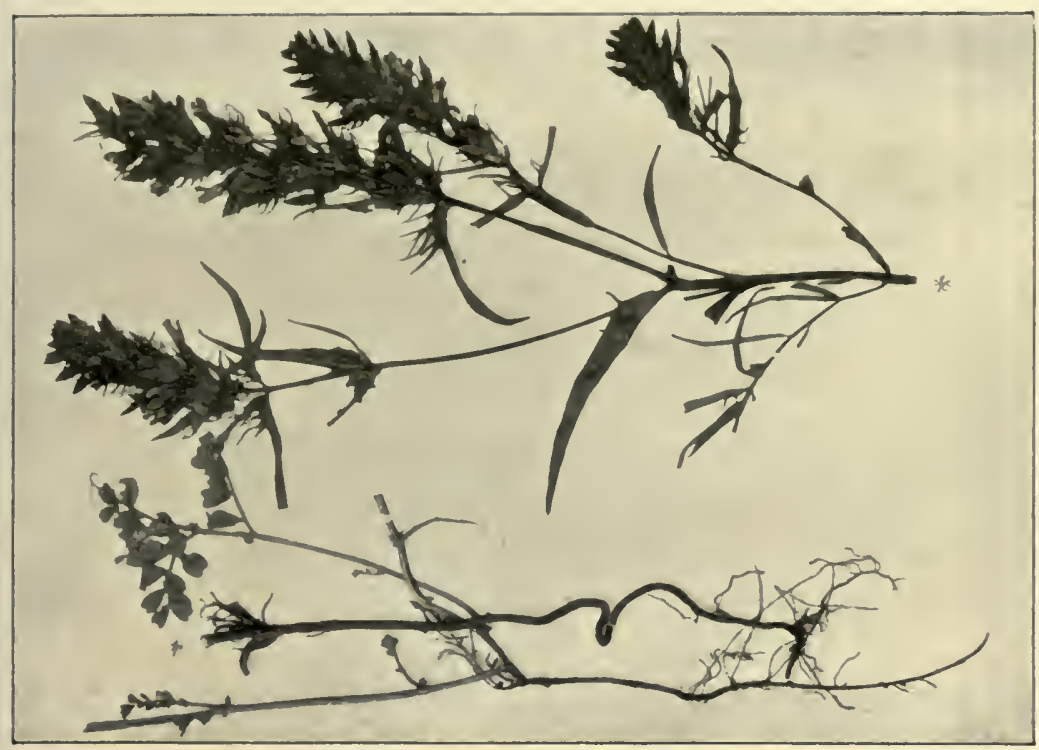

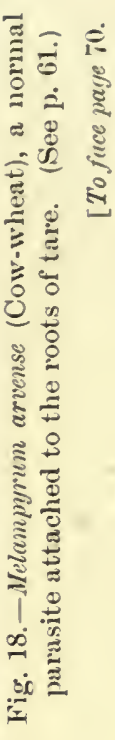

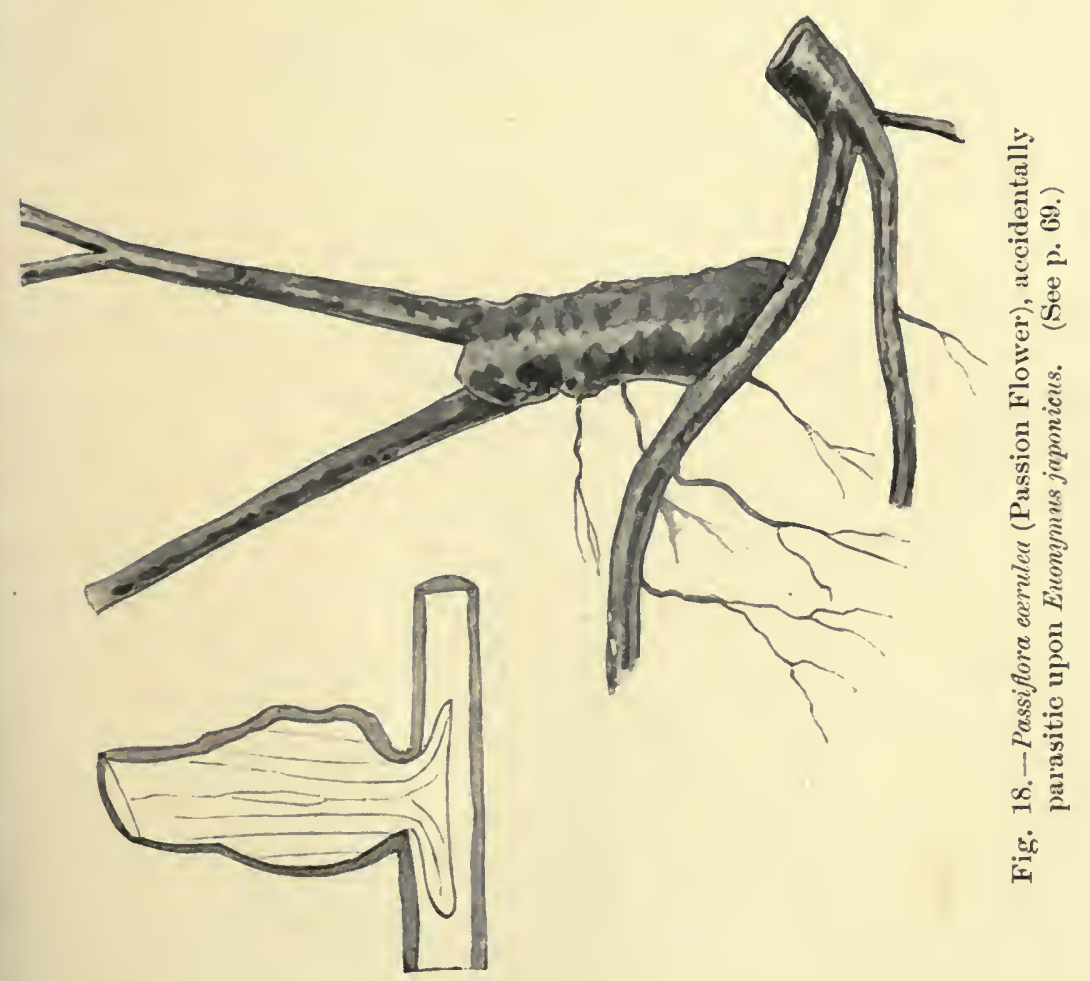



of a musk plant happened to have penetrated a rotten log, running parallel with the grain. They were quite white. Each branch terminated with a bud composed of very arrested scales. The outermost tip protecting the apex was hardened and brown (physiologically acting like a root-cap). The epidermis was without any stomata, delicate and "epithelioid" in character. It had a thick cortex of thin-walled cells apparently full of water. There was a very small central cylinder. Fine thread-like roots were sparingly given off. These were covered with extremely delicate unseptate hairs penetrating the wood in all directions. So far they would seem only to have absorbed water, but on testing the starch, which was sparingly scattered through the cortex, I found that it assumed a bright red colour with tincture of iodine, and not the usual violet tint. Now, this red colour is characteristic of saprophytes.

A usual or perhaps invariable result of these habits is seen in degradations in the structure and functions of parasites and saprophytes. The most obvious sign of degeneracy in many parasites is the want of chlorophyll. They might be grouped artificially into chlorophyllous and non-chlorophyllous. Such represent different stages in degrees of degeneracy; for, although the presence of green leaves in the group Euphrasiea, such as yellow rattle, cow-wheat, 
eyebright, etc., would lead one to conclude on à priori grounds that they could assimilate carbonic acid just as ordinary flowering plants, yet it has been discovered that the abovementioned genera, excepting the last, which in other respects differs somewhat from its allies, do not disengage oxygen in light, whatever be its brightness or the method of investigation employed. The interpretation of this remarkable fact is that the assimilative power is so enfeebled that the oxygen emitted is all reabsorbed for respiration, there being no excess to be given off as in the case of all nonparasitic flowering plants.

Great degeneracy of structure is seen in both the vegetative and reproductive systems. Besides the total absence of chlorophyll, the leaves of such parasites which have none are reduced to scales or are absent altogether. The microscopic details follow suit in the general absence of stomata, etc., while the fibrovascular cylinder of the stem exhibits various anomalies, reminding one of the structures in stems of climbing plants and of monocotyledons. The great dislocation of the cords is a result of parasitism, just as it is in climbing stems, and is a result of an aquatic habit which has set up the well-known arrangement in that class. ${ }^{1}$ In the case of the flowers of parasites a very common

1 "Origin of Plant Structures," pp. 149, 198, 206, 214, 220. 
feature of degeneracy is seen in the ovules, etc. For, while a normal ovule, say of a buttercup, would consist of a central "nucleus" containing the "embryo-sac" within it, and surrounded by two coats, in some parasites, as the mistletoe, there is nothing but a naked embryo-sac. When an ovule becomes a seed, the embryo, instead of having two cotyledons, a plumule and a radicle, may remain arrested in the proembryonic condition of a globular cellular body, the outermost skin of the seed being a simple cellular sac. Such seeds, for example, occur in the broom-rape. This kind of degeneracy in the reproductive system seems to be one of the first conditions, for it occurs in plants unsuspected of parasitism on other grounds, from which true parasites have descended, as e.g., winter-green, from which genus the greenless Bird's-nest has probably been derived.

The extreme degradations of parasites negative Weismann's idea that any characters acquired by the soma cannot affect the reproductive system ; for no plants have more degraded conditions in their ovules and embryos than parasites. If, moreover, it be asserted that such degradations as abound in these plants must be due to the parasitism of each generation, we may ask why it is that colourless parasites never start with green leaves, as do those of the section Euphrasiece of Scrophularinece, and why do 
they not show degradations to colourless leaves as they succeed in growing upon their host plants? There is but one explanation, that parasitism has become hereditary, and the structural degradations produced by it are hereditary also.

Lastly, it is difficult to realise how epiphytes, parasites, and saprophytes could have arisen by congenital variations without any "necessary fitness or correspondence" to such changed conditions of life. This difficulty is insuperably increased when we ask how the penetrating roots and haustoria could have so arisen, upon which parasites depend for their existence. Though the seeds of parasites germinate in the ground, they soon perish if they find no host to which they can attach themselves. Which, therefore, is the more probable, that they are the results of selfadaptation to a host, the existing degeneracy being an hereditary result; or that all this arose by congenital variation quite irrespective of any fitness for parasitism, etc. ? ${ }^{1}$

1 The latest contribution on the parasitism of the cow-wheat is a paper entitled "Sur le Parasitisme du Melampyrum pratense," par M. L. Gautier, Révue Général de Botanique, tome xx. p. 67. 


\section{CHAPTER VIII}

\section{ALPINE AND ARCTIC PLANTS}

The aridity of Arctic and high Alpine regions is well known, while the soil is always of a relatively lower temperature; these, and other causes bring about the dwarf character of plants there. Besides this, they exhibit a compact habit of growth, sometimes giving a moss-like appearance and furnishing the specific names muscoides, bryoides, etc. Others have a certain degree of succulency in their foliage, thus Plantago alpina is closely like $\boldsymbol{P}$. maritima. Many other details might be enumerated which collectively pronounce them as xerophytes of a special type.

That these should also be found in Arctic plants is not strange, for several plants in both regions are identically the same species; the Alpine plants having been, as it is supposed, derived from the Arctic during or after the glacial epoch, having reached the mountains, where they have remained ever since. Though the Arctic regions are somewhat moister, the average characters of the inhabitants are much the same, both being xerophytic. The xero- 
phytic characters of these floras are various, but, as M. Costantin observes from his own investigations :-

"We are led to think, so to say, invincibly, that one can only explain the general characters of Arctic plants by adaptation-c.g., if all Arctic plants are perennial, it is because they live near the Pole. It is the conditions of life which have created this hereditary character." ${ }^{1}$

As most, if not all, the features characteristic of Alpine plants ${ }^{2}$ have been proved by experiment to be the direct outcome of a residence in the environmental conditions afforded by an Alpine climate, we are quite justified in regarding the latter as being their direct cause. ${ }^{3}$

Numerous experiments were made by MM. Bonnier and Flahault and others, upon the effects on lowland plants when grown at high altitudes and latitudes, and vice versâ. Not only do they become dwarfs like native species, but the internal anatomy changes, and becomes similar to the structure of normal Alpine plants.

That the peculiar characteristics of Alpine plants are hereditary, is a fact familiar to any one who has seen a well-made "rockery," as in the Kew Gardens; the characteristic feature of all such is the abundance of "Alpine plants"

1 "Les Végétaux et les Milieux cosmiques," p. 85 (1898).

2 I have enumerated them with descriptions, etc., in my "Origin of Plant Structures," pp. 93ff.

'Op. cit., pp. 112ff. Refs. in note, p. 113. 
which retain the main features of growth, though altering them more or less in adaptation to our English climate.

I have summed up two chapters in my book on "Alpine and Arctic Plants" as follows :-

"The conclusions arrived at from an investigation into the peculiar characteristics of plants growing in high Alpine and Arctic regions are parallel with those already deduced for subtropical deserts, namely, that they are the direct outcome of the action of the climate upon the responsiveness of the plants themselves. First, there are the numerous instances of plants of no affinity whatever, all assuming the same features of "Nanism" "or dwarfs. Certain groups of shrubs and trees have leaves more and more arrested as the altitude increases; conversely, some herbaceous plants have larger and greener foliage than when the same species are growing at lower altitudes and latitudes. There is not infrequently a muscoidal type or a hirsute, villous or tomentose condition; though many may remain glabrous.

"Secondly, experimental evidence has shown how many plants of the lowlands can at once acquire one or more of these features when made to grow at high altitudes and latitudes, and vice versâ.

"On the other hand, cultivation on rockeries, etc., prove that the characteristic features of Alpine plants are retained by heredity, allowing for slight and fresh adaptations to new climatal conditions.

"Hence, as far as the vegetative organs are concerned, we arrive at the conclusion that the 
above-described varietal, sub-specific, or even it may be specific characters, are simply the result of the direct action of the environment upon the plants themselves; which by perpetuation become relatively fixed, stable and hereditary."

I have treated this subject so fully, with a great number of examples, that I would refer the reader to the book already mentioned for further details.

I will here pause to repeat that my object in giving all the preceding details is not to propose any theory whatever, but to show on what facts the two conclusions are based, viz.: (1) that all structures arise by direct adaptation by response; and (2) that they may or may not be hereditary. The condition for the latter is solely a question of time in the number of generations which have been subjected to the same conditions of life (see p. 22). 


\section{CHAPTER IX}

SWOLLEN ROOTS AND TUBEROUS STRUCTURES

The roots of many herbaceous plants grow vertically downwards; and under cultivation, in which much nourishment is artificially supplied, the roots increase in size, until the garden forms are acquired, such as those of the carrot, parsnip, turnip, radish, etc., all of which are wild flowers of England, with wiry inedible roots.

Darwin compared natural selection to artificial selection, and these roots ought to furnish a good illustration. ${ }^{1}$ A profound difference, however, should have been noticed, but is always ignored; and that is, while the majority in the wild state are supposed to perish from some inherent injurious variations of structure; yet if seed happen to reach a new environment, when the gardener selects the best roots and rejects the majority, the latter would have lived just as well as the ones selected. A garden is only an improved environment; how is it that no seedling ever produces a mortal variation ? ${ }^{2}$ It

1 "Origin of Plant Structures," ch. ix., p. 179.

"Called by Darwin "injurious," by which he meant an "inadaptive" variation of structure, the actual cause of death. 
80 ROOTS AND TUBEROUS STRUCTURES [CHAP.

was by selecting the best roots from plants raised by seed of wild plants that Professor Buckman obtained what is now known as the "Student" parsnip in 1851. It is still the best in the trade. M. Carrière raised garden radishes from the wild Raphanus maritimus; M. Vilmorin, the carrot from the native Daucus Carota.

Now a remarkable fact has arisen under these and other experiments. Each of the abovementioned roots has at least two forms, the long and the "turnip" form; and the origin of these is known. Pliny records the fact that the Greeks in his day had found how to obtain the "male," as they called the "turnip," from the rape, the "female," with a long slender root, by simply growing it in a cloggy soil. His words are :-

"The Greeks have distinguished two principal species of rape, the male and the female, and have discovered a method of obtaining them both from the same seed; for when it is sown thick or in a hard cloggy soil, the produce will be male." 1

The rape and turnip are recognised by botanists as being both the same species (Brassica campestris).

M. Carrière grew his radishes in two districts, some in the light and dry soil of the garden of the Museum at Paris; others in the country, where a firmer and calcareo-argillaceous soil prevailed. At Paris the long spindle-shaped 1 "Nat. Hist.," bk. xviii., ch. xxxiv. 
form predominated; in the country it was the contrary.

M. Languet de Sivry likewise found that

"seeds of the short-rooted carrot, when sown in a particular soil in the alluvial deposits formed by a small river in France, yielded immediately during the first generation a number of long-rooted plants, either white or yellow, whose roots were very much larger than those of the parent plants."

These differences in each case are hereditary, for all seed growers can supply their customers according to requirements, and they "come true," sufficiently to be depended upon.

Another result follows from cultivation. The above plants are annuals when wild, but by growing them in a garden soil the foliage becomes greatly enlarged. The result is that far more starch, sugar, etc., is made than the plant can utilise ; hence the enlargement of the root wherein to store it. Secondly, the vegetative season is much prolonged by the vigorous growth of the soma, so that it cannot flower the same season. Thus they become biennials, and ever after retain that habit. ${ }^{2}$ Systematic botanists often distinguish between the annual, biennial, and perennial habits as specific characters.

1 "Experimental Evolution," by H. de Varigny, quoting from Societé Royale et Centrale d'Agriculture, sér. 2, vol. ii. 1846-7, p. 539.

${ }^{2}$ The beet-root is a wild perennial of England, but is also converted into a hereditary biennial. 
82 ROOTS AND TUBEROUS STRUCTURES [снAP. Ix.

It is obvious that these results issuing from cultivation all occur as "acquired characters" by the soma or vegetative structures; because there are no reproductive cells at all to be affected by the external influences-mechanical only in these cases-forming the swollen roots.

With regard to subterranean stems, they may elongate to great lengths, as in sedges and grasses of our sand dunes, or they may terminate abruptly and swell into tubers, as the potato; and although the former has not been converted into the latter, all analogy points to a similar conclusion. That the tuber of a potato is the consequence of growing underground is proved by allowing a shoot to escape into the air. It will then grow into a leafy stem instead of developing tubers; but tubers are hereditary structures, as new sorts can be raised from seed. Some tubers act for water storage, as of $\mathrm{Poa}$ bulbosa; but then the tubers are only found in dry situations and not in moist ones, showing a strict adaptation to the environment.

It is easy to convert an aerial stem into a subterranean one by simply burying the end of the shoot, as of hop, mint, periwinkle, etc. When the apex reappears the portion which has developed underground will be found to have taken on all the characters of normally subterranean and hereditary creeping stems. 


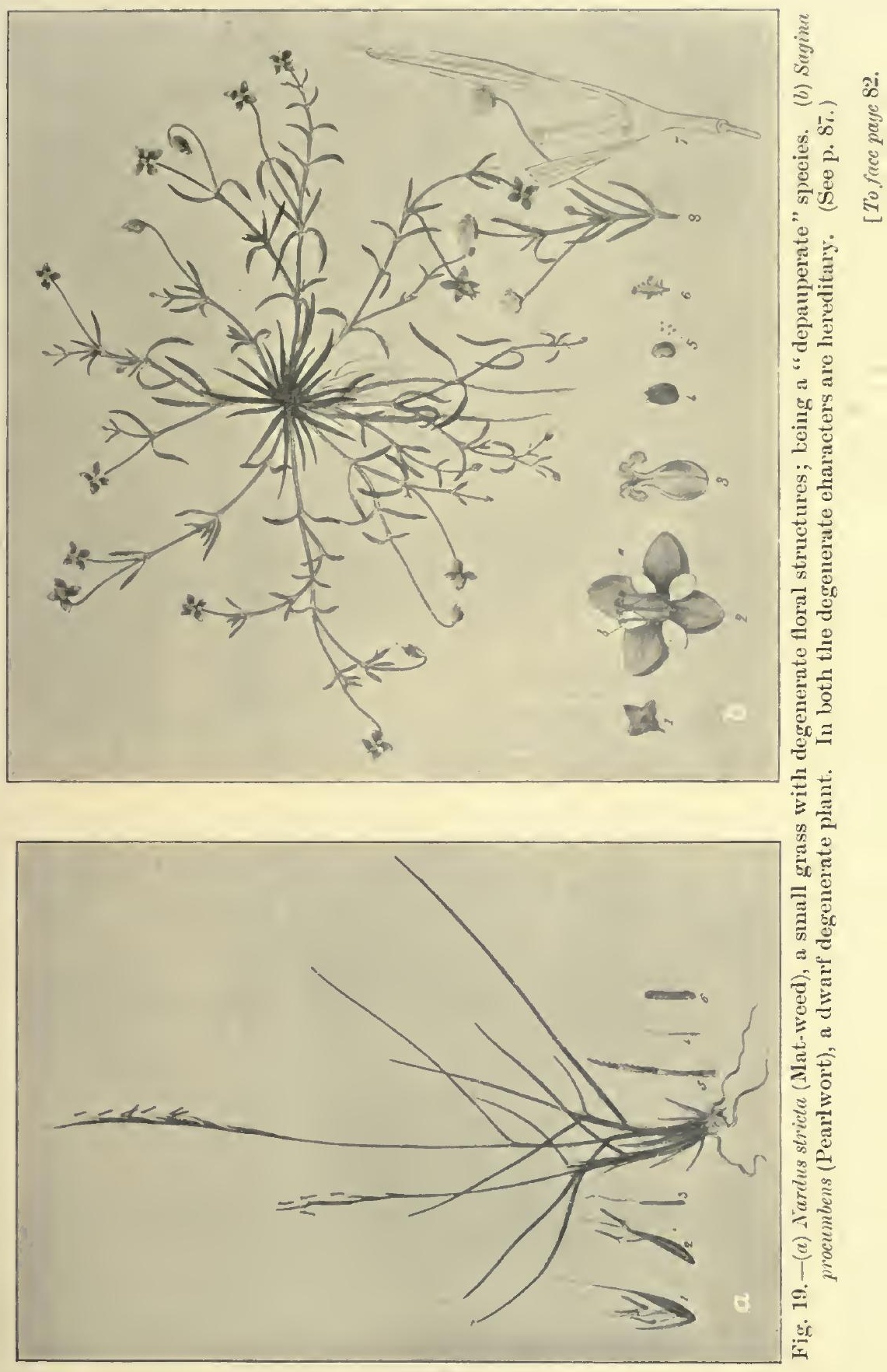





\section{CHAP'TER X}

\section{DEGENERATION}

MR REID has something to say about Regression or "Reversion," generally called " Atavism," i.e., the reappearance of ancestral characters in descendants. Thus horses are occasionally born with three toes on one or more feet, such being the character of the extinct hipparion, its supposed ancestor; but that writer has nothing of importance on the very prevalent feature of "Degeneration" or "Degradation." It is the converse of Evolution, or, perhaps, we might say, a contemporary phase of the process. For when new organs are developed others degenerate, and either remain as "rudimentary organs" or they disappear entirely. There is nothing of a harmful or "injurious" character, to use Darwin's term, about them ; it is simply Nature's way of discarding a part which is no longer required in the plant or animal under new conditions and requirements of the being. Thus all Cetaceans, as the whale, have rudimentary bones of the legs, no longer wanted for walking on land or swimming in the sea. If these 
[CHAP.

members are used they have been converted into paddle-like structures. Four of the horse's toes have actually gone, but the "splint bones" which supported them remain as rudiments. In the cow the hindermost toes still remain as useless appendages. Disuse has brought about such degenerations contemporaneously with developments in other directions; just as a tadpole required a tail for swimming, but this organ becomes absorbed when it develops into a terrestrial frog. As natural selection has obviously nothing to do with this disappearance of the tail of a tadpole, why should it be required in all the cases of toes?

In plants there are certain great causes of degeneration, e.g., the want of, and an excess of, water, as well as great cold and great heat, and diminished light. For a plant to grow luxuriantly, it requires an optimum of each of these conditions for its various functions, respectively. Rarely, if ever, do plants secure all the optima together in any one place of the globe. Perhaps the nearest approach is seen in a moist tropical climate, to which the flora has become adapted. At all events, we find it is there that the most luxurious vegetation flourishes. Taking such as a standard, plants not only decrease in size until they are tiny dwarfs, as willows in Arctic regions, but their various organs, as leaves, become, not only 
diminished in size or are wanting, but the tissues undergo corresponding degradations. It would carry me too far to give many illustrations of each sub-flora, but I must be content with a comparatively few examples from which the reader may safely generalise.

In tropical dry "thorn forests" and open deserts, wherever plants can grow at all, such as the dry water-courses or Wadys of deserts, water remaining at more or less great depths, spinescence is of the commonest occurrence. A true "spine" is an arrested branch terminating in a hard and sharp point. I have already alluded to it in the rest-harrow and Zilla, etc.; but instead of having its internal structure adapted to carry water to the leaves and to enable the shoot to elongate, as it ought, the "mechanical" tissues, as the wood, solidify and become intensely hard, the actual tip of the spine which represents the soft, succulent "growing point" of the shoot being as, hard as the wood fibres below. It is analogous to the wood of the Kauri pine, described by $\mathrm{Mr}$ Reid. This prevalence of spiny processes is not confined to arrested branches, but occurs in leaves (furze, cactuses) and stipules as well as in acacias, etc.

This universal presence of spiny degradations is obviously-i.e., by inductive reasoning-the actual result of what Darwin called the "definite 
action of the conditions of life." Nothing of the sort ever occurs in water plants.

I have given my results of growing the restharrow in moist earth, and showed how the spines were hereditary until fresh adaptations had taken place by the plant's response to the changed conditions of life.

Cactuses and euphorbias of dry regions have not only similar succulent stems, but the leaves are reduced to clusters of spines. These plants, however, have lived so long in their respective regions that when grown in this country they retain their forms, when raised from seed, as Cereus, Echinocactus, Mammilaria, Euphorbia, etc.

I am not discussing hereditary characters of flowers, but in the desert by Cairo there are scarcely any insects, and all the flowers I could find were much degraded as to their corollas, stamens, etc., but they are all self-fertile. ${ }^{1}$

There are very many plants growing on walls, rocks, dry waste places, etc., which are of a diminutive size, as may be expected; I mention a few names in a note, ${ }^{2}$ which any one familiar with our wild flowers will recognise. Sometimes botanists have given as a specific name, depauperata, as indicating their impoverished 1 "Origin of Plant Structures" (Desert Plants); and Journ. Lin. Soc., vol. xxx. p. 257.

2 Erophila vulgaris, Tesdalia nudicaulis, Arenaria tenuifolia, Polycarpon tetraphyllum, Microcala (Cicendia) filiformis, Festuca (Poa) rigida, etc., etc. 
character. Not only are they reduced in size to a few inches only, but the structure of the flowers has often become degenerate as well : as of Nardus stricta (fig. 19) with only one stigma; Sagina apetala, etc.; Potentilla Tormentilla with four, instead of five petals; Senebiera didyma, which is apetalous and with only two stamens, etc. In all cases, we may safely conclude that their depauperised condition compared with their larger mesophytic allies is simply due to impoverishment, yet these characters are fixed and hereditary.

Aquatic plants undergo similar degradations. First, whatever be their size all which have submerged parts are greatly degraded in their histological elements, as we shall see in contrasting Monocotyledons with Dicotyledons; but besides these general features there are several little plants which are comparable with the depauperated land plants mentioned above. Thus in the Cruciferce there is Subularia aquatica, in Plantaginece, Littorella lacustris; Elatine, and Callitriche of Haloragece. Not only is the vegetative system degenerated, but the flowers of the genera, Hippuris, Myriophyllum and Callitriche, are in various stages of degradation. Lastly, Lemna and Azolla represent the very ultimate conditions it would seem possible to attain. Yet in every case the degraded characters are hereditary. 
Inductive reasoning is ample to support the contention that the degenerative structures in the above and many others are the result of the conditions of life-starvation on the one hand, and supersaturation by water on the other. Such are the results of response to the conditions of life, by which-though degradedthey are the best they can do under the circumstances in adaptation to their environments, respectively. Yet all the features are hereditary, and recognised as "specific" or "generic" characters.

It has often been said that when cultivated plants are neglected they will revert to the wild form from which they have been raised. This is not always strictly the case. As all plants will degenerate if they cannot get proper and sufficient nourishment, as shown in the above cases of wild flowers, so especially is it with "ennobled" herbs, etc. ; but they do not appear ever to recover actually and completely the structures characteristic of the original wild plants from which they have been descended; apples degenerate to the "crab" state, but never to the original wild crab. The structure of the root of a carrot, for example, is so profoundly altered under cultivation that it has become perfectly hereditary, but it is impossible to take on the actual wiry structure of Daucus Carota, though it may more or less approximate it. 
This fact shows how the changes wrought by cultivation so completely upset primitive arrangements of cells and tissues, that they-though entirely due to the direct action of a prepared garden soil-are hereditary and fixed.

Mr Reid says with regard to "monsters," which so often appear under cultivation, that, "lacking adaptation to the environment invariably perish." 1 This may be true with animals, yet it is by no means the case with plants. Monstrosities, as they are called, are common in flowers, such as double flowers, in which the sexual organs may be entirely suppressed, yet they thrive well. Or they may be "multifold" flowers, in which the number of the parts is increased, as in the "campanulate" foxglove and the garden variety "Victoria " of forget-menot, as well as the old form of tomato. Yet these monstrous flowers are hereditary, and the plants grow in as perfect adaptation to the environment as the normal species do. Similarly "fasciated" stems, which are allied to multifold flowers in the multiplication of the fibro-vascular bundles, are not infrequently hereditary.

1 Op. cit., p. 86. 


\section{CHAPTER XI}

THE ORIGIN OF MONOCOTYLEDONS

IT has been generally supposed, from their somewhat simpler character, that monocotyledons preceded dicotyledons in the evolution of plants; but the negative evidence of the most modern researches in palæontology lends no countenance to this view. It would seem that the latest discoveries of intermediate forms connecting gymnosperms with cryptogams, and the prevalence of two cotyledons, indicate a probable line of development into dicotyledonous angiosperms, but no undoubted link has yet been found.

On the other hand, simpler structures may indicate degradations and not necessarily primitive features, as shown in the last chapter; and such would seem to be the case with monocotyledons. One of the earliest known members of this class, if it be such, is a plant called Protolemna, described by M. Saporta from a deposit at Cercal in Portugal, of the later Jurassic rocks. It appears to resemble our duckweeds (Lemna) in some respects, but is of a higher type, possessing a stem or distinct axis bearing 

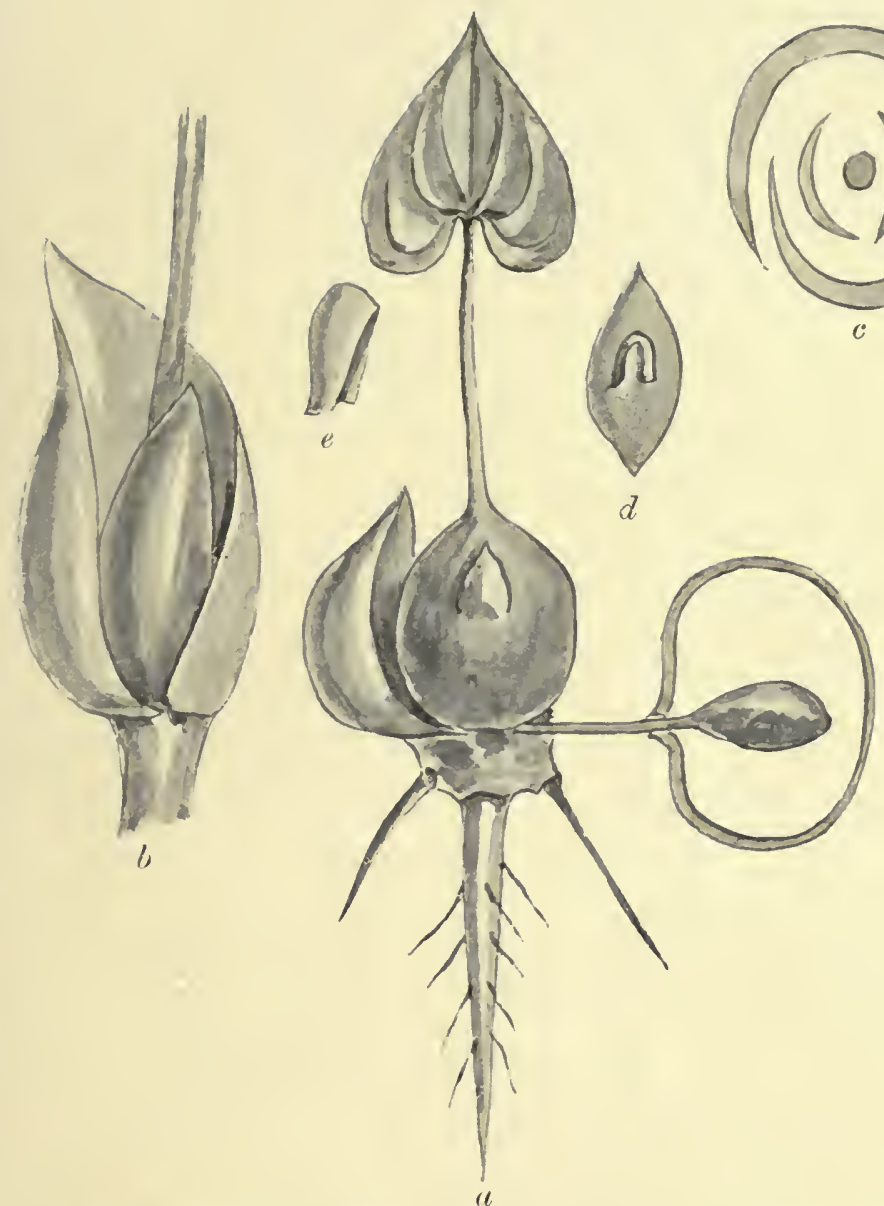

Fig. 20.-Tamus communis (a) (Black Briony), Asparagus officinalis $(b, c)$, (Asparagus) and Avena sativa (d, e), (Oat); embryos showing two cotyledons. (a) The second cotyledon acts as an absorbing organ, renaining within the endosperm; $(b)$ the embryo with two cotyledons; (c) diagram showing two cotyledons and the first pair of leaves, at right angles to the former; (d) embryo showing the second cotyledon (lobule); (c) lobule removed. (See p. 91.) 

leaves of a very delicate nature and presenting a venation like that of a dicotyledon. If this be a correct description, then our existing duckweeds or Lemnac are still further degradations.

My contention is that monocotyledons were descended from very early aquatic dicotyledons. The many reasons for so thinking are based entirely on induction, as it is in but few cases possible to prove it experimentally; but the number of coincidences in point of structure between the morphological and histological details are so extremely numerous that they supply a very large amount of "cumulative probabilities" leading to a logical "moral conviction" that such has been the line of descent.

Of course the primary morphological distinction of monocotyledons is the single cotyledon, from which follows naturally the ternary arrangement of the floral whorls, through the phyllotaxis $\left(\frac{1}{2}\right.$ and $\left.\frac{1}{3}\right),{ }^{1}$ and the parallel venation and forms of the leaves (really phyllodes).

The anatomical structure of the stems is the next prominent feature, the woody bundles being separate and scattered, and not in well defined cylinders as in all our trees; but there are many other minute details, to be alluded to hereafter.

A significant fact must here be stated. If monocotyledons were descended from aquatic dicotyledons it would be an $\grave{a}$ priori probability

1 See "Origin of Floral Structures," p. 28 ; and Trans. Lin. Soc. Sec. Ser. Bot., vol. vii. p. 153 (1907). 
that the proportion of families would be greater which are more or less aquatic. Such proves to be the case, when percentages are taken; for such amount to 33 per cent., while among dicotyledons they are only 4 per cent. Such a marked difference, one must suppose, points to some connection between an aquatic habit and structure; for since dicotyledons are more than four times as numerous as monocotyledons, the chances in favour of a preponderance of the former occurring in rivers, lakes, ponds, etc., is much the greater. 'Thus, e.g., Mr Guppy found about twenty-eight seeds and fragments of plants capable of growing, of dicotyledons in the Thames and Lea; but only about fourteen of monocotyledons. ${ }^{1}$ I will now consider some points of similarity between these two classes of angiosperms.

Commencing with the embryo, the first observation is that the development from the egg-cell to the pro-embryonic condition is the same in both classes; i.e. up to the period and even beyond it, of the quadrature of the terminal cell. The visible differences begin when the globular pro-embryo becomes unsymmetrical in monocotyledons. With regard to the origin of the single cotyledon in the latter $\mathbf{M}$. Ph. van Tieghem observes that, of the two cells formed by the first longitudinal partition of the embryo cell at the end of the suspensor, if they are

1 "The River Thames as an Agent in Plant Dispersal," Journ. Lin Soc. Bot., vol. xxix. p. 333. 

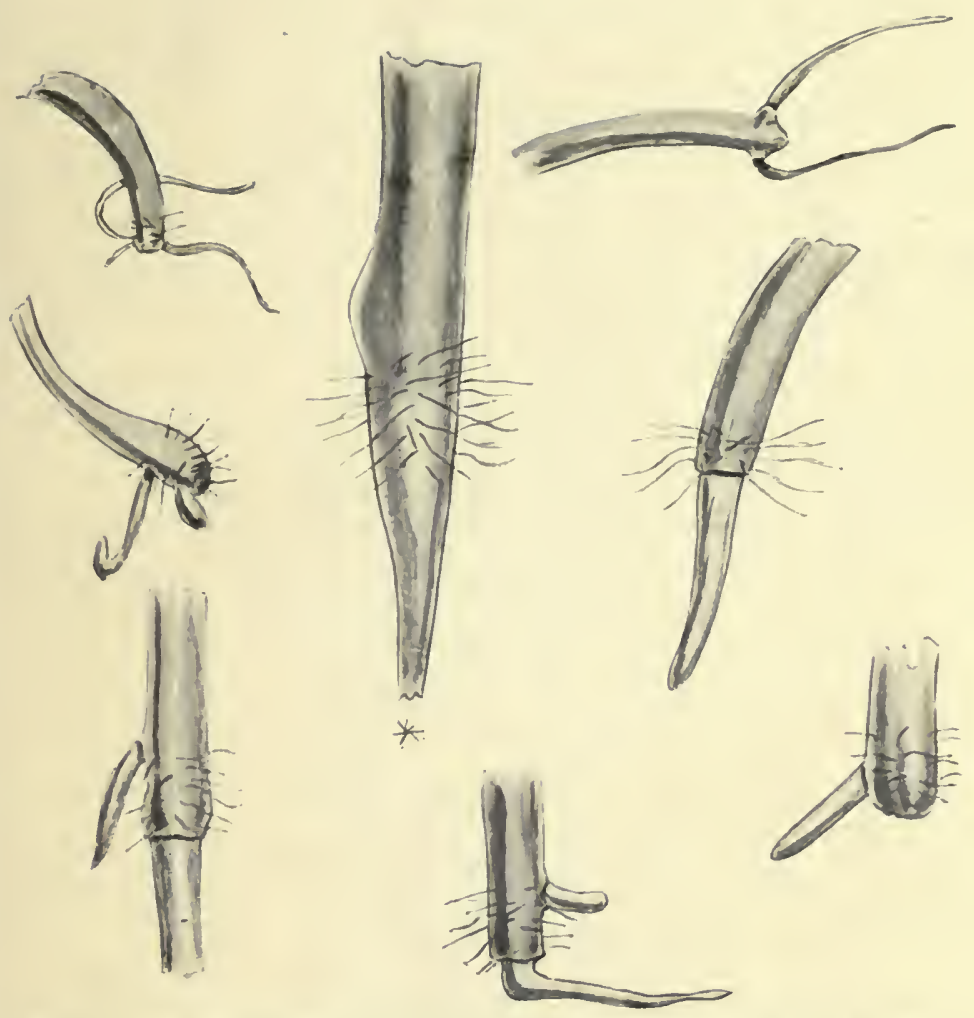

Fig. 21. - $R$. heterophyllus, germinating embryos, showing the frequent arrest of the axial root, as occurs in all monocotyledons. (See p. 97.)

[To face page 92. 

equal in size, they lay the foundation of a dicotyledonous embryo; but if they be unequal [i.e. by the arrest of further development], then the larger one only becomes a cotyledon. ${ }^{1}$

It must not be overlooked that, while these two terminal cells are regarded as the forerunners of the two cotyledons, they have to supply the axis and plumule as well between them; so that they really are of a "thalloid" character. In dicotyledons this axis is continuous with the root in a straight line; but in monocotyledons it is curved towards one side in consequence of the growth of the single cotyledon, one cotyledon being thus seen to be arrested from the earliest stage. From numerous figures by other observers, the inequality observed by Van Tieghem does not appear to be always present, but the energy of growth is what is arrested in the one and not in the other cotyledon. ${ }^{2}$ This superior vigour soon makes the cotyledon to grow apparently in the same line with the axis; but it is not really "terminal," the apex of the plumule being the actual end of the axis. The first leaf is usually opposite to, but not at the same level or node with the cotyledon. This gives rise to the "distichous" arrangement of leaves seen almost universally in monocotyledons. 'The laws of phyllotaxis, however, permit of three

${ }^{1}$ Ann. des Sci. Nat., 5 sèr. tom. xiii. p. 24.

2 "A Theoretical Origin of Endogens from Exogens, through SelfAdaptation to an Aquatic Habit" (Journ. Lin. Soc., vol. xxix. p. 485). 
leaves being in any circle; so that they may arise at an angular distance of $120^{\circ}$. Such is the case in sedges and in the floral whorls; but the $\frac{2}{5}$, which supplies the quinary arrangements of flowers in dicotyledons, cannot arise directly from a single cotyledon.

Of course the inference here suggested of the single cotyledon, is that it is due to the action of water in arresting the growth of the second. The reader might ask if there are any examples of dicotyledonous monocotyledons now existing; i.e. monocotyledons showing a trace of a second cotyledon. Tamus communis appears to have one (fig. 20, 1). One cotyledon is described as forming a club-shaped absorbing organ, which is embedded in the endosperm, the other being a concave scale, while the epicotyl forms a tuber, upon which the first two leaves arise in a plane at right angles to that of the cotyledons. Asparagus (fig. 20, 2,6) has also two, one overlapping the other, the first pair of leaves being at right angles to them, as in Tamus. Certain grasses, as the oat, has a lobule opposite the cotyledon, the plumule arising between them (fig. 20, 4, 5). Certain monocotyledons develop relatively large absorbing organs. I would suggest that these also represent the cotyledon which is usually suppressed. ${ }^{1}$

${ }^{3}$ I would refer the reader to Dutrochet's paper.-C Observations sur la Forme et la Structure primitives des Embryons Végétaux," Nouv. Ann. du Mus., vol. iv. 1835. Also to Grof zu Solms-Laubach's 


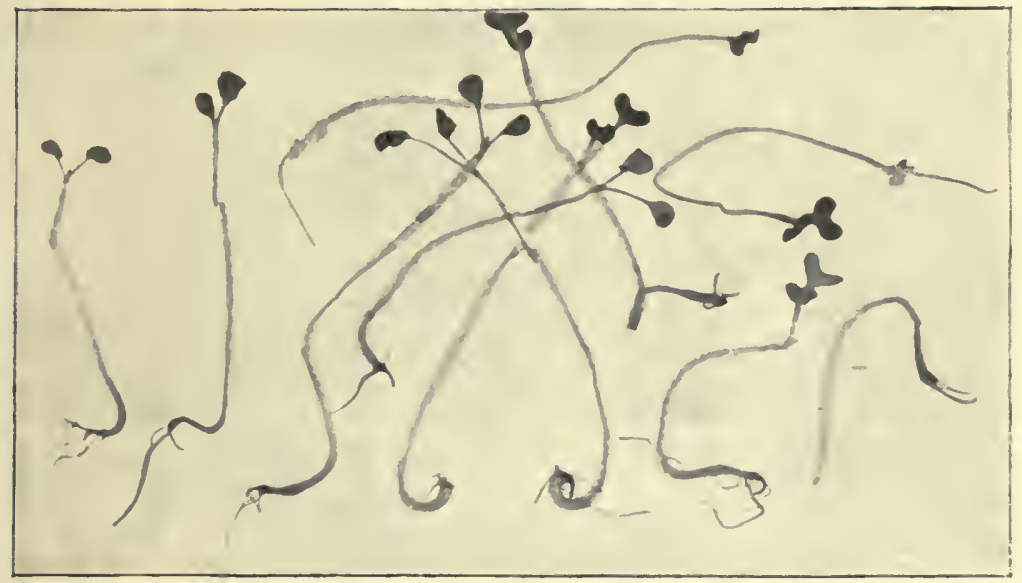

Fig. 22.-Mustard seed germinating in water, with arrested axial roots. (See p. 97.)

[ To face page 94 . 

Ranunculus Ficaria, the lesser Celandine, is descended from an aquatic ancestor. It has lost one of its cotyledons. Miss Sargant notices that the slow maturation of the embryo in the seed of this plant is comparable with "the slow germination of many monocotyledons." ${ }^{1}$ It may be added that the subsequent phyllotaxis is distichous, like that of a monocotyledon; and is followed by a ternary calyx and eight or nine petals ; $\frac{3}{8}$ ths bring a nearer angular distance $\left(135^{\circ}\right)$ to $\frac{1}{2}\left(120^{\circ}\right)$ than $\frac{2}{5}$ ths $\left(144^{\circ}\right)$. If there be 9 petals, these are obtained from 3 whorls $+1 .^{2}$ This plant is, therefore, a true monocotyledon, but betrays its origin by its floral affinities with other species of Ranunculus.

It has been observed in water-lilies that the embryo is at first pear-shaped. There is then formed a "cotyledonary ridge," at first one-sided; from this the cotyledons arise. This ridge may perhaps be the first indication of a sheathing petiole, so characteristic of aquatic dicotyledons, as in Ranunculacece, Umbelliferce, etc., and in all monocotyledons. ${ }^{3}$

figures of Tamus communis, showing the development of one cotyledon and the arrest of the other, Bot. Zeit. 1878, Taf. iv. figs. 21-25. lllustrations of the "absorbing" organ will be found in Ann. Jard. Botan., Buitenzorg, vol. ix. 1890-91, pl. xvi. fig. 5ff. of Elattaria Cardamomum.

1 "Theory of the Origin of Endogens," etc., p. 84.

2 " Origin of Di-trimerous Whorls in Dicotyledons," Trans. Lin. Soc. 2nd ser., Bot. vii. p. 153.

s "The Embryogeny of Some Cuban Nymphaacea," by M. T. Cook, Bot. Gaz., vol. xlii. p. 376 (November 1906), pls. xvi.-xviii. 
With regard to the development of the embryo, the first noticeable part is the arrest of the primary or axial root, with the subsequent production of adventitious roots in an ascending series from the stem, a universal feature in monocotyledons. The stem thus assumes the form of a cone tapering downwards. It is characteristic of aquatic dicotyledons, as in Nymphacacex, Umbelliferce, Ceratophylhum, Ranunculus heterophyllus, etc. Mirbel, ${ }^{1}$ in 1810, noticed that the arrest of the root was correlated to that of the cotyledon as having lost its sources of nourishment; but we may go further. Since the development of roots depends upon the foliage, it is easy to see that when cotyledons are raised above ground, and act as leaves, as in mustard and cress, they can maintain the existence of the tap-root and enable it to grow until the foliage of the plumule is developed. In submerged aquatic plants, however, the first leaves are more or less rudimentary and arrested in character. Moreover, being under water and the protoplasm weakened by supersaturation, they are unable to develop organs equal in degree to those of aerial plants. The consequence is that the primary root, which must be supplied with nourishment from the first formed leaves, suffers and perishes. 'This is true for aquatics of both classes; but having become a fixed and 1 "Examen de la Division des Vegetaux en Endorhizes et Exorhizes," Ann. Mus. d"Hist. Nat., 1810. 
hereditary feature, it is now characteristic of all monocotyledons, whether they be terrestrial or aquatic in habit.

My experiments with germinating seeds of the water crowfoot (fig. 21) showed how the axial root characteristic of terrestrial dicotyledons is rarely $\left({ }^{*}\right)$ produced, but adventitious endogenous roots are given off instead. An experiment with mustard grown in water showed the same thing (fig. 22). The apex became arrested while secondary roots appeared at its base. Rather long axial roots are produced in palms and Indian corn when germinating, pointing to an ancestral dicotyledonous habit, but they soon perish, being followed by adventitious roots in ascending series.

With regard to many minute anatomical structures, I must refer the reader to the details given in my paper, only mentioning that a large number of additional facts can now be added not recorded at the time; such as the origin of the root-cap, that it is early differentiated and grows separately from the initial cells of the root in monocotyledons and the Nymphacaceo, but it is not so in gymnosperms and dicotyledons generally.

I have already alluded to aeriferous canals and aerenchyma, as aeriferous tissue is called, as characteristic of all aquatic plants, and as originally acquired by growing in water; but they 
98 THE ORIGIN OF MONOCOTYLEDONS [CHAP.

can become hereditary by appearing when the plant is raised from seed and grown on land, as in the figwort. But when a plant is amphibious, growing on land or in water, the power of adaptation to either is retined, but appears not to be hereditary. Thus (fig. 23) shows a section of a root of Bidens cernua in water and on land. In the latter no lacunoe or airchambers are present; but in the water-plant there are large ones both in the cortex and path. Moreover, other indications of degeneration are seen, as in the much reduced mechanical tissues or woody bundles, etc.

With regard to rhizomes and aerial stems, the former in the water-lilies is precisely like monocotyledonous stems. The origin of the irregular arrangement of the woody strands may be traced to some extent in Nelumbium, ${ }^{1}$ the Lotus, because, in that plant, the fibro-vascular bundles are still arranged in a long internode in concentric circles. The rive outer zones are traceable into leaves. If we compare this with such simple herbaceous flowering-stems as those of anemone and narcissus, which have their strands in more than one zone, we begin to see that the zones in Nelumbium represent a first stage in the degradation of the compact xylemcylinder characteristic of woody dicotyledons.

This last condition is the result of response to

1 "Comp. Anat. of Phan, and Ferns," by De Bary, p. 255, fig. 112. 


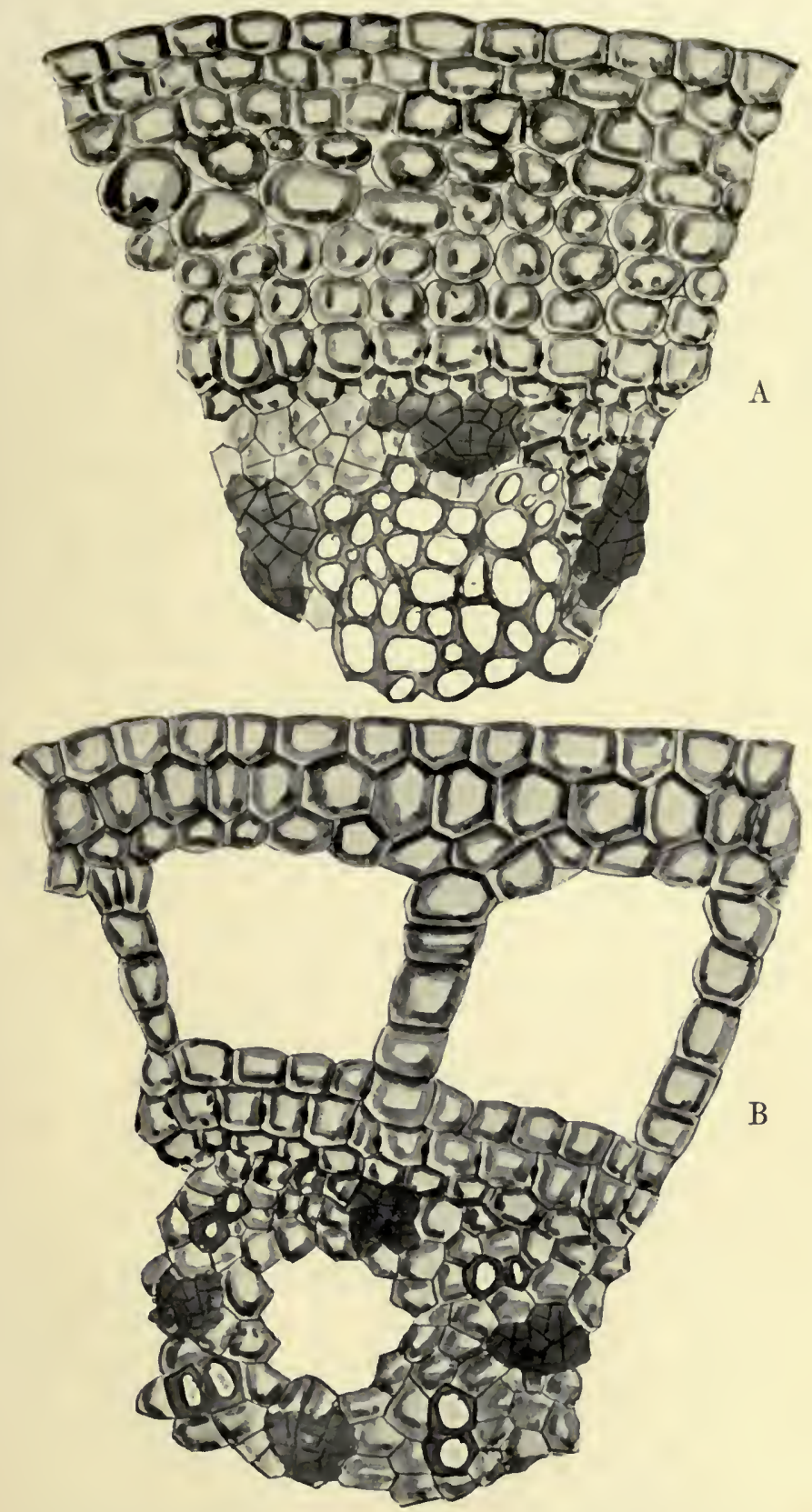

Fig. 23.-Bidens cernua (Bur-Marigold) (a) section of the root of a land plant without lacunæ; $(b)$ Do. of water-plant, with lacune, and much reduced woody strands. 

gravity, which builds up a stem really composed of woody girders to meet the ever increasing weight of the stem. Such is not necessary in submerged or subterranean rhizomes, so degradation at once sets in.

The order of retrogression may be speculatively suggested to have been as follows:-First, the cords of the xylem-cylinder remain isolated, no interfascicular cambium completing the zone; secondly, a second series of cords forming another zone belonging to the next sheathing leaf-base forms a second circle, then a third, fourth or more would follow. The result would be a series of concentric circles as are seen in Nelumbium. The last and easy stage is reached, when the internodes are arrested, and may, perhaps, result from a simple dislocation of the cords, so that the regular circles are broken up, and the ordinary type of a monocotyledonous stem results.

If we compare the development of the leaves of a member of the Nymphoeacea with that, say, of Sagittaria sagittcefolia, we see very remarkable coincidencies. In a germinating plant of Victoria regia (fig. 24) the first leaf is altogether deprived of a limb, being reduced to a petiole with a medial rib; the second has a lanceolate limb, the third a hastate, and the fourth sagittate-peltate. The subsequent, perfect floating leaves are orbicular-peltate. 
100 THE ORIGIN OF MONOCOTYLEDONS [снAP.

Similarly with Sagittaria sagittafolia, there are ribbon-like phyllodes in deep water, the plant when bearing them alone being known as the form vallisneriifolia. Then follow consecutively, as the surface of the water is approached, the spatulate and hastate forms. Finally, there occurs the sagittate type, but this is now aerial. The sagittate-peltate form is attained by Caladium and Alocasia, but the orbicular form is not reached in these genera. It is seen, however, in Hydrocharis, resembling the dicotyledonous Limnanthemum, etc. Conversely, the ribbon-like form so characteristic of monocotyledons is imitated by the leaves of Lobelia Dortmanni, Limosella aquatica, Hippuris, Callitriche, Littorella lacustris, etc. ${ }^{1}$ From the above considerations one arrives at the conclusion that those terrestrial monocotyledons which still retain a linear form (e.g., grasses and sedges), or ensiform (Iris), or other similar type of leaf, or rather phyllode, may be regarded as representing the ancestral submerged ribbon - like forms; and those monocotyledons with distinct blades of a lanceolate or oval shape (Convallaria) represent the floating type, like Potamogeton natans; while the sagittate form, so characteristic of the Aroidece,

${ }^{1}$ Such leaves perhaps resemble those of the earliest monocotyledons, being developed from a primitive cotyledonary type. It is noticeable that the cotyledons of many of the allied order Onagracece have only a single midrib. 


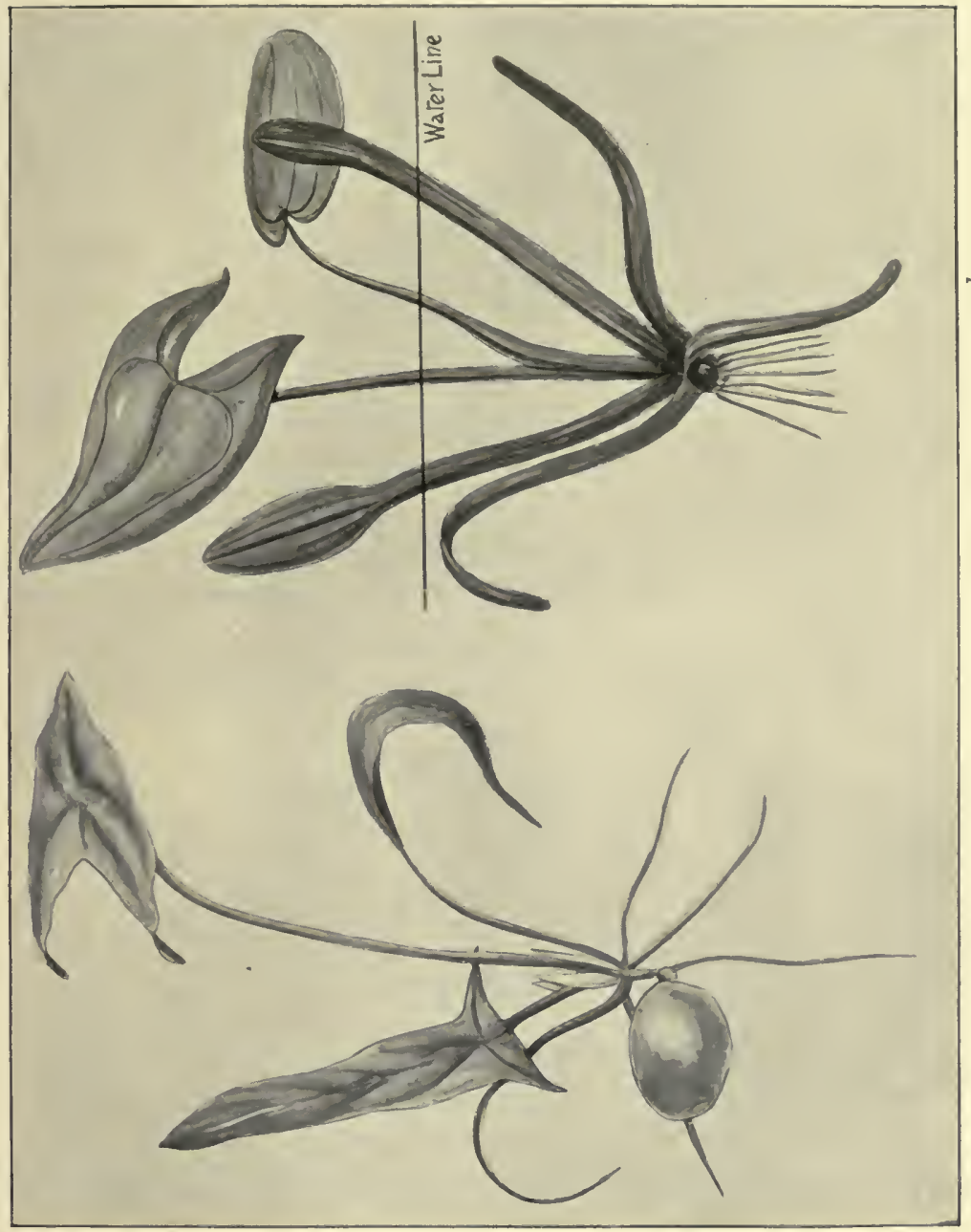

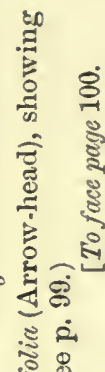

\%

है

$\approx$

है

동

एँ

$\therefore 0$

'를

옹요

का

.

ธิํํ ڤ

응

홀

$\div 8$

造藍

है

I

क्ष

ic 

has primarily arisen, like the same forms in the Nymphoeacece and Sagittaria, from an aquatic habit.

The reader will conclude that all the forms of leaves submerged or floating represent so many adaptations to their environment. This is particularly well seen in the formation of the linear ribbon-like form of monocotyledons and the prevailing dissected type of dicotyledons. For these can be more or less produced at will. 'Thus M. Costantin has shown that if a leaf of Sagittaria which has begun to form a sagittate blade, by developing the two basal extensions as of a spear near the surface, be suddenly plunged into deep water, the form is instantly changed; the blade now develops an elongated point, attempting, in fact, to return to the deep-water ribbon form. I have, however, a specimen in which all the three points appear to have been affected; and although the blade is sagittate, the points have grown out into elongated and narrow prolongations.

As another instance of immediate adaptation, I have found grasses growing completely submerged, the leaves of which, instead of being of the ordinary short-lengthed type, had the elongated ribbon form, while the anatomy was the same as that of ordinary and normal ribbonlike types of submerged leaves.

Similarly with Ranunculus heterophyllus, leaves 
can often be procured, one half being of the floating type, the other half of the leaf being dissected. I have already observed that if the aerial terrestrial plant with dissected leaves be plunged into water, all the adult leaves at once perish, new ones in adaptation to water soon taking their place; but all half-developed leaves continue to grow, their new growths, however, conforming to the watery medium.

We are indebted to $\mathrm{Mr}$ W. P. Hiern for demonstrating the truth of one adaptation, for he has shown by mathematical calculations that the best form of the margin of floating leaves for resisting the strains due to running water is circular, or at least the several portions of the margin would be circular arcs, showing that nature had adopted what was most serviceable, in this respect, in such leaves as Ranunculus, Nymphceacece, Limnanthemum, and Hydrocharis. Mr Hiern concludes his paper with the following very significant remarks:

"It is a tenable hypothesis, and by no means improbable, that during much or most of the time, when actual growth is taking place, and when the velocity of the current is subject to many and various vicissitudes, the plant has the power of adapting its growing efforts to the circumstances just necessary for its development." 1

This hypothesis is completely in accordance 1 "A Theory of the Forms of Floating Leaves in Certain Plants," Proceedings, Camb. Phil. Soc., fol. xiii. 1872. 
xi.] ALL THE FEATURES, HEREDITARY 103

with modern ecological views, though stated thirty-six years ago.

The reader will find many more coincidences between monocotyledons and aquatic dicotyledons in my paper, and $I$ repeat there are many more not therein mentioned. Now their significance, from the present point of view, is that all the characters of existing monocotyledons are, of course, hereditary. It is upon them that the entire class is based, being taken from the roots, stems, leaves, flowers and seeds. The amount of evidence for the heredity of acquired characters would be considered ample to support the argument in any other branch of science. It is insuperably greater than the probabilities upon which Huxley founded his belief in the evolutionary history of the horse, and in the many other lines of descent discovered since of extinct animals.

General Conclusions.-The reader must clearly perceive that the amount of evidence given in this book is a mere fraction of the inductive and experimental proofs that could be supplied; as Darwin said in his letter to Professor Wagner in 1876 of the evidence of the "direct action of the conditions of life"- "Now the proofs are plentiful." That is, he then realised in his own mind that these were so. I would only change the word "plentiful " into " universal."

I will, in conclusion, quote the last paragraph 
in my book, "The Origin of Plant Structures, by Self - Adaptation to the Environment," published thirteen years ago:

"It would not avail anything to add extra chapters on other parallel lines of evidence, such as the origin of depauperised states of parasitic and saprophytic plants, etc., materials for which I have at hand ; ${ }^{1}$ for if a reader be not convinced of the truth of my contention with the amount of evidence herein brought forward, he would probably remain unconvinced, however much might be added.

"On the other hand, I trust that the majority, if not all of my readers, will accept the conclusion that the Origin of Species is due to the joint action alone of the two great factors of evolution - Variability and Environmentwithout the aid of natural selection; although we are, and are likely to remain, profoundly ignorant of the mysterious process (of Response). within the organism by which it is effected."

Even Dr Weismann contends that:

"We are driven to the conclusion that the ultimate origin of hereditary individual differences lies in the direct action of external influences upon the organism." ${ }^{2}$

- That is why I have introduced them in this book.

${ }^{2}$ Essays on Heredity, etc. Eng. Trans., p. 279. 


\section{INDEX}

Aceurnen characters, 7 ; explained, 9 ; in animals (note), 9

Adaptation, Costantin on, 4 ; with heredity, 5; based on induction and experiment, $5 \mathrm{ff}$. ; direct, accepted by Darwin, 6 ; a proved fact, 8 ; of saprophytes, 68 ; of parasites, 74

Fcidium berberidis, origin of parasitism of, 60

Alpine and Arctic plants, $75 \mathrm{ff}$; hereditary characters of, 76 ; Costantin on, 76 ; Bonnier and Flahault on, 76 ; summary of, 77 Annuals, changed to biennials, 81 Araucaria, hard wood of, hereditary, 30

Bad Nauherm, wild plants affected by salt at, 51,52

Birth-variations, 2

CLzvarIs, sensitive petiole of, 40

Climbing plants, $38 \mathrm{ff}$. ; origin of, 44 ; stem of, normal at first, 45

Conditions of life, direct action of, 1-4

Convolvulus, climbing species, 38 ; non-climbing, 44

Cyrilla, 37; and Proserpinaca, foliage of, not hereditary, 37

DARwis, his alternative to natural selection, 1; an ecologist in 1876, 8; his letter to Wagner, 8; a refutation of natural selection, 26 ; on transitional structures, 49 ; his theory unsupported, 4

Definite variations, as acquired characters, 3
Degeneration, 83ff. ; spinescent characters of xerophytes, hereditary, 85,86 ; floral, 87 ; of monocotyledonous stems, $98 \mathrm{ff}$.

Depauperation in terrestrial plants, 86 ; of aquatic plants, 87 ; causes of, 88

Destruction, natural cause of, among plants, 16, 17

Dicotyledons, monocotyledonous, 95

Direct action of the conditions of life, 1-4; on the soma, 6 ; affects the subsequent reproductive organs, 10

Eberifardt's experiments with woody stems, 31

Ecologists accept Darwin's alternative, 12

Ecology, its importance, 23 ; procedure of study, 24 ; discovery of adaptation by response as a natural law, 25

Environment, the influence of, 21

Epiphytes, adaptations of, 56, 57 ; types and distribution of, 57,58 ; due to response, 59

Euphrasiea, lost the power of photosynthesis, 71,72

Evolution, description of process, 5,6 ; Mr Reid and theories of, 11 ; the true and only method of, 18

Expérimental verification, 5 ; by Nature, 26

Granyatoritzlow, as a saprophyte, 70

HerentTy, conditions for, of 
Heredity-continued

acquired characters, 7,21 ; Carrière on, 7 ; Darwin on, 7

Hiptage, climbing power in abeyance and renewed, 47

Hunter, on the origin of climbing stems, 46

Huxley, misstatement of Lamarchism, 43

InDIvidUAI differences, 2 ; Wallace on, 3

Induction, 5

Influence of enviroument, 21

Injurious structures, no proof of, 16 Inuate variability, unproven, 2 Ivy, climbing roots of, 38,39

Kauri pine, description of xerophytic timber, 30

LANKESTER, on birth variations, 2 Lesage, on action of salt on plants, 51

Littorella lacustris, a hydrophyte by direct adaptation, 52

MacCallum, experiments with Proserpinaca, 35

Malthus, misapplication of, 15 ; not concerned with evolution, 15

Melampyrum, described, 61-65

Methods of proof, scientific, 5

"Misunderstandings," Thomson's, 20

Modifications, power of acquiring explained, 13

Monocotyledons, origin of, 90 ; characters of proembryo and embryo of, $91-93$; dicotyledonous, 94; arrest of axial root of, 97 ; structure of stems of, 98 ; leaves of, $98 \mathrm{ff}$.

Monotropa, 61

Monstrosities, hereditary, 89

Müller, on the origin of climbers, 44

Musk, saprophytic by adaptation, 70,71

Mutations, origin of, 19

Mutilations and evolution, 17

NARAVELIA, tendril - climber by adaptation, 40
Natural selection, only a metaphor, 14 ; Wallace on, 3

ONONIS SPINOSA, experiments with, 32

Origin of floral structures, 5

Origin of species, 17,18

Parasires and saprophytes, $60 \mathrm{ff}$. ; with chlorophyll, 60 ; anatomy of, $61 \mathrm{ff}$; ; leafless, 61 ; origin of, 67; due to irritation, 67, 68; degradations of, 72 ; in the flowers, 72,73 ; sexual cells affected, 73 ; impossible to have originated congenitally, 74

Passion-flower, parasitic, 69

Periwinkle, climbing induced, 46

Plants made succulent by salt, 51

Plasticity of plants, 54

Platycerium, adaptations of, 57

Plocamium, with adhesive pads, 41

Proofs of the heredity of acquired characters, chaps. iv.-xi., 29-104

Proserpinaca, experiments with, 35,36

Protolemna, 90

Pyrola, 60

$R_{A N O N C O L O S}$, Nature's experiments, 35

Ranunculus Ficaria, 95 ; aquatic origin of, 52

Ranunculus heterophyllus, experiments with, 34 ; form of submerged leaf hereditary, 37

Reaumuria, secretions of salt by, 50

Reid, on the principles of heredity, 7 ; on theory of adaptation, 14

Response to physical irritations, hereditary, 10 ; immediate, 35

Reversion to wild forms, 88

Roots, origin of edible, 79-81; arrest of primary, by water, 96 ; tuberous, $79 \mathrm{ff}$.

SALICORNEA, a succulent and physiological xerophyte, 52

Salsola, adaptations of, 53

Saprophytes, origin of, 69,70

Scrophularinece, leafy parasites of, 61 
Sedum, sp., adaptations of, 53

Self - adaptations, recognised by Wallace and Weismann, 27; by Reid, 29,30 ; by Hiern, 102 Solanum Dulcamara, variations in the structure of stems, 42

Soma, responses by the, hereditary, 11

Spines, hereditary, 32

Sports, origin of, 18

Stems, self-supporting compared with climbing, 42,43

Strawberry rummers, hereditary roots of, 39

Struggle for existence, explained, 17

Subterranean stems, origin of, 82

Succulency in plants, chap. v., 50 ; caused by salts, 50 ; use of, 51 ; evidence of response, 51 ; permanent and hereditary, 54 ; tenacity of life, 54

TAMARIX, secretions of, 50

Thomson, on Heredity, 19

Tillandsia, adaptations of, 57

Timber, xerophytic, 30

Transitional structures, 48
Trichosanthes, forming adhesive pads, 41

UsE and disuse, effects of inherited, 12

VARIATION, innate, not proved, 2 ; definite and indefinite, origin of, 2 ; as acquired characters, 3 Virginia creeper, response in, 10

W ALlace, recognises self-adaptation, 27; that there is "no valid evidence of the transmission of modifications" disproved, 36

Warming, on the origin of climbing plants, 44,45

Weismann, recognises self-adaptation, 27,104 ; his theory refuted, 73

Wisturia, climbing and self-supporting stems, compared, 42

$Z_{I L L A}$, experiment with, showing hereditary character of spines, 33 
PRINTED AT THE EDINBURGH PRESS, 9 AND 11 YOUNG STREET. 

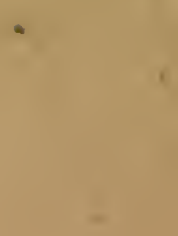

4

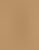

$-$

,

$-$ 



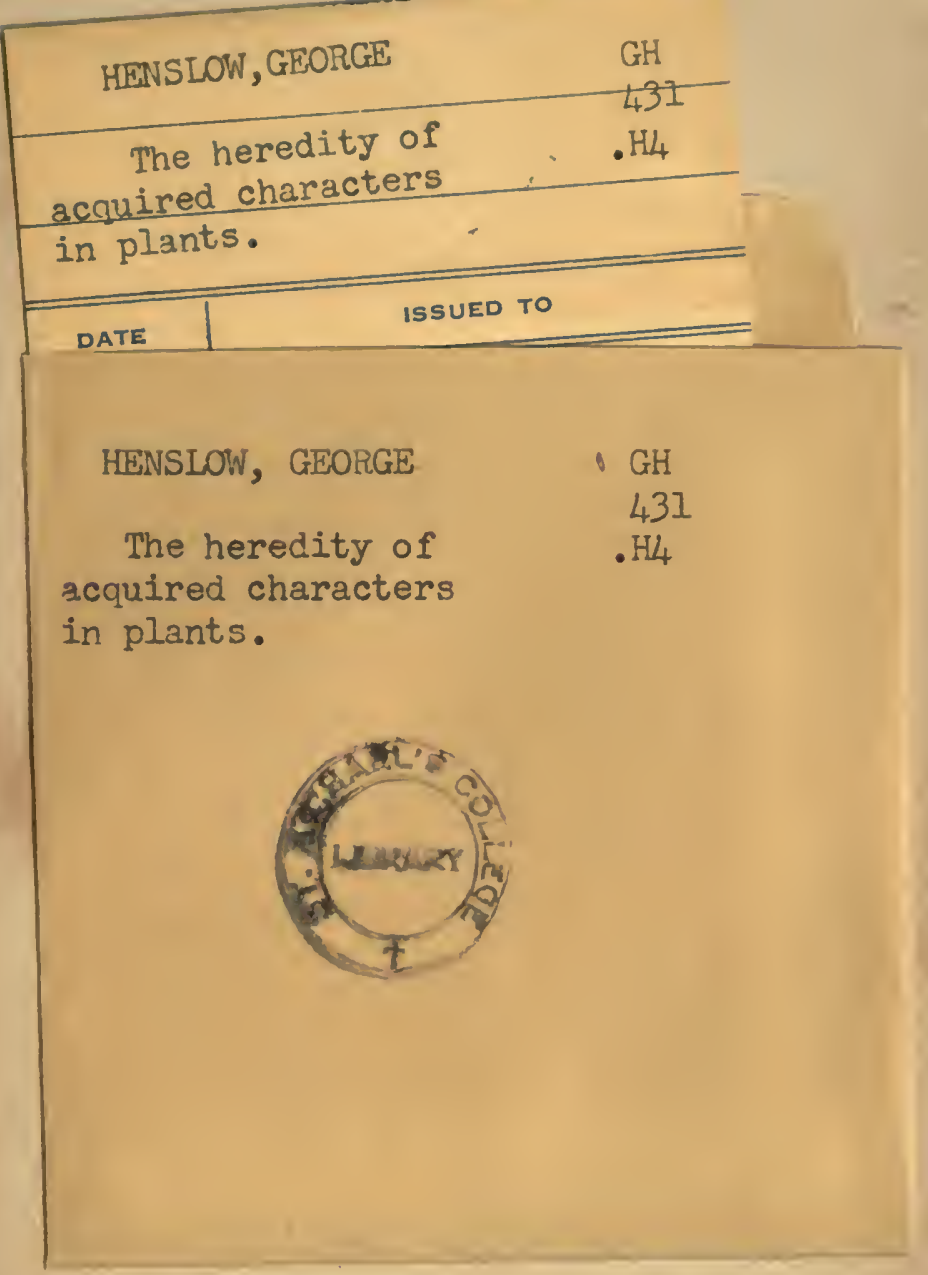




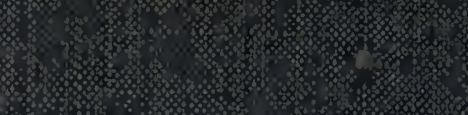
$80 \%$ os

$x+3$

\% 3 .

8. $20 \%$. \%

0
0 